\title{
COPY BUT NOT PASTE
}

\author{
Citation for published version (APA):
}

Waterval, D. G. J. (2018). COPY BUT NOT PASTE: An exploration of crossborder medical curriculum partnerships. [Doctoral Thesis, Maastricht University]. Datawyse / Universitaire Pers Maastricht. https://doi.org/10.26481/dis.20180426dw

Document status and date:

Published: 01/01/2018

DOI:

$10.26481 /$ dis.20180426dw

Document Version:

Publisher's PDF, also known as Version of record

\section{Please check the document version of this publication:}

- A submitted manuscript is the version of the article upon submission and before peer-review. There can be important differences between the submitted version and the official published version of record.

People interested in the research are advised to contact the author for the final version of the publication, or visit the DOI to the publisher's website.

- The final author version and the galley proof are versions of the publication after peer review.

- The final published version features the final layout of the paper including the volume, issue and page numbers.

Link to publication

\footnotetext{
General rights rights.

- You may freely distribute the URL identifying the publication in the public portal. please follow below link for the End User Agreement:

www.umlib.nl/taverne-license

Take down policy

If you believe that this document breaches copyright please contact us at:

repository@maastrichtuniversity.nl

providing details and we will investigate your claim.
}

Copyright and moral rights for the publications made accessible in the public portal are retained by the authors and/or other copyright owners and it is a condition of accessing publications that users recognise and abide by the legal requirements associated with these

- Users may download and print one copy of any publication from the public portal for the purpose of private study or research.

- You may not further distribute the material or use it for any profit-making activity or commercial gain

If the publication is distributed under the terms of Article $25 \mathrm{fa}$ of the Dutch Copyright Act, indicated by the "Taverne" license above, 


\title{
COPY BUT NOT PASTE
}

\author{
An exploration of crossborder \\ medical curriculum partnerships
}




\section{Maastricht University in Learning!}

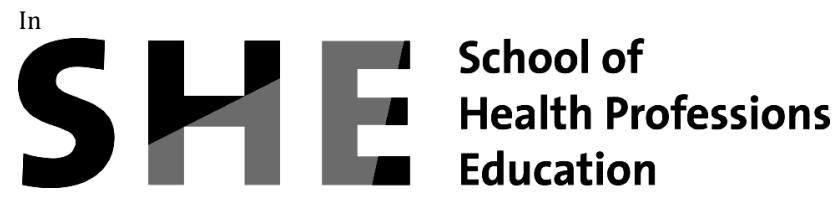

Explanation Cover

The cover represents two phases in a crossborder curriculum partnership. Each square symbolizes the transported curriculum, containing various curriculum courses (shapes) and educational formats (colors). The left side represents the curriculum implemented at the home institution; the right side represents the transported curriculum at the host institution.

The top two squares symbolize the first stages of a crossborder curriculum partnership. The flow of information -curriculum material and people- mainly goes from the home institution to the host institution. The original home curriculum (top left) is adjusted in the host context (top right). Examples of these adaptations are: adding specific host content to existing home courses (extended light green), deleting too specific home courses (orange), implementing the same learning objectives but a different didactic format (colour change), and adding specific host courses (orange striped/gray).

The bottom two squares symbolize the same curriculum partnership over time: the flow of information and people has become more bilateral (two arrows). In addition, some elements and adjustments from the host context have found their way in the home curriculum (light gray) and new courses are developed by both partners (purple). Compared to the initial phase, both curricula are more closely intertwined, but retaining specific contextual elements.

Design: Annelies Vossen

(C) copyright D. Waterval, Maastricht 2018

Printing: Datawyse | Universitaire Pers Maastricht ISBN 9789461597908

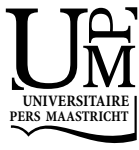




\title{
COPY BUT NOT PASTE An exploration of crossborder medical curriculum partnerships
}

\author{
PROEFSCHRIFT \\ ter verkrijging van de graad van doctor aan de Universiteit Maastricht, \\ op gezag van de Rector Magnificus, Prof. dr. Rianne M. Letschert, \\ volgens het besluit van het College van Decanen, \\ in het openbaar te verdedigen \\ op donderdag 26 april 2018 om 16:00 uur \\ door
}

Dominique Gerardus Josephine Waterval 
Promotoren

Prof. dr. E.W. Driessen

Prof. dr. A.J.J.A.Scherpbier

\section{Co-promotor}

dr. J.M. Frambach

\section{Beoordelingscommissie}

Prof. dr. M.G.A. OudeEgbrink (voorzitter)

Prof. dr. A. Krumeich,

Prof. dr. P. McCrorie, University of Nicosia Medical School

Prof. dr. W.N.K.A. van Mook,

Prof. dr. A.C. Whitehead, University of Toronto 
To: All crossborder students 



\section{Contents}

Chapter 1. Introduction to crossborder medical curriculum partnerships

Chapter 2. A literature review of crossborder curriculum partnerships

Published as: Waterval DGJ, Frambach JM, Driessen EW, Scherpbier AJJA:

Copy but Not Paste: A Literature Review of Crossborder Curriculum

Partnerships. Journal Studies in International Education. 2014, 19(1):65-85.

Chapter 3. An exploration of crossborder medical curriculum partnerships:

Balancing curriculum equivalence and local adaptation

Published as: Waterval DGJ, Frambach JM, Oudkerk Pool A, Driessen EW,

Scherpbier AJJA: An exploration of crossborder medical curriculum

partnerships: Balancing curriculum equivalence and local adaptation.

Medical Teacher. 2016, 38(3):255-262.

Chapter 4. Connected, attracted, and concerned: A Q study on medical

crossborder curriculum partnerships

Accepted for publication: Waterval DGJ, Frambach JM, Driessen EW,

Muijtjens A, Scherpbier AJJA. Connected, attracted, and concerned:

$A Q$ study on medical crossborder curriculum partnerships.

Medical Teacher. 2018

Chapter 5. Crossborder curriculum partnerships: Medical students' experiences

83 on critical aspects

Accepted for publication: Waterval DGJ, Frambach JM, Scott S, Driessen EW, Scherpbier AJJA. Crossborder curriculum partnerships: Medical students' experiences on critical aspects. BMC Medical Education. 2018.

Chapter 6. Exporting a student-centred curriculum: a home institution's perspective

Published as: Waterval DGJ, Tinnemans-Adriaanse M, Meziani MA, Driessen EW, Scherpbier AJJA, Mazrou A, Frambach JM: Exporting a student-centred curriculum: a home institution's perspective.

Journal of Studies in International Education. 2017, 21(3):278-90.

Chapter 7. Twelve tips for crossborder curriculum partnerships in medical education

Accepted for publication: Waterval DGJ, Driessen EW, Scherpbier AJJA, Frambach JM. Twelve tips for crossborder curriculum partnerships in medical education. Medical Teacher. 2018.

Chapter 8. Discussion 
Chapter 9. Summary

Chapter 10. Samenvatting 159

Chapter 11. Valorisation

Chapter 12. Acknowledgments / Dankwoord

Chapter 13. About the author

173

Chapter 14. SHE dissertation series

175 


\section{Chapter 1.}

\section{Introduction to crossborder medical curriculum partnerships}



"Currently, there are more students studying for a UK degree outside the United Kingdom than international students inside the United Kingdom". ${ }^{1}$ While somewhere else on the globe, due to disagreements with its partner institute, "John Hopkins Medical College is ending its medical partnership in Singapore despite initial investments."

These two distinctive headings from recent publications on international collaboration, illustrate the high potential as well as the risks of a relatively new form of internationalisation in higher education: crossborder curriculum partnerships. In the past, internationalisation in higher education was predominantly considered a movement of people, namely students and staff. Since the turn of the century, however, curricula and even institutions have been on the move as well. Curriculum mobility differs from international student mobility, where a student from country X goes to study in country $Y$ to undertake a short-term student exchange following a number of courses. Curriculum mobility refers to the movement of a complete curriculum developed in one location (home) that is transposed and delivered to students in another location (host). ${ }^{3}$ The terms home and host institution reflect the different relationships of the partner institutions with the curriculum. Before this chapter continues with a discussion, derived from existing theory and literature, of the main actors and their motives, the challenges inherent to a curriculum partnership, the gaps in the literature, and the research questions, it first expands on the different definitions and descriptions of crossborder curriculum partnerships.

\section{Terminology}

Those who are interested in internationalisation in higher education will notice the variety of ways in which crossborder curriculum partnerships are described and discussed in the literature.4-6 According to Knight" "Internationalisation of higher education means different things to different people and different institutions, because it can be viewed from many perspectives. Similar meaning is given to different terms and different meaning to similar terms." However, to further develop this field, it is important to have a common framework for researchers, policymakers and academic leaders. The terms offshore education, transnational education and crossborder education are most commonly used to label this form of internationalisation. The next paragraph briefly explains each of them.

The term "offshore education" is frequently used to label partnerships where the overseas/offshore campuses or institutions serve students from the home institution. ${ }^{8}$ This term is predominantly used in the context of US schools establishing partnerships in the Caribbean and in the Australian context. Transnational education is a broader term that includes all types of higher education study programmes, sets of courses or educational services (including distance education) in which the learners are located in a country different from the one where the awarding institution is based. ${ }^{9}, 10$ Crossborder education is described by Knight ${ }^{11}$ as "higher education that takes place in situations where the teacher, students, programme, institution/provider or course materials cross national jurisdictional borders. Crossborder education may include higher 
education by public/private and not-for-profit/for-profit providers." This terms is used by the Organisation for Economic Co-operation and Development (OECD) ${ }^{12}$ and the Cross-Border Education Research Team (C-BERT) of the University of Albany.

The first term, offshore education, is less appropriate for this study because it excludes countries that are not located near the seashore. The latter two are fairly similar concepts and can just as well be replaced by one another. However, throughout this dissertation, the term "crossborder" is used to emphasise the crossing of borders by materials, knowledge and people, as well as its implications.

Table 1.1: Typology of crossborder curriculum mobility ${ }^{13}$

\begin{tabular}{ll}
\hline Types of Mobility & Description \\
\hline Franchise & An arrangement where an institution/provider in the source country A authorises a \\
& provider in another country B to deliver their course/programme/service in country B or \\
& other countries. The qualification is awarded by the institution/provider in country A. \\
& This is usually a for-profit commercial arrangement. \\
& A situation where an institution/provider in the source country A collaborates with an \\
institution/provider located in country B to develop an articulation system allowing & \\
students to take course credits in country B and/or source country A. Only one & qualification is awarded by the institution/provider in source country A. This may or may \\
& not be on a commercial basis. \\
Double/Joint Degree & An arrangement where institutions/providers in different countries collaborate to offer a \\
programme for which a student receives a qualification from each institution/provider or \\
a joint award from the collaborating providers. This is normally based on an academic \\
exchange model, not a commercial model, but this is changing, especially for MBA \\
programmes. \\
Various types of articulation arrangements between institutions/providers in different \\
countries permit students to gain credit for courses/programmes offered/delivered by \\
collaborating institutions/providers. \\
Validation arrangements between institutions/providers in different countries which \\
allow provider B in the receiving country to award the qualification of provider A in the \\
source country. \\
Arrangements where institutions/providers deliver courses/programmes to students in \\
different countries through distance and online modes. These may include some face-to- \\
face support for students through domestic study or support centres.
\end{tabular}

Under the umbrella of crossborder education, different types of partnerships can be distinguished: twinning, franchises, dual- and joint-degree programmes, research partnerships and other instances of higher education collaboration crossing national boundaries (Table 1.1). ${ }^{8}$ This dissertation focuses explicitly on those types that entail the transfer of a complete curriculum from the place where the curriculum was developed (home institution) to the place where the curriculum is being delivered (host institution). Curriculum is broadly defined to include content, pedagogy and assessment. This transfer of the curriculum can be done through various legal forms ranging from actual bricks and mortar at a branch campus to delivery agreements with an independent public or private host institution. This concept includes partnerships where the host students legally belong to the home institution as well as the host institution. In the former situation, the degree-awarding institution is the same; in the latter, this is not necessarily the case. Of course, this influences the way the partnership is shaped, but the overarching communality of these partnerships is to provide a comparable learning experience to students at both institutions. The work of Knight ${ }^{14}$ provides a 
more detailed description of the various modalities. Before exploring medical crossborder curriculum partnerships and their particular challenges in greater depth, this chapter first provides background information regarding the main actors as well as the magnitude and principal driving forces of this phenomenon.

\section{Main actors and magnitude of crossborder curriculum partnerships}

The main actors of this phenomenon have historically considered education as a tradable commodity. Countries such as Australia, the United Kingdom and the United States have been pioneers in offering crossborder education and are nowadays also the main actors, with established partnerships in the Middle East, Far East and East Asia. Many of the major receiving countries on their side have deliberate policies to attract foreign providers by establishing educational hubs, such as Qatar, Singapore and Malaysia. ${ }^{14}$

These curriculum partnerships are expanding at a brisk pace in terms of the number of students enrolled, the type of programmes and the delivery locations. ${ }^{15}$ At the turn of the century, there was hardly any reference to this type of programme, ${ }^{16}$ but by 2011-2012, Australia had set up 394 partnership programmes and UK universities had set up 1,395 crossborder programmes abroad. ${ }^{17}$ There are now over 200 branch campuses around the world. ${ }^{18}$ The United Kingdom is a leading provider of crossborder education programmes, with approximately 360,000 students actively enrolled, involving around $80 \%$ of UK universities. ${ }^{17}$ Unfortunately, except for Australia and the United Kingdom, there is no central registration for crossborder programmes; therefore, there is little data available on how many students are actually enrolled in crossborder higher education programmes worldwide. ${ }^{19}$ There is strong evidence that the United States, which has the most campuses abroad, is the biggest provider of cross-border education in the world. ${ }^{20}$

The future of crossborder education in terms of demand looks bright. ${ }^{21}$ Recently, the British Council ${ }^{17}$ estimated that international student mobility would slow down by 2020 but that crossborder delivery of higher education programmes would grow in terms of the number of participating institutions, the variety of programmes offered and the volume of students enrolling. This signals that student and curriculum mobility are not subsidiary to one another as forms of internationalisation but rather complementary.1,22 The growth of the latter does not occur at the expense of the other.

On the surface, one will notice a predominant flow from West to East, but if one looks more closely, a more diversified picture emerges, perhaps contrary to what one would expect. Based on data from C-BERT, Zhang, et al. ${ }^{23}$ unravelled a distinct pattern from East to West and South to North. There are examples of Indian universities establishing branches in Western Europe. China is exporting curricula to Africa and Southeast Asia as well. An Indian University together with a University in Ghana are offering PhD programmes in Liberia. ${ }^{24}$ The assumption that crossborder education is something offered exclusively by Western countries to the developing world is incorrect. Crossborder education is a global, rising phenomenon that illustrates the competitive power 
of emerging nations such as China, India, Brazil and Russia. ${ }^{25}$ It is important to understand the myriad of reasons that drive these partnerships, why host countries would welcome such partnerships and how this might fit with their national development agendas.

\section{Stakeholders' motives}

The question of what drives higher education institutions into these new types of partnerships has interested several researchers. Healey ${ }^{26}$ investigated parallels in internationalisation between business and higher education. He found many similarities in terms of timing and pace between the globalisation of products and services and the internationalisation of education due to two global forces that have set the stage and made these kinds of partnerships feasible and desirable. First, improved information and communication technologies have removed the hurdles that prevented efficient and effective communication in the past. As a result, crossborder curriculum partnerships can now be organised at reasonable costs.

The second major driving force is a fast-growing middle-income consumer class. According to a report from the Boston Consulting Group, 100 million people have entered the middle-income consumer class in Asia by 2015, creating a huge need for affordable high-quality education"?27 This boom is expected to open up a new market of students who are willing to pay for a global educational experience while staying in their country of residence. They are called "glocals" - individuals with global aspirations and local experiences. ${ }^{28}$ Glocals are those who can afford the higher tuition fees and are looking for educational quality but may be unable or unwilling to study outside their country of residence due to work, family commitments and financial or other reasons. ${ }^{29-34}$ These students are likely to present the next big opportunity for institutions that want to increase their global profile.

While these two forces have set the stage on the global level, they say little about the individual, institutional or national motives that might explain the growth of crossborder education. A valuable model that can unravel the different motives differentiates between supply-side motives, which push the educational content towards the host setting, and demand-side factors, motives that pull the educational content towards the host context. ${ }^{5}$

\section{Supply-side factors}

Starting at the national level, governments of home institutions are increasingly adopting policies which attempt to stimulate the export of educational expertise. For instance, in the United Kingdom, there are national platforms for higher education institutions to share ideas and experiences. ${ }^{35}$ Governments are looking for ways to facilitate the export of educational expertise wherever possible. In the Netherlands, a new law will be passed this year which opens up opportunities for higher education institutions to offer their programmes abroad. ${ }^{36}$ Home governments are driven by the expectation 
that such policies will boost the higher education sector in terms of revenues and employment.

At the home institutional level, commercial interests might be the first supply factor that comes to mind. Some higher education institutions are mainly attracted by potential financial gains. However, according to Healey ${ }^{26}$ this motivation should not merely be seen as a catalyst for commercialisation and a way to increase profits. Institutions are motivated because, due to the decline in government spending, ${ }^{37}$ they are looking for new ways to generate income to expand or at least maintain their current level of activities and safeguard jobs at the university in the future. ${ }^{38,}{ }^{39}$ Besides revenue streams, other driving forces that have been identified are enhancing research and knowledge capacity, ${ }^{40}$ increasing cultural understanding, contributing to the development of middle-income countries and increasing the university's international profile. ${ }^{41,}{ }^{42}$ At the students' level, there are no supply factors, but these do play out in the demand side of the story.

\section{Demand-side factors}

Starting at the government level, for some countries, attracting foreign educational providers is often regarded as an effective strategy to increase domestic human capacity development. ${ }^{14}$ The British Council and German Academic Exchange Service (DAAD) ${ }^{43}$ investigated the potential advantages for host countries by interviewing students and higher education leaders in 24 countries. Their report highlighted not only the academic advantages (e.g. crossborder delivery of education can develop host institutions' teaching and assessment methods and quality assurance processes), but also the economic advantages (e.g. cross-border delivery of education allows host students to gain an international education while studying part time and remaining in employment). Crossborder curriculum partnerships can also generate local income by attracting international students from neighbouring countries. As a result, some countries, most notably in the Middle and Far East, aim to become regional educational hubs and boost their knowledge-based economies by offering incentives and advantages to attract foreign providers. ${ }^{14,44-46}$ China is another example of a country that has benefitted significantly from access to prestigious international institutions, which have brought them quality educational resources, highly qualified staff and strong research linkages. ${ }^{4}$

For a host institution, crossborder curriculum partnerships can be a highly attractive strategy for acquiring and delivering different types of academic programmes and pedagogy aside from what is already available. ${ }^{47}$ They can also attract different types of students and reduce the investment costs of building a curriculum from scratch.

Perhaps the biggest factor contributing to pulling foreign education towards a host country comes from glocals. These glocals seem to have a mixture of motivations compared with conventional exchange students. ${ }^{48}$ According to the British Council and German Academic Exchange Service (DAAD) ${ }^{43}$ many host students chose their crossborder curricula to develop their skills and advance their careers. Many students believe that crossborder education increases their hiring and promotion prospects espe- 
cially compared with other alternatives. In the same study, another social-cultural motivation mentioned was the opportunity to study in English and develop an understanding of other cultures. The work of Burgess and Berquist ${ }^{49}$ provides a more detailed description of the various motives for crossborder education.

\section{Educational challenges for crossborder curriculum partnerships}

From the above, it is clear that crossborder provision of higher education is a popular and growing phenomenon because of its perceived benefits for many of the stakeholders involved. Nevertheless, it is by no means an easy form of internationalisation in higher education. Reports of the Observatory of Borderless Higher Education (OBHE) found that $10 \%$ of the registered branch campuses have closed since the mid-1990s. ${ }^{50}$ Although this is not an upsettingly high number given the entrepreneurial characteristics of these partnerships, it is a clear signal that this is not an easy endeavour. Unfortunately, academic reports on the reasons and underlying mechanisms in terms of educational processes and strategies are seldom available. This is a pity, as these partnerships have an inherent educational dilemma that needs further understanding.

An educational tension exists within crossborder curriculum partnerships, as the implemented curriculum in the host institution has to be as identical as possible to that of the home institution; at the same time, the legislation, organisational resources, and learning and teaching culture of the host context might differ from those of the home context. As a result, on the one hand, a partnership's curriculum adaptations to the host context are unavoidable and desirable, while on the other hand, the learning experience of both groups of students ought to be comparable., 7, 31 This dilemma in the internationalisation of higher education has a parallel with globalisation in international business.

On top of that, cross-border partnerships often have a skewed relationship because, since the curriculum initially comes from the home institution, the home institution is automatically perceived as the dominant, expert party. This unbalanced relationship directly and indirectly affects the quality of curriculum delivery. The next paragraphs expand on these educational challenges.

\section{The paradox: Standardisation versus adaptation}

In the early 1980s, Levitt ${ }^{51}$ noticed a growing tendency to harmonise and standardise products around the world. He stressed the growing similarities in preferences around the world, which offered global players opportunities to standardise and harmonise production. He urged companies to produce similar goods and services at various locations around the world. This idea was criticised and refined by Douglas and Wind ${ }^{52}$ who claimed that certain products or elements are better tailored to local customs and preferences. Douglas and Wind did not so much reject Levitt's idea as emphasise that a blind harmonisation of all elements would harm businesses. Instead, they advised 
businesses to tailor to the local circumstances of the country in which their subsidiary was located. They referred to this strategy as glocalisation-adapting a standardised working process to local needs and preferences.

A perfect illustration of this marketing strategy is McDonald's. McDonald's has a recognisable global brand and uses standardised working processes; at the same time, the company attempts to adapt essential product characteristics to the local situation: one can order a McBaguette in France or a McWrap in Mexico. By doing so, McDonald's tunes into the eating culture of the host context, with the objective of increasing consumer satisfaction levels. Transferring this concept to the educational domain, the paradox just like that of McDonald's for crossborder partnerships seems to be that the two institutions' curricula should be identical as well as locally adapted. ${ }^{31}$ However, the provision of education is different from selling hamburgers. What are the areas that require adaptation? How far can or should a partnership go in this adaptation process?

Researchers have identified curriculum content, didactics, staffing and assessment as eligible areas in which the trade-off between adaptation and standardisation might play out when implementing a curriculum across borders. Failing to do so might result in host graduates lacking the required skills to work in the host context. ${ }^{53}$ Kinser and Lane $^{54}$ reported a range of ways in which crossborder curricula have been implemented. At one extreme, some host staff were expected to replicate the curriculum developed in the home institution without considering the host conditions. At the other end of the spectrum, host faculty had the freedom to achieve learning outcomes in the ways they thought best. Besides the suitability of content, the mobility of the curriculum also means the transfer of the didactical system. Educational formats of the home institution, often from the West, are implemented in other regions of the world. There are valid concerns about whether these home educational models and tools are appropriate for crossborder implementation because of differences in the context, cultural values and backgrounds of teachers and students. ${ }^{55}$ How is this dilemma managed within a crossborder curriculum partnership?

Partnerships also have to make strategic decisions with respect to staffing. ${ }^{31}$ Some host institutions' partnerships rely almost exclusively on short-term staff coming from the home institution to deliver courses. These so-called fly-in, fly-out home staff stay for only a limited period at the host institution. Others primarily use host teachers to give all or certain courses in the curriculum. There are also partnerships that use a mixed form, which means that host staff in key positions are seconded.

Similar considerations between standardisation from the home institution and adaptation to the host institution have to be made in the area of assessment: Should test and exam methods exclusively come from home, or should they also be made by the host institution? Or will there be a mix? In the first case, exam dates and times have to be synchronised. In the latter case, the challenge will be to ensure an equal level of difficulty. This is tricky because it might evoke reactions of host staff feeling evaluated, not least because of a second inherent characteristic of crossborder curriculum partnerships. The next paragraph places this relationship in a broader context. 


\section{The unbalanced relationship}

All curriculum partnerships in the initial phase are, to a certain degree, unbalanced. Most of the information in terms of curriculum content and didactics is concentrated within the home institution, as it develops most of the educational materials. The host staff fully depends on the collaboration for the provision of the curriculum. This collaboration requires intensive multi-level and on-time communication. This inherent dependency makes the relationship vulnerable. Furthermore, curriculum partnerships are often formed along colonial lines. The transfer of didactics and philosophy might be more challenging given the unbalanced relationship. This unbalanced relationship within the partnership has also been reflected by some case studies that reported superior attitudes among home staff members and inferior feelings among host staff members. ${ }^{56}$ In the long run, the partnership has to develop into a more balanced one. But what are the educational gains for the home institution? If there are gains, how can they flow back to the home institution? How does this unbalanced relationship affect sustainability, teachers' job satisfaction and the quality of education within the partnership?

\section{Research gaps}

Crossborder curriculum partnerships are expanding and have high potential growth rates, but research and monitoring of transnational education programmes is not keeping pace with the worldwide boom in such programmes. ${ }^{16,17}$ Most crossborder curriculum partnerships stem from disciplines like business, ICT and engineering. This is not surprising, as these programmes are perceived to be more global in nature. ${ }^{49}$ There is an urgent call for more domain-specific research on the educational and project management challenges of these partnerships. ${ }^{13,57}$ This dissertation answers this call, as it examines how pioneering institutions in the medical domain deal with the aforementioned educational challenges. These challenges exist in the medical domain as well, perhaps to a greater degree, as illustrated by the opening quotes of Chapter 1 . Whitehead ${ }^{58}$ and $\mathrm{Eva}^{59}$ pointed out the long and fruitful international traditions of medical education while stressing the dangers of ethnocentricity. For instance, some of the medical home content (e.g. diseases, skills and behaviour) may be inapplicable to the host context. Moreover, home medical programmes often have a student-centred approach. Hodges, et al. ${ }^{60}$ argued that not all elements of medical competences are universal. They proposed that activities which seem to promote the dissemination of Western values should be carefully planned and studied.

\section{Aim and research questions}

Cross-border provision of education has attracted attention from governments and regulatory bodies. Their main focus is on ensuring quality and safeguarding the system 
from rogue providers. ${ }^{46} 61$ This has resulted in a number of global guidelines on how to provide quality in curriculum partnerships. ${ }^{10,13,62,63}$ However, these codes are quite general and pay little attention to the educational processes within crossborder curriculum partnerships.

As curriculum partnerships are expected to grow in the medical domain as well, ${ }^{64}$ this study aims to be of guidance to well-intentioned leaders and programme directors who are on the verge of establishing similar types of partnerships. Therefore, this study does not use a philosophical approach that elaborates on the potential merits and dangers of this phenomenon. Nor does it intend to evaluate the quality of medical curriculum implementation. Instead, it takes the growth and existence of medical curriculum partnerships as a given and focuses on identifying educational challenges and issues in medical crossborder curriculum partnerships. As this dissertation is the first of its kind to address the educational challenges in the medical domain, it has an explorative character guided by the following research questions:

Research question 1: What are the main challenges when establishing and maintaining a crossborder medical curriculum partnership?

Research question 2: How do crossborder medical curriculum partnerships balance standardisation and adaptation?

Research question 3: What are the strategies for establishing and maintaining a sustainable crossborder medical curriculum partnership?

To answer these questions, the dissertation looks at medical crossborder curriculum partnerships from five different angles. Chapter 2 presents a narrative literature review of the challenges that hinder and the strategies that promote crossborder curriculum partnerships. This review includes publications almost exclusively from outside the medical domain. Chapter 3 discusses the results of interviews with medical programme directors of host and home institutions. These interviews explore whether the challenges and strategies identified in the literature review resonate with the interviewees' experiences and whether they encountered additional challenges in medical curriculum partnerships. Chapter 4 concentrates on the experiences of host teachers who play a crucial role in the actual delivery of the curriculum. It attempts to identify the types of perceptions that might prevail among the host teachers' population using $\mathrm{Q}$ methodology. Chapter 5 focuses on the host students within various medical institutions. As key stakeholders, they provide valuable insights on how they experience the host curriculum. Chapter 6 analyses, by means of a case study, the role of a home institution in the transfer of the actual curriculum and the overall setup of the relationships and working procedures. Chapter 7 recommends strategies that can contribute to successful and sustainable medical crossborder curriculum partnerships. It presents 12 tips that aim to guide those on the verge of establishing similar types of partnerships. The chapter synthesises the insights from the dissertation. Finally, Chapter 8 summarises and discusses the findings in relation to the research questions. It touches upon a debate on whether this form of internationalisation is desirable in the first place by looking at a number of ethical arguments and how they relate to the study findings. It briefly addresses some conditions for the future of crossborder education, as well as 
potential areas for further research. Finally, the chapter concludes with the strengths and limitations of this dissertation. Although each chapter addresses a different perspective with a different methodology, together, they are complementary and designed to provide a comprehensive albeit not exhaustive picture of crossborder medical curriculum partnerships.

\section{Reflexivity}

The assumptions of reality and knowledge that underpins this dissertation can be classified as a constructivist lens. ${ }^{65}$ The data collection and my interpretations are coloured by my experiences and perceptions of the respondents. Therefore, before proceeding to the next chapters, I provide relevant background information on my experiences that can contribute to a better conceptualisation of my research findings.

Looking back, my career seems to have followed a well-planned, highly structured path, with the pieces of the puzzle fitting neatly into one another. Yet, when I obtained my Master's degree in international economics at Maastricht University in 2002, the career I would be pursuing, back then, was far from obvious. Relevant personal and professional experiences on the theme of this dissertation started one year later when I moved to Mozambique, where I became involved in implementing a student-centred economics curriculum in a low-resource environment and experienced the challenges of this endeavour. My main responsibilities were related to faculty development and helping the Mozambican staff members grasp the deeper concepts and work with student-centred educational materials, mostly coming from Maastricht University. This experience is where I obtained my first set of lenses.

In 2005, I had a more or less comparable experience in Saudi Arabia, where I, was recruited locally and responsible for the adaptation of the assessment component of an Australian medical curriculum. I witnessed the challenges teachers and students face when working with a new didactic system and materials/ideas that were developed elsewhere. Besides the struggle, I also noticed pride and optimism among my teacher colleagues and students.

In 2009, I returned to Maastricht University as a project leader of a crossborder medical curriculum partnership between the Faculty of Health Medicine and Life Sciences and a newly established college in Saudi Arabia. Because of my past experiences, I was a bit familiar with some of the elements that could exist on the recipient's side; little to no prior experiences, ideas or convictions did I have, however, of the exporting side of medical curricula. Ever since the first day, I have wondered whether such partnerships are feasible in the first place. More importantly, will they create host institution graduates who are welcomed in the host country? These questions, among others, triggered the start of this dissertation in 2012.

To recap, it were these three work experiences in particular that influenced the way I perceive and conceptualise this form of internationalisation. They have coloured the lenses through which I relate to this phenomenon. I do not consider myself an apostle of this phenomenon; I continue to wonder about the desirability and added value of 
this form of internationalisation. I have experienced this process in different cases and from different positions; of course, it is nearly impossible to generalise the findings to all types of institutions, countries and disciplines. Case-specific motivations and circumstances highly influence the outcome of the aforementioned questions. 


\section{References}

1. Levatino A. Transnational higher education and international student mobility: determinants and linkage. High Educ. 2017;73(5):637-53.

2. Sharma Y. US-Malaysia medical school collaboration collapses. 2014. [Internet] Available from [http://www.universityworldnews.com/article.php?story=20140819111911158]; Accessed December 2015.

3. Coleman D. Quality assurance in transnational education. J Stud Int Educ. 2003;7(4):354-78.

4. Lane JE. Importing Private Higher Education: International Branch Campuses. J Comp Pol Anal. 2011;13(4):367-81.

5. OECD. Internationalisation and Trade in Higher Education Opportunities and Challenges. Paris: OECD 2004.

6. OECD, World Bank. Cross-border tertiary education a way towards capacity building. 2007. [Report] Available from [http://hdl.handle.net/10986/6865]; Accessed February 2012.

7. Knight J. Higher Education in Turmoil, vol. 13. Toronto: Sense Publishers; 2008.

8. McBurnie G, Pollock A. Transnational Education: An Australian Example. International Higher Education. 1998;10:12-4.

9. McBurnie G, Ziguras C. Transnational education: Issues and trends in offshore higher education: Routledge; 2007.

10. Unesco, Council of Europe. The UNESCO-CEPES/Council of Europe code of good practice for the provision of transnational education. 2001. [Report] Available from [http://www.cepes.ro/hed/recogn/groups/ transnat/code.htm]; Accessed September 2013.

11. Knight J. Crossborder education: An analytical framework for program and provider mobility. In: Higher Education: Handbook of Theory and Research. Volume 21. Edited by Smart JC. Dordrecht: Springer Netherlands; 2006: 345-95.

12. Vincent-Lancrin S, Pfotenhauer S. Guidelines for Quality Provision in Cross-Border Higher Education: Where Do We Stand? 2012. [Report] Available from [http://www.oecd-ilibrary.org/education/guidelinesfor-quality-provision-in-cross-border-higher-education_5k9fd0kz0j6b-en]; Accessed September 2013.

13. Knight J. Borderless, offshore,transnational and crossborder education-definitions, and data dilemmas. 2005. [Report] Available from [http://www.obhe.ac.uk/documents/view_details?id=35]; Accessed August 2015.

14. Lee JT. Education hubs and talent development: policymaking and implementation challenges. High Educ. 2014;68(6):807-23.

15. Matthews D. Transnational education growing at 'brisk pace'. 2013. [Internet] Available from [http://www.timeshighereducation.co.uk/news/transnational-education-growing-at-briskpace/2007101.article]; Accessed September 2013.

16. Kosmutzky A, Putty R. Transcending Borders and Traversing Boundaries: A Systematic Review of the Literature on Transnational, Offshore, Cross-Border, and Borderless Higher Education. J Stud Int Educ. 2016;20(1):8-33.

17. British Council. The shape of things to come 2. The evolution of transnational education: data, definitions, opportunities and impacts analysis. 2013. [Report] Available from [https://www.britishcouncil.org/education/ihe/knowledge-centre/transnational-education/the-shape-of-things-to-come-2]; Accessed August 2013.

18. Healey NM. Managing International Branch Campuses: What Do We Know? Higher Education Quarterly. 2015;69(4):386-409.

19. Wilkins S. Transnational Higher Education in the 21st Century. J Stud Int Educ. 2016;20(1):3-7.

20. Lawton W, Katsomitros A. International branch campuses: data and developments. 2012. [Report] Available from [http://www.obhe.ac.uk/documents/view_details?id=894]; Accessed June 2013.

21. Böhm A, Follari M, Hewett A, Jones S, Kemp N, Meares D, Pearce D, Van Cauter K. Vision 2020 Global student mobility. 2004. [Report] Available from [https://www.britishcouncil.org/sites/default/files/vision2020.pdf]; Accessed September 2016.

22. Wilkins S, Balakrishnan MS, Huisman J. Student Choice in Higher Education: Motivations for Choosing to Study at an International Branch Campus. J Stud Int Educ. 2012;16(5):413-33.

23. Zhang L, Kinser K, Shi Y. World Economies and the Distribution of International Branch Campuses. International Higher Education. 2014;8(77):8-9. 
24. Tokpah WN. Association of Liberian Universities, Partners Sign Memorandum of Understanding. 2017. [Internet] Available from [http://www.frontpageafricaonline.com/index.php/news/5218-association-ofliberian-universities-partners-sign-memorandum-of-understanding]; Accessed August 2017.

25. de Wit H. New sources of cross-border HE are emerging. 2017. [Internet] Available from [http://www.universityworldnews.com/article.php?story=20170508235113407]; Accessed May 2017.

26. Healey NM. Is higher education in really 'internationalising'? High Educ. 2008;55(3):333-55.

27. Chin V, Koch A, Meyer M, Tan E, Waltermann B. The Companies Piloting a Soaring Region. 2012. [Blog] Available from [https://www.bcgperspectives.com/content/articles/globalization_growth_companies_ piloting_soaring_region_2012_southeast_asia_challengers/]; Accessed June 2016.

28. Choudaha R. The rise of 'glocal' students and transnational education. 2012. [Blog] Available from [https://www.theguardian.com/higher-education-network/blog/2012/jun/21/opportunities-intransnational-education]; Accessed August 2014.

29. Miller-Idriss C, Hanauer E. Transnational higher education: offshore campuses in the Middle East. Comp Educ. 2011;47(2):181-207.

30. Chapman A, Pyvis D. Quality, Identity and Practice in Offshore University Programmes: Issues in the Internationalization of Australian Higher Education. Teach High Educ. 2006;11(2):233-45.

31. Shams F, Huisman J. Managing Offshore Branch Campuses: An Analytical Framework for Institutional Strategies. J Stud Int Educ. 2012;16(2):106-27.

32. van der Wende MC. Globalisation and Access to Higher Education. J Stud Int Educ. 2003;7(2):193-206.

33. Fang W. The Development of Transnational Higher Education in China A Comparative Study of Research Universities and Teaching Universities. J Stud Int Educ. 2012;16(1):5-23.

34. Verbik L, Rumbley LE, Altbach PG. The international Branch campus -Models and Trends. 2006. [Report] Available from; Accessed September 2013.

35. O'Mahony J. Enhancing Student Learning and Teacher Development in Transnational Education 2014. [Report] Available from [http://www.heacademy.ac.uk/resources/detail/internationalisation/enhancingTNE]; Accessed October 2016.

36. Smith B. Netherlands one step closer to full degrees overseas as TNE bill passes. 2017. [Internet] Available from [https://thepienews.com/news/netherlands-one-step-closer-full-degrees-overseas-tne-billpasses/]; Accessed Juli 2017.

37. Tilak JBG. Higher education: a public good or a commodity for trade? PROSPECTS. 2008;38(4):449-66.

38. Mönkkönen J. Transnational education holds great potential. 2015. [Blog] Available from [https://blogs.uef.fi/keeping-the-lead/2015/06/17/transnational-education-holds-great-potential/]; Accessed August 2016.

39. Wallace M, Dunn L. Teaching in Transnational Higher Education: Enhancing Learning for Offshore International Students. New York: Routledge; 2013.

40. Altbach PG. Peripheries and Centres: Research Universities in Developing Countries. Asia Pacific Educ Rev. 2007;10(1):15-27.

41. Eckel PD, Green MF, Affolter-Caine B. Curricular Joint Ventures: A New Chapter in US Cross-Border Education? Pol Futures Educ. 2004;2(2):299-315.

42. Wilkins $\mathrm{S}$, Huisman J. The international branch campus as transnational strategy in higher education. High Educ. 2012:64(5):627-45.

43. British Council, German Academic Exchange Service (DAAD). Impacts of transnational education on host countries. 2014. [Report] Available from [https://www.britishcouncil.org/sites/default/files/tne_study_ final_web.pdf]; Accessed August 2015.

44. Sidhu R. How to assemble a knowledge economy: Singapore's transnational education project. Perspect Educ. 2006;24(4):45-56.

45. Knight J, Morshidi S. The Complexities and Challenges of Regional Education Hubs: Focus on Malaysia. HETIJHEEP. 2011;62(5):593-606.

46. Mok KH. The Quest for Regional Hub of Education: Growing Heterarchies, Organizational Hybridization, and New Governance in Singapore and Malaysia. J Educ Policy. 2011;26(1):61-81.

47. Levy DC. The unanticipated explosion: Private higher education's global surge. Comp Educ Rev. 2006;50(2):217-40.

48. Wilkins S, Balakrishnan MS, Huisman J. Student Choice in Higher Education. J Stud Int Educ. 2012;16(5):413-33.

49. Burgess P, Berquist B. Cross-Border Delivery Projects, Programs, and Providers. In: The SAGE Handbook of International Higher Education Edited by Deardorff DK, de Wit H, Heyl JD, Adams T. Thousand Oaks, California: SAGE Publications, Inc.; 2012: 325-42. 
50. Kinser K, Lane JE. International Branch Campuses: Evolution of a Phenomenon. International Higher Education. 2016;85:3-5.

51. Levitt T. The globalisation of markets. Harv Bus Rev. 1983;61(3):92-102.

52. Douglas SP, Wind Y. The myth of globalization. Columbia J World Bus. 1987;22(4):19-29.

53. Heffernan T, Morrison M, Basu P, Sweeney A. Cultural Differences, Learning Styles and Transnational Education. J High Educ Pol Manag. 2010;32(1):27-39.

54. Kinser K, Lane JE. Managing the oversight of international branch campuses in higher education. HEMP. $2014 ; 24(3)$.

55. Schapper JM, Mayson SE. Internationalisation of curricula: an alternative to the Taylorisation of academic work. J High Educ Pol Manag. 2004;26(2):189-205.

56. Dobos K. "Serving two masters" - academics' perspectives on working at an offshore campus in Malaysia. Educ Rev. 2011;63(1):19-35.

57. Lane JE, Brown II, Christopher M, Pearcey MA. Transnational campuses: Obstacles and opportunities for institutional research in the global education market. New Directions for Institutional Research. 2004;2004(124):49-62.

58. Whitehead CR. On gunboats and grand pianos: medical education exports and the long shadow of colonialism. Adv Health Sci Educ Theory Pract. 2016;21(1):1-4.

59. Eva KW. Witnessing the globalisation of medical education first-hand. Med Educ. 2009;39(43):628-36.

60. Hodges BD, Maniate JM, Martimianakis MA, Alsuwaidan M, Segouin C. Cracks and crevices: Globalization discourse and medical education. Med Teach. 2009;31(10):910-7.

61. Lane JE, Kinser K. The Cross-Border Education Policy Context: Educational Hubs, Trade Liberalization, and National Sovereignty. New Dir High Educ. 2011;(155):79-85.

62. Quality Assurance Agency for Higher Education. Code of practice for the assurance of academic quality and standards in higher education. Section 2. Collaborative provision and flexible and distributed learning (including e-learning). 2010. [Report] Amplified version of the second edition 2010. Available from [http://www.bbk.ac.uk/linkinglondon/resources/apel-creditresources/pub_Nov2010_QAA_COP_section_2_HE_guidance.pdf]; Accessed August 2017.

63. Knight J. Higher Education Crossing Borders. A Guide to the Implications of the General Agreement on Trade in Services (GATS) for Cross-Border Education. 2006. [Report] Available from [http://www.col.org/colweb/site/pid/4059]; Accessed November 2012.

64. Harden RM. International medical education and future directions: a global perspective. Acad Med. 2006;81(12):S22-S9.

65. Bergman E, de Feijter J, Frambach J, Godefrooij M, Slootweg I, Stalmeijer R, van der Zwet J. AM Last Page: A Guide to Research Paradigms Relevant to Medical Education. Acad Med. 2012;87(4):545. 


\section{Chapter 2.}

\section{A literature review of crossborder curriculum partnerships}

Published as: Waterval DGJ, Frambach JM, Driessen EW, Scherpbier AJJA: Copy but Not Paste: A Literature Review of Crossborder Curriculum Partnerships. Journal of Studies in International Education. 2014, 19(1):65-85. 


\section{Abstract}

Introduction: Crossborder curriculum partnerships, entailing the transposition of an entire curriculum and the related degree(s) from "home" to "host" institution, are a rather new phenomenon in internationalisation in education. The literature describes successful and unsuccessful partnerships, but critical factors for the success or failure of sustainable partnerships remain to be identified.

Methods: We conducted a narrative literature review to find such factors. Using an iterative approach, we analysed 39 articles retrieved from Web of Science, Google Scholar, ERIC, PubMed, and PsycInfo and meeting the inclusion criteria.

Results: We developed a framework of 13 factors in four domains: students, teachers, curriculum, and soft and hard project management.

Discussion: Simply copy-pasting a curriculum is generally considered to be destined for failure. To overcome challenges, partners should take preventive and affirmative measures across multiple domains. The findings may provide guidance to those considering or engaged in designing, developing, managing, and reviewing a crossborder partnership. 


\section{Introduction}

Implementing and delivering a curriculum outside its country of origin is an internationalisation strategy that is gaining increasing popularity among higher education institutions. In the 1980s, internationalisation consisted mainly of students, followed by faculty, crossing borders in search of high-quality educational experiences. In the next internationalisation wave in the late 1990s, it was not only students and faculty but also courses, materials, and even complete curricula that moved across borders ${ }^{1}$, and this trend is continuing today driven by the steep rise in global demand for highquality education. Bohm, et al. ${ }^{2}$ predict a fourfold increase in the number of students pursuing an international higher education degree from 1.8 million students in 2000 to 7.2 million in 2025. Some of these students will be international (exchange) students, taking courses in Western countries, but a significant proportion will prefer to remain in their home country. This offers an opportunity for established academic institutions to expand and internationalise their curricula, which is especially attractive in times of dwindling government funding ${ }^{3}$ and explains why, recently, many institutions have taken the step of exporting their curriculum. ${ }^{4}$

Delivery of a curriculum outside national borders has different shapes. In literature, concepts and definitions are not used uniformly, similar meaning is given to different terms such as "offshore education," "borderless education," "transnational education," and "crossborder education" and different meaning to similar terms. ${ }^{5-8}$. We will follow the definition by Knight ${ }^{9}$ and use the term "crossborder," which emphasizes the crossing of national jurisdictional borders by teachers, students, curricula, institutions and/ or course materials, we extended this term to crossborder curriculum partnership (CCP) to highlight our focus on partnerships set up to transpose the curriculum of the "home" institution to the "host" institution (located in different countries).

CCPs can be established through formal delivery agreements or by establishing a branch of the home institution in the host country. ${ }^{9-11}$ The terms host and home institution reflect the different relationships of the partner institutions to the curriculum: The curriculum of the home institution is in some way transposed to the host institution ${ }^{12}$ CCPs may differ in legal aspects and the division of responsibilities between partners, but they generally share the following elements: (a) the host institution is largely responsible for the recruitment of (often local) students and staff, (b) while the home institution provides the educational program, and (c) is responsible for quality assurance. The overall objective of CCPs is to provide the same educational experience to students in both institutions and in most cases to confer a similar degree on completion of the curriculum.

CCPs can be an attractive option for students who are looking for a foreign qualification but-for cultural, financial, or other reasons-prefer to stay in their country of residence. Host countries benefit from CCPs because they contribute to the internationalisation and modernisation of the higher education sector, facilitate education and training of a skilled workforce, retain students and enhance a country's geopolitical status. The benefits to home institutions include financial gains, enhancement of institutional profile, expansion of the student base, and enhanced opportunities for student 
and staff mobility, development of new curricula, research and development, and strategic network building. ${ }^{13,14}$ Student exchange between institutions also offers opportunities to develop student's intercultural competences and skills. Transposing a curriculum in its entirety to a context for which it was not designed and where it is to be delivered by staff that was not involved in its construction is a delicate process, to say the least. Students and faculty of the host institution are inevitably less familiar with the curriculum and the educational approach than their counterparts at the home institution, and this complicates the implementation and delivery of the curriculum. Lane, et al. ${ }^{15}$ (p.59) call for "institutional research to aid institutional decision makers in understanding the important factors associated with operating a postsecondary campus in an environment outside the country of institutional origin." To contribute to this research, we conducted a literature review to identify factors that appear to play a crucial role in the success and failure of sustainable CCPs.

\section{Methods}

We conducted a structured narrative review of the literature, assuming that this would enable us to generate a comprehensive inventory of factors impacting the sustainability of CCPs. Using the search terms "transnational education," "cross(-)border education," "offshore education," and "borderless education," we searched all publications in Web of Science, Google Scholar, ERIC, PubMed, and PsycInfo published before January 2013. In PubMed and PsycInfo, we searched "any field"; in ERIC and Web of Science, we searched titles, abstracts, and key terms; and in Google Scholar, we searched titles. The searches were limited to publications in English and Dutch. To identify any studies not turned up by the initial search, we searched the references of the articles retrieved by the initial search. Using a convergent search strategy, we initially included all types of publications on CCPs in any discipline and any geographical location, and then gradually narrowed the search to journal articles on factors contributing to success and failure of sustainable CCPs in which it is the stated intention of both partners to deliver the same educational experience and educational outcomes to students at the host and home institution. In the final review, we included only articles published in peerreviewed journals dealing with crossborder delivery of full curricula, which meant exclusion of articles addressing capacity development partnerships, joint degree partnerships, and government policy to promote or regulate CCP at a national level.

Concurrently with Rounds 1 and 2 (Figure 2.1), we conducted an iterative process aimed at identifying factors with relevance to success or failure of CCPs. Based on the articles that were read 13 factors were identified and grouped into four domains. Agreement on the factors and domains was reached by all the authors through discussion. The 13 factors were used to code sections of the articles that contained descriptions of one or more factors and/or suggestions for remedial steps to counteract negative effects. This process is summarized in the data abstraction form in the appendix 2.1, which lists the articles with research methods, geographical context, discipline, and main factors for success or failure. 


\section{Results}

\section{Search Results}

Of the 751 publications resulting from the initial search, 681 did not meet the criteria, and the 70 remaining articles were reduced to 39 in the second round (Figure 2.1).

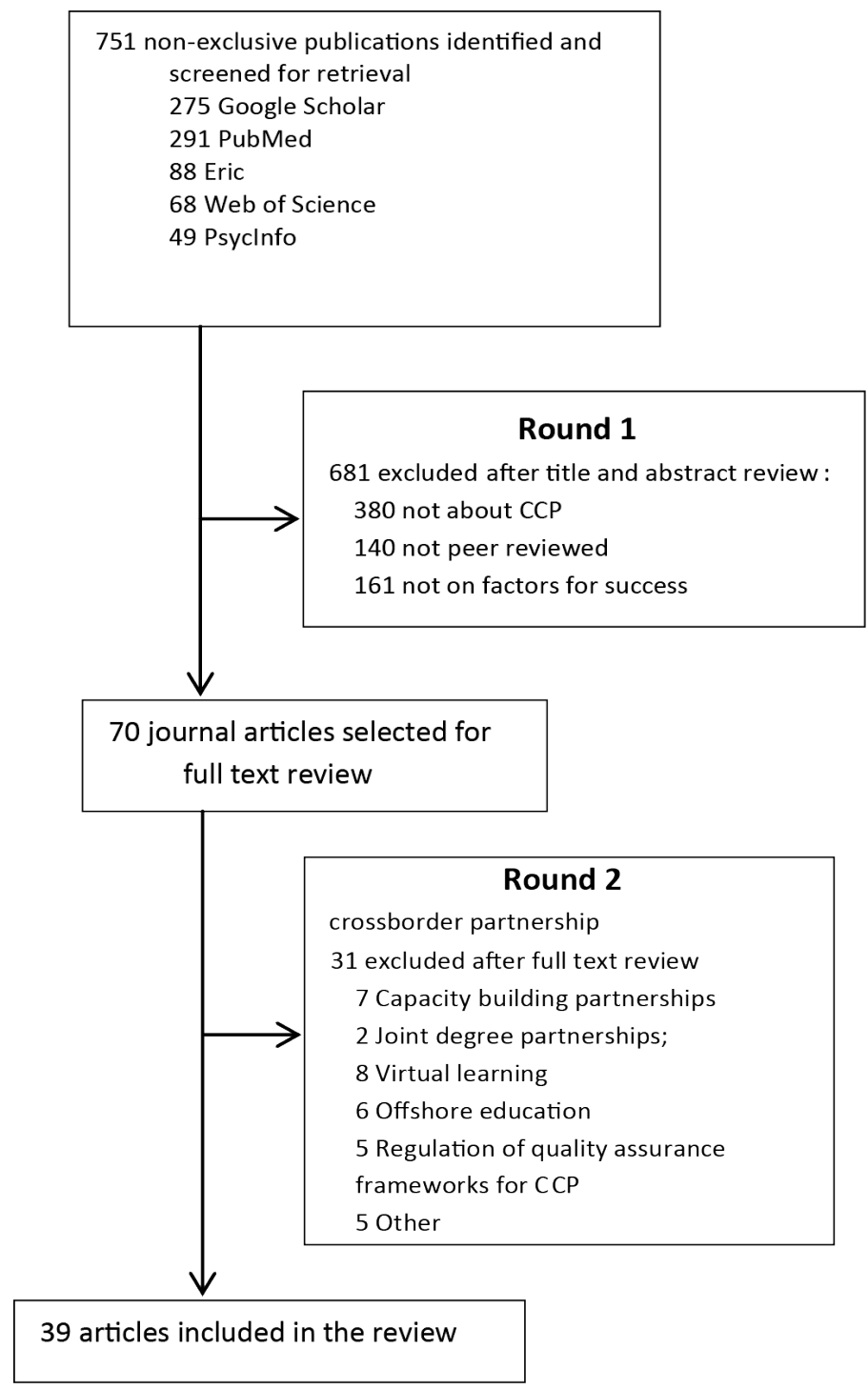

Figure 2.1: Review process.

Note. $\mathrm{CCP}=$ crossborder curriculum partnership. 
All studies used a qualitative approach but methods varied: document analysis, interviews, questionnaires, focus groups, literature reviews, and observations (see appendix 2.1).

From the analysis of the coding, we derived a framework of four domains encompassing the main factors for success and failure of sustainable CCPs (Figure 2.2). The first three domains relate to differences between host and home institution, which potentially impact curriculum implementation and delivery. These three domains are context sensitive, that is, their applicability differs across partnerships. The fourth domain is concerned with soft and hard project management ${ }^{16}$ and relates to factors that must be managed properly for CCPs to be successful.

The essential factors for CCP were clustered into meaningful domains to structure the framework, but it should be noted that all factors and domains are strongly interconnected. As the scope of this article does not permit in-depth discussion of each factor, we provide references to relevant studies. We discuss the domains and the factors within them in the order in which they are presented in Figure 2.2. In addition, we present measures to avoid pitfalls and enhance the success of CCPs proposed in the articles reviewed.

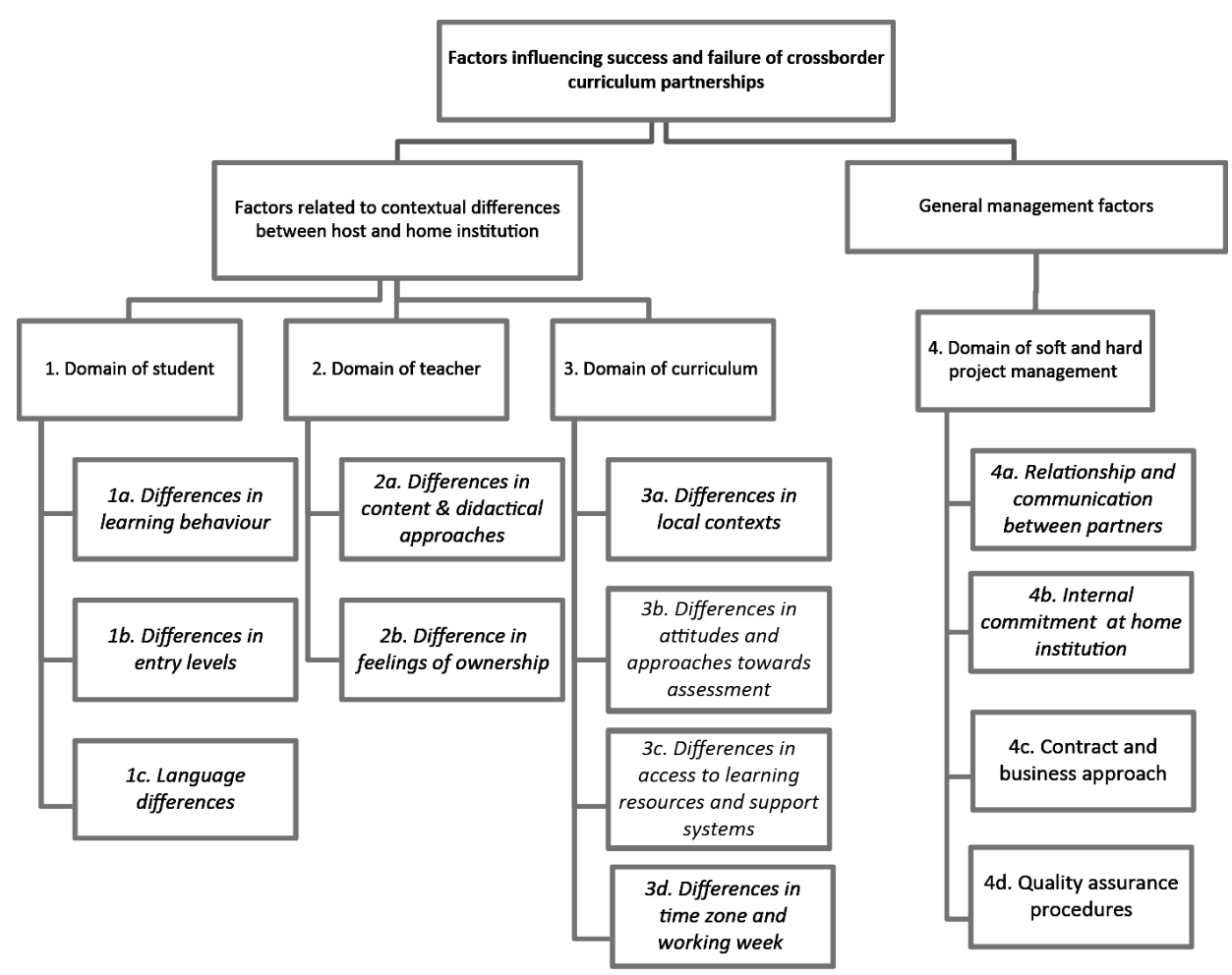

Figure 2.2: Framework of factors influencing the success and failure of crossborder curriculum partnerships. 


\section{Domain of the student}

The student domain contains three factors that challenge the success of CCPs. Factor $1 \mathrm{a}$ (Figure 2.2) relates to differences between home and host institution with regard to students' learning behaviours, which may interfere with the objective of comparable study experiences for all students. Briguglio ${ }^{17}$, Castle and Kelly ${ }^{18}$, Gregory and Wohlmuth ${ }^{19}$, Heffernan, et al. ${ }^{20}$, and Wilson ${ }^{21}$ report that the student-centered educational approach that is characteristic of many export curricula can be difficult to cope with for students of the host institution, due to the predominantly "spoon-fed" approach in secondary education. Chapman and Pyvis ${ }^{22}$ report that teachers at the home and host institution observed a "subtle cultural variation in [students'] style of learning and thinking" (p. 299), which became manifest in certain situations, for example, when students were expected to show active, self-directed study behaviour. In a study on nursing programs, Wilson ascribes differences in classroom dynamics not to differences in learning behaviour but to different feelings about prestige and hierarchical relationships within student groups. For example, students were less likely to participate in classroom discussions if they perceived a risk of losing face. ${ }^{21}$ A study from Pimpa $^{23}$ on a partnership between an Australian and a Thai institution makes a similar point and additionally emphasizes differences in communication patterns, motivation, and attitudes toward work.

Measures to address differences in learning behaviours are reported by Ziguras ${ }^{24}$ and Eldridge and Cranston ${ }^{25}$, who found that students, regardless of their prior learning behaviour, were able to adapt to a different learning approach, especially if during the initial transition phase supportive measures were in place, such as study skill workshops, adaptation of learning tasks to the local context and interactive, supportive e-learning tools. A review on learning styles in CCP contexts by Eaves ${ }^{26}$ confirms these findings reporting tentative evidence for culture-specific learning styles, which appear to be adaptable between educational contexts.

Factor $1 \mathrm{~b}$ (Figure 2.2) relates to different admission requirements, which can jeopardize the attainment of similar outcomes in both institutions. Assuring equivalence of entry levels is no sinecure, however, considering the likelihood of differences in secondary education systems between home and host country..$^{19}$ Moreover, in a comparative case study by Dunworth ${ }^{27}$, some interviewees talked about a tendency among host institution recruitment officers to give priority to admitting high numbers of students, yielding high income from tuition fees, over strict adherence to home institution entry criteria. The study reports tension between enrollment figures and educational standards.

Lane $^{1}$ mentions that differences between entry levels could be overcome by introducing an (obligatory) preparatory year to bridge the gap between host country secondary education and home institution entry criteria. Castle and Kelly ${ }^{18}$ suggest that in the early years of the partnership, admission to the host institution might (partly) be managed by the home institution to institutionalize admission procedures that ensure equivalent entry levels. After some time, these procedures and the entry criteria should be evaluated and, if needed, adapted to meet the partnership objectives.

Factor 1c (Figure 2.2) concerns the risk of language differences between the partner institutions interfering with the equivalence of learning experiences and outcomes. 
As English is the first language of many home countries but a second language for students in the host institution, language problems can complicate learning. Similarly, for teaching staff at the host institution, English is often the second or third language. ${ }^{28}$ Gregory and Wohlmuth ${ }^{19}$ report that adequate proficiency of English for daily usage did not automatically imply competence to use English academically, and Briguglio ${ }^{17}$ states that difficulties adapting to an unfamiliar learning methodology, which are frequently reported by students at host institutions, may have more to do with English proficiency than with learning and teaching styles.

A remedial approach proposed by Lane, Brown, Christopher and Pearcey ${ }^{15}$ and Gregory and Wohlmuth ${ }^{19}$ is to improve English language support by establishing language centers, providing tailor-made courses, actively encouraging students to enrol in various programs and targeting all cohorts instead of first-year students only. Briguglio ${ }^{17}$ takes this approach a step further by recommending that teaching staff should take on the double role of subject and language teacher.

\section{Domain of the teacher}

The two factors in the domain of the teacher relate to curriculum delivery and implementation challenges due to the requirement to provide similar learning experiences and outcomes to students at both institutions. Factor $2 \mathrm{a}$ is concerned with the need for teachers at the partner institutions to possess comparable content knowledge and didactic skills relevant to the delivery of the curriculum in question. ${ }^{29}$ Not surprisingly, this is a difficult requirement to meet as recruitment of host institution teachers is usually the province of the host institution. Coleman ${ }^{12}$ notes that most teachers at the host institution lack the required knowledge and experience to competently present the content and apply the methodology of the new curriculum, and bringing teachers up to par is an essential factor for the success of CCPs. A similar view is presented by Ziguras ${ }^{24}$ : "Teachers' reluctance to relinquish control of their teaching was seen as a major impediment to the introduction of new leaning approaches from the Australian home institution" (p. 15).

Studies by Heffernan and Poole ${ }^{30}$, Lim $^{31}$, Shams and Huisman ${ }^{32}$, and Smith ${ }^{33}$ emphasize the importance of a sound faculty development induction program to minimize differences in didactic skills and content knowledge. Dobos ${ }^{28}$ recommends extra support and peer-to-peer mentoring to help faculty transition from their original teaching philosophy to the one required for the new curriculum. To strengthen host teachers' competence, Shams and Huisman propose frequent visits from staff of the home institution to teach at the host institution and act as a role model for local staff. A more radical solution proposed by Dunworth ${ }^{27}$ and $\operatorname{Dobos}^{28}$ is that, if feasible, the home institution should recruit at least part of the host institution's teaching staff to safeguard quality and at the same time educate the host institution's recruitment officers in selecting suitable staff members.

Factor $2 \mathrm{~b}$ (Figure 2.2) relates to difference between staff members' feelings of ownership of the programme. In a study of host teachers' experiences of a CCP, Dobos ${ }^{28}$ cites teachers' perceptions, such as "just follow the syllabus" and "we are just here to follow the home institution." Similar moods are reported in a study by Smith. ${ }^{33}$ Such 
feelings are to be expected when the need for the host institution to create new materials is limited because the program is adopted from the home institution.

\section{Domain of the curriculum}

The focus of the curriculum-related domain is educational materials. Factor 3a (Figure 2.2) relates to adaptation of educational materials due to contextual differences. Although materials should be similar, some degree of adaptation to the local context may be inevitable and even desirable. ${ }^{19}$, 28, 34-36 McBurnie $^{35}$ observes that in most host countries, education serves not only an educational but also a nation-building goal, which is reflected in courses on national values and ethics. In most CCPs, the nation-building curricular component is represented by flanked courses and activities as add-ons to the curriculum of the home institution. In addition, legal and ethical elements of the home curriculum that are not relevant to the host country should be replaced by elements fitting the local context. ${ }^{34}$ The same holds for certain cases, assignments, and recommended readings that are specifically oriented to (professional) practice in the home country. ${ }^{19}$

Factor 3b (Figure 2.2) relates to assessment. If host and home institution aim to provide students with similar learning experiences leading to similar degrees, it is crucial to ensure comparability of assessment programs. ${ }^{12}$ Eldridge and Cranston ${ }^{25}$ and Miliszewska and Sztendur ${ }^{37}$ testify that assessment is an obstacle to sustained crossborder partnerships, especially when host institution teachers have to use unfamiliar assessment instruments and grading and standard setting procedures. To address this problem, the host institution can be made responsible for assessment. ${ }^{18,} 37$ Partner institutions should aim for a delicate balance between comparable assessment rules and procedures on one hand and small adaptations, on the other, to ensure acceptance and fit within the host context. ${ }^{32}$

Factor 3c (Figure 2.2) relates to learning resources and student support systems. Coleman $^{12}$, Stella ${ }^{38}$, Castle and Kelly ${ }^{18}$, and Wilson ${ }^{21}$ report a lack or limited availability of educational resources and student support systems, such as libraries, access to online resources and student counselors, particularly in young host institutions. Paucity of resources and support in privately funded host institutions may be related to cost considerations or host institutions placing less value on support structures compared with the home institution. ${ }^{27}$

To address this challenge, Coleman ${ }^{12}$ recommends that the details of these services be described meticulously and comprehensively when the partnership contract is drafted. Gregory and Wohlmuth ${ }^{19}$ propose practical short-term measures, such as smart use of e-learning techniques and negotiating with publishers for online access to literature for students in the host institution ${ }^{18}$

Factor $3 \mathrm{~d}$ represents curriculum delivery problems due to host and home countries being located in different time zones and having different working weeks. Studies by Dunworth ${ }^{27}$, Lane, Brown, Christopher and Pearcey ${ }^{15}$, and Lim $^{31}$ point at the importance of on-time material exchange, synchronisation of assessment papers, and immediate support. A nice illustration coming from Lane ${ }^{1}$ are home institution IT administrators, who schedule an update in the middle of the night to minimize impact on 
users. However, the middle of the night in the home country maybe the middle of the day in the host country and thus cause severe disruption in services.

\section{Domain of project management.}

The domain of project management is divided into soft and hard project management, with soft management relating to communication and personal relationships and teacher commitment, whereas hard management is concerned with rules, regulations, documentation, and record keeping.

Many studies have addressed communication and personal relationships (Factor 4a, Figure 2.2). In an investigation of 10 CCPs, Heffernan and Poole ${ }^{30}$, Heffernan and Poole ${ }^{39}$ identified effective, interculturally sensitive communication as one of the critical factors. Similarly, case studies by Eldridge and Cranston ${ }^{25}$ and Shanahan and McParlane ${ }^{40}$ show that effective communication creates and boosts trust between partner institutions. Sidhu ${ }^{41}$, Stella ${ }^{38}$, and Olcott $\mathrm{Jr}^{42}$ confirm this and point out that this applies at the level of teachers, project managers, and higher management. Effective communication also means using new technological tools to deal with time zone differences. ${ }^{28}$

Project managers should pay careful attention to relationships with teaching staff, because the relationship between the teachers of the partner institutions is inherently unequal. $28,33,43-45$ Shams and Huisman ${ }^{32}$ show that staff of the host institution tend to feel inferior, as illustrated by $\operatorname{Dobos}^{28}$ (p. 27), "We (the teachers of the host institution) do not feel professional equals... we have a master-slave relationship, which is not good". Such feelings can be exacerbated by a negative attitude and behaviour of home institution staff, who may consider crossborder commercial activities anathema and irreconcilable with the academic notion of free, publicly funded higher education. ${ }^{12,} 40$ Differing attitudes to CCP can also be a source of conflict among staff within the home institution, and studies also report that home institution staff are not uniformly familiar, confident, or experienced to work with international colleagues and students. Dunn and Wallace ${ }^{43}$ conclude that many universities do not have effective programs to induct and develop academic teaching in CCPs. Chapman and Pyvis ${ }^{22}$, Coleman ${ }^{12}$, Seah and Edwards ${ }^{44}$, and Smith ${ }^{33}$ recommend offering faculty a preparatory course to stimulate reflection and discussion, supported by a mentoring system for experienced and novice home staff.

Measures to promote successful relationships and communication are proposed in several studies. Dunworth ${ }^{27}$ demonstrates the importance of an intangible click between the partners at levels of higher and project management. If such a click is present, the relationship should be cherished and revitalized by frequent visits and, if absent, Heffernan and Poole ${ }^{39}$ recommend replacing key personnel at an early stage. Effective behaviour to create and maintain a sustainable relationship consists in "doing the little things" and acknowledging that any problem is a joint problem. ${ }^{19}$ According to Heffernan and Poole ${ }^{39}$, Dobos ${ }^{28}$, and Smith ${ }^{33}$, effective communication in CCPs can be maintained by a small, decentralized, dedicated project management group consisting of a key manager, a senior staff, and an external consultant, who meet regularly at fixed times. Castle and Kelly ${ }^{18}$ note that this is a good way to avoid time-consuming committee decision making, which is only detrimental to the dynamics of curriculum delivery and day-to-day management. 
Factor $4 \mathrm{~b}$ entails commitment in the home institution. Sidhu ${ }^{41}$, Lane ${ }^{1}$, Shanahan and McParlane ${ }^{40}$, Heffernan and Poole ${ }^{39}$, and Olcott $\mathrm{Jr}^{42}$ show that partnerships can deteriorate when staff at the home institution do not endorse the importance of the partnership, feeling that partnership endeavours distract them from other, more important tasks, such as research. Sidhu shows how promises made at top management level, such as sending in home institution staff, proved impossible to fulfil at a later stage and eventually resulted in the termination of activities.

The third factor in this domain (Factor 4c) concerns hard project management and relates to technical aspects, such as procedures, formal agreements, and other tools, which can be considered prerequisite for successful collaboration. We labelled this factor "contract and business approach." When contracts are not drawn up carefully and in sufficient detail, many partnerships struggle or fail entirely due to disagreements about responsibilities and key roles. ${ }^{35}$ As partnerships mature, collaboration becomes more complex and forecasts of the past may not be borne out by actual events. ${ }^{36}$ Examples are lower enrolment rates than expected, insufficient administrative support staff, recruitment problems, visit and flight arrangements, minute taking, visa issues, scheduling of academic calendars, and synchronisation of activities. ${ }^{27}, 28,36$ Issues like these, and many others, can jeopardize the quality and sustainability of partnerships.

Davies $^{46}$ sees the solution in meticulous attention to contract details. Other authors highlight characteristics of carefully drawn up CCP contracts: (a) they identify the key roles and responsibilities; ${ }^{35,39}$ (b) they address the interests of all the stakeholders; ${ }^{34,39}$ (c) they integrate financial and educational objectives; ${ }^{39}$ and (d) they clearly state the type and issue of the degree for students of the host institution. ${ }^{19}$

Sidhu ${ }^{41}$ and Wilkins and Huisman ${ }^{14}$ attribute partnership problems also to the fact that many universities have not (yet) developed a business oriented mind-set. Lane ${ }^{1}$ suggests that a host institution should invest time and effort in getting acquainted with their potential partner from a legal and financial perspective and also with the context of their future operations. As goals, principles, values, and interests are important factors in making rational decisions concerning the appropriate mode and partner, these concepts should be clearly defined by both parties before entering into a partnership. ${ }^{27}$ Bolton and $\mathrm{Nie}^{34}$ additionally stress the importance of an overall view of the consequences of the partnership. Based on experiences of Monash University, one of the biggest providers of crossborder education from Australia with various types of delivery agreements with partners all over the world, McBurnie and Pollock ${ }^{13}$ emphasize the importance of scenario planning, marketing research, and mapping stakeholders' risks and opportunities. A sound and professional risk analysis and risk management plan is advocated by Shanahan and McParlane ${ }^{40}$ while Vinen and Selvarajah ${ }^{36}$ recommend that home institutions should put into place a systematic and strategic planning process.

The major challenge to both partners, the degree granting home institution in particular, is quality assurance of the program (Factor $4 \mathrm{~d}$ ) as this is crucial to the program's perceived academic integrity. ${ }^{13,15}$ Coleman $^{12}$ points out that the overall objective of quality assurance in curriculum partnerships is to generate information about the similarity of educational experiences for all students, urging that CCPs be "moni- 
tored as rigorously and comprehensively as regular home university operations (p.373)"12. Castle and Kelly ${ }^{18}$, Dunworth ${ }^{27}$, and Shams and Huisman ${ }^{32}$ recommend setting up a proper system of internal quality assurance modelled on the system established at the home institution and ensuring frequent and transparent evaluations. Evaluation outcomes should be discussed among partners and used to sustain a continuous cycle of quality improvement. Apart from an adequate internal quality system, Lim $^{31}$ advocates external review of the crossborder program and strict adherence to the host country's national accreditation requirements.

\section{Discussion and Conclusion}

CCPs are to a certain extent paradoxical arrangements, with institutions which differ hugely in various domains striving to offer students equivalent learning experiences and degrees. Based on our literature review, we developed a framework that may offer guidance on managing these differences and challenges to achieve successful partnerships. We would like to stress that almost all included articles describe partnerships in an early development stage, which is characterized by a junior-senior institutional relationship. By time, these CCPs will evolve into more balanced partnerships.

With respect to students, the framework recommends investing efforts to bring the host institution up to par with the home institution in terms of students' learning behaviour, prior knowledge, and language proficiency. Some relevant procedural measures are available around the world, such as intensive language courses, a preparatory year, and comparable admission criteria. Nevertheless, it is evident that there are no quick fixes to resolve differences in learning behaviours, particularly when cultural differences are involved. It should be noted also that there is an ongoing debate about whether it is even necessary for the host institution to aim for full conformity of learning behaviours and teaching styles with those of the home institution. ${ }^{8,} 23$, 47-50 Regardless of the outcome of this debate, creating awareness among teachers and project leaders of differences in learning behaviours, and considering them in setting partnership objectives may well be prerequisite for successful CCPs.

Continuous support for faculty of the host institution is considered advisable to help them overcome didactic differences, and this can be achieved by a continuous, wellplanned intensive faculty development program tailored to the needs of the partnership. It may be more problematic, however, to find ways to generate a feeling of ownership of the curriculum among host institution teachers, as absence of such feelings may constitute a barrier to staff commitment to the program, which in turn can negatively impact on the quality of curriculum delivery. We found no articles that proposed ways to address this issue. On one hand, one might hypothesize that it is a threat to the sustainability of the program when staff are demotivated because they have to use foreign learning materials, but on the other hand, one might hypothesize that working with foreign, Western study materials can be inspirational as it offers a completely new experience.

In most cases, learning and assessment materials must be adapted to the local professional context of the host institution. These modifications should strike a balance 
between acceptability within the host institution and adherence to partnership objectives. This raises the question of who should be responsible for making and implementing these adjustments. The literature on this issue does not deal with this topic indepth and most articles do not go beyond stating that the "curriculum should be adapted". 12, 20, 32 An interesting solution described by Vinen and Selvarajah ${ }^{36}$ is establishing a course advisory committee comprised of teaching staff from both institutions and other stakeholders. The main function of this committee was to evaluate the design and preparation of all course materials and review changes in course delivery. This might be an appropriate procedure to assure a sustainable and broadly supported local adaptation of the program as well as adherence to the partnership's objective of offering students a comparable degree.

The success of CCPs depends on managing both the partnership and differences in context between host and home institution. The literature shows that most partnerships deteriorate due to mistrust and disturbed relationships, suggesting that top priority should be given, especially within the home institution, to steering, monitoring, and watching interactions and personal collaboration at all levels. Several cases showed that the input of project managers and academic leaders was crucial, as failure or success of the partnership seemed to depend on their attitude and culturally sensitive communication competence. ${ }^{30,36,39,42}$ This applies not only to interaction with the partner institution but also to interaction within the home organisation to generate and boost commitment among staff.

Despite general acknowledgment that institutions need to adopt a more businesslike approach, especially when planning, negotiating, and drafting a CCP contract, most of the articles addressing this issue described that the majority of institutions still have a long way to go to achieve this, although fast gains might be made by using tools derived from the business world.

Attention to internal quality assurance is generally considered vital because the reputation of the home institution depends on it and it can help to distinguish between rogue providers of CCPs. On a national level, assuring quality should be on top of the research agenda. Currently, there is a debate in the literature about which agencies should accredit, monitor, and register crossborder programs and how this should be done. ${ }^{38,51,52}$ Home country accreditation agencies do not have a formal framework for assessing CCPs, and in host countries, quality assurance frameworks are (as yet) nonexistent or do not extend to foreign education providers. As a result, crossborder programs often lack a legislative quality assurance framework. To address this issue, codes of good practice have been developed to guide home institutions in how to set up and manage international collaborations in such a way as to ensure that academic standards and student experiences are not compromised..$^{53}$ These codes address the roles and responsibilities of the degree awarding institution and the partner institution, issues of equivalence and opportunities for adaptation of curricula to meet global and local requirements. One study by McBurnie ${ }^{35}$ provides an informative description of a quality review process for an Australian exporter of higher education. It is interesting to note that this process assessed the host program on criteria that look for comparability, not similar outcomes. ${ }^{38}$ As this a not a clear-cut distinction, there is a need for good examples from case-based research to determine where the line is best drawn. A 
slightly different point of view is advocated by Pyvis ${ }^{54}$, who stresses that frameworks or codes should not be applied too rigidly, claiming that the relative quality of foreign programs should be judged by comparing them with other programs in the host country (rather than by comparing programs offered by the home institution through the host institution and at home).

Research on the effectiveness of CCPs deals with an educational context that is not homogeneous, but involves different types of educational providers, students, and partner institutions across many countries as well as a variety of program delivery models. In addition, the educational context is constantly evolving due to the emergence of new technologies leading to the introduction of new ways of teaching and learning Miliszewska and Sztendur ${ }^{37}$. Currently, CCPs are predominantly set up between conventional Australian, British, and U.S. home institutions and Asian Pacific, Middle Eastern, Eastern European, and Southern American host institutions. ${ }^{55-58}$ This is reflected in the fact that of the 39 articles we reviewed 34 report studies of partnerships with at least one Australian home institution. However, the Observatory for Borderless Education reports that new trends such as South-South partnerships and intraregional CCPs are emerging 57 , indicating that the future landscape of CCPs will show more variation. In addition, the disappearance of traditional political, economic, and geographical boundaries makes way for multi-campus university models, such as New York University ${ }^{58}$, in which there is no distinction between home or host institutions but rather a network of global center for research and education. Future research might focus on how these new models can take shape. Also, to create a comprehensive and culturally sensitive picture of the CCP phenomenon, we recommend that case studies be conducted of CCPs that do not have a home institution of Australian origin. Moreover, the Australian predominance means that the findings of the present study may not generalize to other contexts.

Furthermore, the findings suggest that there is a need for further research into the management and practical implementation of CCPs, especially in terms of their crosscultural context. Issues that seem to be of particular importance in this respect are as follows: How to create teams of host and home teachers? How to deal with validity concerns when comparing similar assessments across cultures and languages? How to promote a sense of ownership among host institution staff? How to manage the acceptance of and competencies for a more student-centered approach among staff and students of host institutions? We would also recommend further research to explore the student perspective, because students' input may be valuable in improving the delivery of crossborder curricula. ${ }^{22,37}$ Although over time CCPs are expected to evolve to a more balanced participation of both institutions, at present most CCPs are characterized by a dominant flow of information, expertise, and materials from the home to the host institution, with an inherent danger of neglecting or even ignoring the contextual factors. The overall conclusion of our study is that a blunt copying of curricula does not seem a wise nor feasible strategy. Although the curriculum aims to deliver a comparable educational quality to home and host students, its "copy" in the host institution needs thorough adaptation and a culturally sensitive implementation strategy before it can be adopted by the host institution and adopted in a different environment. 


\section{References}

1. Lane JE. Global Expansion of International Branch Campuses: Managerial and Leadership Challenges. New Dir High Educ. 2011;(155):5-17.

2. Bohm A, Davis T, Meares D, Pearce D. Global student mobility 2025: Forecasts of the global demand for higher education. In: 16th Australian International Education Conference. Hobart, Tasmania; 2002.

3. Altbach PG, Knight J. The Internationalization of Higher Education: Motivations and Realities. J Stud Int Educ. 2007;11(3-4):290-305.

4. Naidoo V. Transnational Higher Education A Stock Take of Current Activity. J Stud Int Educ. 2009;13(3):310-30.

5. OECD. Internationalisation and Trade in Higher Education Opportunities and Challenges. Paris: OECD 2004.

6. OECD, World Bank. Cross-border tertiary education a way towards capacity building. 2007. [Report] Available from [http://hdl.handle.net/10986/6865]; Accessed February 2012.

7. Unesco, Council of Europe. The UNESCO-CEPES/Council of Europe code of good practice for the provision of transnational education. 2001. [Report] Available from [http://www.cepes.ro/hed/recogn/groups/ transnat/code.htm]; Accessed September 2013.

8. van der Wende MC. Globalisation and Access to Higher Education. J Stud Int Educ. 2003;7(2):193-206.

9. Knight J. Cross-border education: Conceptual confusion and data deficits. Perspect Educ. 2006;24(4):1527.

10. Miller-Idriss C, Hanauer E. Transnational higher education: offshore campuses in the Middle East. Comp Educ. 2011;47(2):181-207.

11. Verbik L, Rumbley LE, Altbach PG. The international Branch campus -Models and Trends. 2006. [Report] Available from; Accessed September 2013.

12. Coleman D. Quality assurance in transnational education. J Stud Int Educ. 2003;7(4):354-78.

13. McBurnie G, Pollock A. Opportunity and risk in transnational education-issues in planning for international campus development: an Australian perspective. High Educ Eur. 2000;25(3):333-43.

14. Wilkins S, Huisman J. The international branch campus as transnational strategy in higher education. High Educ. 2012:64(5):627-45.

15. Lane JE, Brown II, Christopher M, Pearcey MA. Transnational campuses: Obstacles and opportunities for institutional research in the global education market. New Directions for Institutional Research. 2004;2004(124):49-62.

16. Crawford L, Pollack J. Hard and soft projects: a framework for analysis. International Journal of Project Management. 2004;22(8):645-53.

17. Briguglio C. Language and Cultural Issues for English-as-a-Second/Foreign Language Students in Transnational Educational Settings. High Educ Eur. 2000;25(3):425-34.

18. Castle R, Kelly D. International Education: quality assurance and standards in offshore teaching: exemplars and problems. Qual High Educ. 2004;10(1):51-7.

19. Gregory VL, Wohlmuth SR. Planning for the Internationalization of a Postgraduate Professional Degree Programme in Library and Information Science. High Educ Eur. 2002;27(3):261-68.

20. Heffernan T, Morrison M, Basu P, Sweeney A. Cultural Differences, Learning Styles and Transnational Education. J High Educ Pol Manag. 2010;32(1):27-39.

21. Wilson M. Transnational nursing programs: models, advantages and challenges. Nurse Educ Today. 2002;22(5):417-26.

22. Chapman A, Pyvis D. Dilemmas in the Formation of Student Identity in Offshore Higher Education: A Case Study in Hong Kong. Educ Rev. 2006;58(3):291-302.

23. Pimpa N. Learning problems in transnational business education and training: The case of the MBA in Thailand. Int J Train Dev. 2009;13(4):262-79.

24. Ziguras C. Educational technology in transnational higher education in South East Asia: the cultural politics of flexible learning. Educational Technology \& Society. 2001;4(4):8-18.

25. Eldridge K, Cranston N. Managing Transnational Education: Does National Culture Really Matter? J High Educ Pol Manag. 2009;31(1):67-79.

26. Eaves M. The Relevance of Learning Styles for International Pedagogy in Higher Education. Teachers and Teaching: Theory and Practice. 2011;17(6):677-91.

27. Dunworth K. Ideas and realities: Investigating good practice in the management of transnational English language programmes for the higher education sector. Qual High Educ. 2008;14(2):95-107. 
28. Dobos K. "Serving two masters" - academics' perspectives on working at an offshore campus in Malaysia. Educ Rev. 2011;63(1):19-35.

29. McBurnie G, Ziguras C. Transnational Education: Issues and Trends in Offshore Higher Education. Abingdon: Routledge; 2007.

30. Heffernan T, Poole D. In Search of "The Vibe": Creating Effective International Education Partnerships. HETIJHEEP. 2005;50(2):223-45.

31. Lim FCB. Do Too Many Rights Make a Wrong? A Qualitative Study of the Experiences of a Sample of Malaysian and Singapore Private Higher Education Providers in Transnational Quality Assurance. Qual High Educ. 2010;16(3):211-22.

32. Shams F, Huisman J. Managing Offshore Branch Campuses: An Analytical Framework for Institutional Strategies. J Stud Int Educ. 2012;16(2):106-27.

33. Smith L. Sinking in the Sand? Academic Work in an Offshore Campus of an Australian University. HERD. 2009;28(5):467-79.

34. Bolton D, Nie R. Creating value in transnational higher education: The role of stakeholder management. Academy of Management Learning \& Education. 2010;9(4):701-14.

35. McBurnie G. Quality Matters in Transnational Education: Undergoing the GATE Review Process. An Australan-Asian Case Study. J Stud Int Educ. 2000;4(1):23-38.

36. Vinen DG, Selvarajah C. A framework for sustainability of an offshore education program: a systems based approach. Journal of International Business and Economics. 2008;8(2):160-9.

37. Miliszewska I, Sztendur E. Critical Success Attributes of Transnational IT Education Programmes: The Client Perspective. Journal of Information Technology Education. 2011;10:123-37.

38. Stella A. Quality assurance of cross-border higher education. Qual High Educ. 2006;12(3):257-76.

39. Heffernan T, Poole D. "Catch Me I'm Falling": Key Factors in the Deterioration of Offshore Education Partnerships. J High Educ Pol Manag. 2004;26(1):75-90.

40. Shanahan P, McParlane J. Serendipity or strategy? An investigation into entrepreneurial transnational higher education and risk management. Horizon. 2005;13(4):220-8.

41. Sidhu R. The 'brand name' research university goes global. High Educ. 2009;57(2):125-40.

42. Olcott Jr D. Global Connections to Global Partnerships: Navigating the Changing Landscape of Internationalism and Cross-Border Higher Education. J Cont High Educ. 2009;57(1):1-9.

43. Dunn L, Wallace M. Australian academics and transnational teaching: An exploratory study of their preparedness and experiences. HERD. 2006;25(4):357-69.

44. Seah WT, Edwards J. Flying in, flying out: Offshore' teaching in higher education. Aust J Educ. 2006;50(3):297-311.

45. Smith K. Transnational Teaching Experiences: An Under-Explored Territory for Transformative Professional Development. International Journal for Academic Development. 2009;14(2):111-22.

46. Davies JL. A Revolution in Teaching and Learning in Higher Education: The Challenges and Implications for the Relatively Traditional University. High Educ Eur. 2001;26(4):501-14.

47. Chan BT-Y. Postgraduate Transnational Education in Nonbusiness Subjects: Can It Fit Conceptualizations of Curriculum Internationalization? J Stud Int Educ. 2011;15(3):279-98.

48. Lien D. Economic Analysis of Transnational Education. Education Economics. 2008;16(2):149-66.

49. Nguyen PM, Elliott JG, Terlouw C, Pilot A. Neocolonialism in education: Cooperative Learning in an Asian context. Comp Educ. 2009;45(1):109-30.

50. Wang T. Intercultural dialogue and understanding: Implications for teachers. In: Teaching in transnational higher education: Enhancing learning for offshore international students. 1. Edited by Dunn L, Wallace M. New York: Routledge; 2008: 57-66.

51. Knight J. Cross-border Higher Education: issues and implications for quality assurance and accreditation. 2007. [Report] Available from [http://hdl.handle.net/2099/8109]; Accessed November 2012.

52. Ziguras C, McBurnie G. Transnational higher education in the Asia-Pacific Region: From distance education to the branch campus. In: Higher Education in the Asia-Pacific. Edited by Marginson S, Kaur S, Sawir E. Dordrecht: Springer; 2011: 105-22.

53. Smith K. Assuring Quality in Transnational Higher Education: A Matter of Collaboration or Control? Stud High Educ. 2010;35(7):793-806.

54. Pyvis D. The need for context-sensitive measures of educational quality in transnational higher education. Teach High Educ. 2011;16(6):733-44.

55. Fang W. The Development of Transnational Higher Education in China A Comparative Study of Research Universities and Teaching Universities. J Stud Int Educ. 2012;16(1):5-23.

56. Knight J. Higher Education in Turmoil, vol. 13. Toronto: Sense Publishers; 2008. 
57. Lawton W, Katsomitros A. International branch campuses: data and developments. 2012. [Report] Available from [http://www.obhe.ac.uk/documents/view_details?id=894]; Accessed June 2013.

58. Wildavsky B. The great brain Race. New Jersey: Princeton University Press; 2010. 


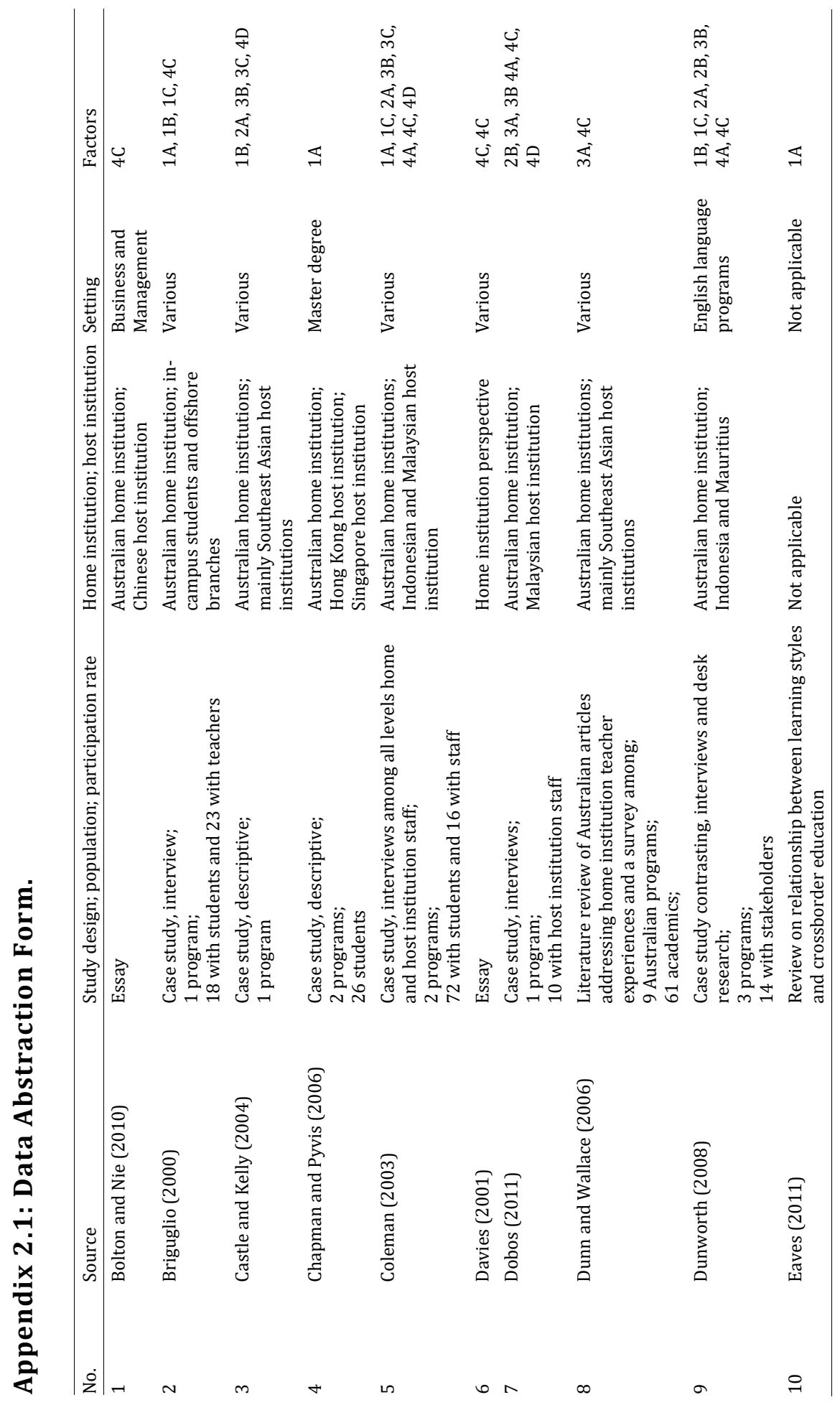


A literature review of crossborder curriculum partnerships

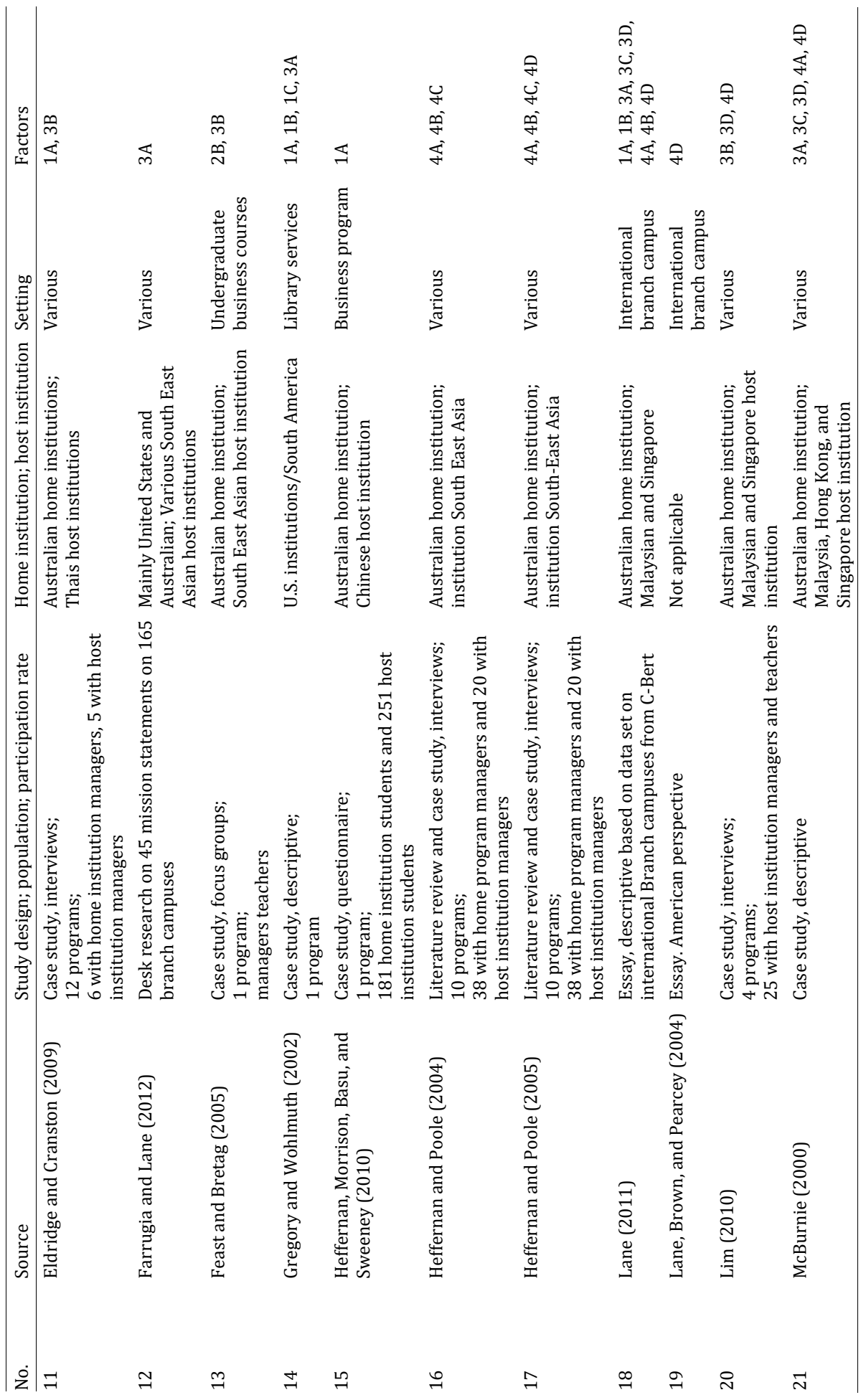




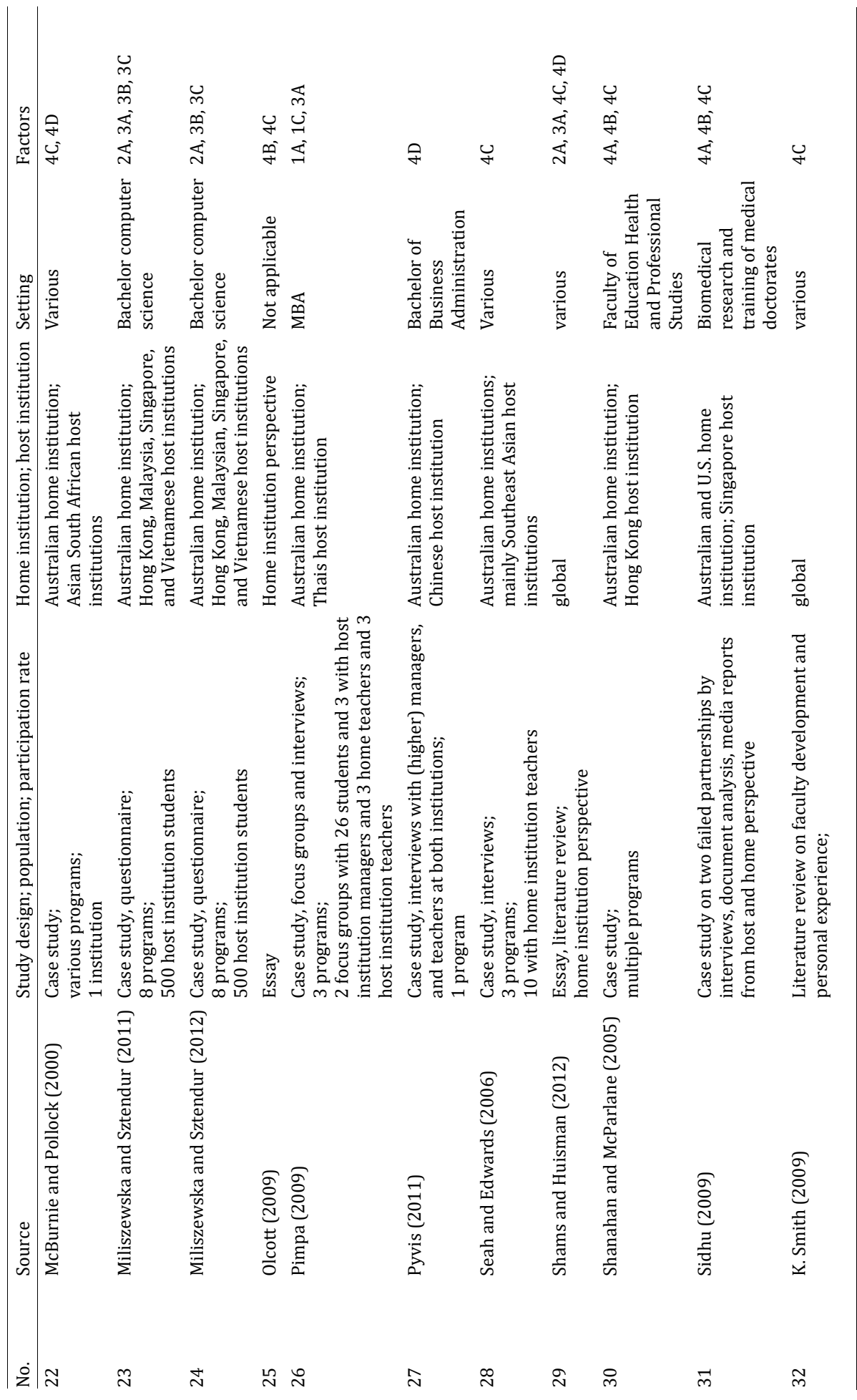




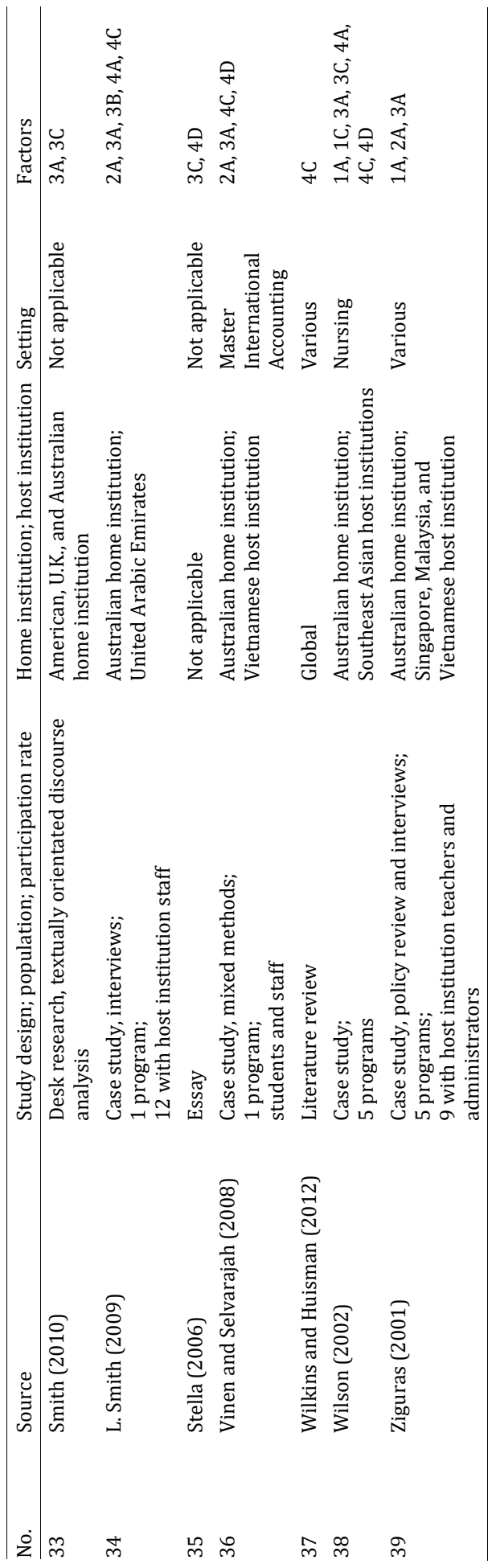





\section{Chapter 3.}

\section{An exploration of crossborder medical curriculum partnerships: Balancing curriculum equivalence and local adaptation}

Published as: Waterval DGJ, Frambach JM, Oudkerk Pool A, Driessen EW, Scherpbier AJJA: An exploration of crossborder medical curriculum partnerships: Balancing curriculum equivalence and local adaptation. Medical Teacher. 2016, 38(3):255-262. 


\begin{abstract}
Introduction: Worldwide, medical schools have entered into crossborder curriculum partnerships (CCPs) to provide equivalent curricula and learning experiences to groups of geographically separated students. Paradoxically, this process also involves adaptation of curricula to suit local contexts. This study has focused on challenges faced by medical Crossborder curriculum programme directors and strategies they employed to overcome these.
\end{abstract}

Methods: We conducted a qualitative study on six CCPs using document analysis and semi-structured interviews with 13 programme directors from 12 medical schools. Interview transcripts were coded iteratively, followed by cross-case analysis.

Results: The challenges faced by CCP programme directors are fourfold, springing from differences in health care systems, legislation and political interference, teaching and learning environments, and partnership. Deliberate strategies, such as intensifying interactions between partners in all academic echelons, can help to overcome these. Partnerships vary in their setup and collaboration strategy.

Conclusion: Medical CCPs are challenging though seem feasible. Partnerships with more solid integration of academic operations appear robust in terms of ownership and provide, besides financial, also academic advantages to both institutions. However, more research is needed on the long-term effects on quality of graduates and impact on the host health care system. 


\section{Introduction}

Several medical schools have established crossborder curriculum partnerships (CCPs) as one of their internationalisation strategies. ${ }^{1,2}$ In crossborder curriculum partnerships, two institutions located in different countries strive for equivalence - i.e. comparability - in terms of curriculum content and learning experiences to students in both institutions. ${ }^{3}$ Although these partnerships can take many different legal forms, such as branch campuses, delivery agreements, or franchises of complete programmes, they all share that the curriculum developed in one place, the home institution, is transferred across borders to the other, or host institution. ${ }^{4-6}$ CCP has been mentioned as a logical next development phase of globalisation in Higher Education following the student and teacher exchanges of the previous decades. ${ }^{7}$ A report from the British Council ${ }^{8}$ indicates that this type of partnership is expanding and has high-potential growth rates.

Although rising in popularity, CCPs are often featured by opposing inside forces that create an educational tension: on the one hand, partners strive for curriculum equivalence to meet the host students' expectations - also from a quality assurance perspective differences cannot be too large -, whereas on the other hand, there is a need for adaptation of the home institution's programme to the host institution's local context and organisational culture.9-11 The paradox of crossborder curriculum partnerships, then, seems to be that the two institutions' curricula should be identical as well as locally adapted. ${ }^{11}$ This paradox is particularly challenging in the medical domain where national variations in health care systems in which clinical learning is situated, abound. Furthermore, most medical curricula incorporate a range of domain-specific methods of instruction, such as clinical skills and communication training, ethics and professional behaviour training. Differences in learning and teaching environments can complicate the implementation of such methods in the host institution's context. The recent end of the medical curriculum partnership between Johns Hopkins University (USA) and Perdana University (Malaysia) is an example that illustrates the complexity of these kinds of collaborations. ${ }^{12}$

Previous studies on CCPs report that an identical curriculum is neither possible nor desirable. ${ }^{13,14}$. Although they underline the importance of curriculum adaptations, no clear guidance is given as to where to depart from there. Instead, most studies are generic in scope, focusing for instance on effective training programmes for visiting staff, ${ }^{15}$ or on the influence of English as a foreign language on student performances. ${ }^{16}$ Heffernan and Poole ${ }^{17}$ found that the volatility of partnerships and, with that, curriculum delivery was often due to cultural differences in communication; especially a lack of personal 'vibe' proved to be detrimental. A recent review of the literature on crossborder curriculum partnerships revealed that few studies have been conducted in the specific context of health care education and none of these have taken crossborder curriculum partnerships as their primary focus. ${ }^{18}$

As the specific features of medical partnerships call for further research, we turned to the experiences of pioneering medical schools that have embarked on such partnerships. Our goal was to describe the challenges they faced and the strategies they used to ensure both curriculum equivalence and local curriculum adaptation. 


\section{Methods}

\section{Case selection}

We conducted a qualitative, multiple case study of six crossborder medical curriculum partnerships using semi-structured interviews. We used an explorative approach because this form of internationalisation is relatively new and we did not want to miss any essential features. Potentially eligible partnerships were identified using a snowballing technique: twelve international medical education experts were approached in person or by email, which yielded 22 potential partnerships. By means of an Internet research and email inquiry, this selection was further condensed to include only those partnerships that met the following criteria:

- The partnership has for its aim to equalise the learning experience of students in both settings by delivering equivalent curricula;

- The partnership has existed for a period of at least three years and preferably has at least one batch of graduates.

The six partnerships that matched these criteria were all willing to participate and are listed in table 3.1, being randomly coded as partnership A to F. Partnerships varied between them with respect to type of medical curriculum, type of degree, and main method of instruction. Yet, they were all geared to achieving curriculum equivalence. Ethical approval was sought and obtained from the Netherlands Association for Medical Education Ethical Review Board (NVMO file number 304).

\section{Data collection and analysis}

First, we conducted an analysis of online publications, curriculum descriptions, and public partnership reports pertaining to the six partnerships. With the background information that was retrieved this way each interview guide was geared to characteristics of the particular partnership.

Subsequently, semi-structured interviews were conducted with 13 CCP medical programme directors, six of which represented a host and seven a home institution's perspective. Participants were purposively selected for their primary responsibility to oversee the academic quality of the curriculum being delivered and their involvement since the start of the partnership. Invitations were sent by email and, prior to the interview, informed consent was obtained. The interviews lasted about one hour and were conducted online or, when feasible, face-to-face by the first (DW) and third author (AO) in the period between December 2013 and August 2014. All interviews were digitally recorded and transcribed verbatim. Participants were randomly labelled with a number that did not correspond to the partnership codes reported in table 3.1. 
Table 3.1: Overview of included partnerships and their characteristics

\begin{tabular}{|c|c|c|c|c|c|c|c|}
\hline \multicolumn{2}{|c|}{ Partnership } & \multicolumn{2}{|c|}{$\begin{array}{l}\text { Country } \quad \text { Type of } \\
\text { (private or public programme } \\
\text { institution) }\end{array}$} & \multirow{3}{*}{$\begin{array}{l}\text { Degree } \\
\begin{array}{l}\text { Separate } \\
\text { degree }\end{array}\end{array}$} & \multirow{3}{*}{$\begin{array}{l}\begin{array}{l}\text { First } \\
\text { batch }\end{array} \\
2006 \\
\end{array}$} & \multirow{3}{*}{$\begin{array}{l}\text { Faculty } \\
\text { Mainly local }\end{array}$} & \multirow{3}{*}{$\begin{array}{l}\text { Main } \\
\text { methods of } \\
\text { instruction } \\
\text { Lectures and } \\
\text { PBL }\end{array}$} \\
\hline A & Home & $\begin{array}{l}\text { UK } \\
\text { (public) }\end{array}$ & $\begin{array}{l}5 \text { yrs. under- } \\
\text { graduate } \\
\text { curriculum }\end{array}$ & & & & \\
\hline & Host & $\begin{array}{l}\text { Egypt } \\
\text { (private) }\end{array}$ & $\begin{array}{l}5+1 \text { under- } \\
\text { graduate } \\
\text { curriculum }\end{array}$ & & & & \\
\hline \multirow[t]{2}{*}{ B } & Home & $\begin{array}{l}\text { Netherlands } \\
\text { (public) }\end{array}$ & $\begin{array}{l}6 \text { yrs. under- } \\
\text { graduate } \\
\text { curriculum }\end{array}$ & \multirow[t]{2}{*}{$\begin{array}{l}\text { Separate } \\
\text { degree }\end{array}$} & 2010 & Local & \multirow[t]{2}{*}{ PBL } \\
\hline & Host & $\begin{array}{l}\text { Saudi Arabia } \\
\text { (private) }\end{array}$ & $\begin{array}{l}5+1 \text { under- } \\
\text { graduate } \\
\text { curriculum }\end{array}$ & & & Regional & \\
\hline \multirow[t]{2}{*}{$\mathrm{C}$} & Home & $\begin{array}{l}\text { USA } \\
\text { (private) }\end{array}$ & $\begin{array}{l}4 \text { yrs. graduate } \\
\text { entry curriculun }\end{array}$ & \multirow{2}{*}{\multicolumn{2}{|c|}{ Joint degree 2007}} & Local & Lectures \\
\hline & Host & $\begin{array}{l}\text { Singapore } \\
\text { (public) }\end{array}$ & & & & $\begin{array}{l}\text { Local and } \\
\text { seconded higher } \\
\text { management }\end{array}$ & $\begin{array}{l}\text { Lectures and } \\
\text { team-based } \\
\text { learning }\end{array}$ \\
\hline \multirow[t]{2}{*}{ D } & Home & $\begin{array}{l}\text { USA } \\
\text { (private) }\end{array}$ & $\begin{array}{l}4 \text { yrs. graduate } \\
\text { entry curriculun }\end{array}$ & \multirow{2}{*}{\multicolumn{2}{|c|}{$\begin{array}{l}\text { Degree with } \\
\text { indication } \\
\text { of location }\end{array}$}} & Mainly local & \multirow[t]{2}{*}{$\begin{array}{l}\text { Lectures and } \\
\text { PBL }\end{array}$} \\
\hline & Host & $\begin{array}{l}\text { Qatar } \\
\text { (public) }\end{array}$ & $\begin{array}{l}2 \text { yrs. pre- } \\
\text { medical }+ \\
4 \text { yrs. graduate } \\
\text { entry curriculun }\end{array}$ & & & International & \\
\hline \multirow[t]{2}{*}{$\mathrm{E}$} & Home & $\begin{array}{l}\text { UK } \\
\text { (public) }\end{array}$ & \multirow{2}{*}{$\begin{array}{l}5 \text { yrs. under- } \\
\text { graduate } \\
\text { curriculum }\end{array}$} & \multirow[t]{2}{*}{$\begin{array}{l}\text { Similar } \\
\text { degree }\end{array}$} & \multirow[t]{2}{*}{2009} & Local & \multirow{2}{*}{$\begin{array}{l}\text { Lectures and } \\
\text { case-based } \\
\text { learning }\end{array}$} \\
\hline & Host & $\begin{array}{l}\text { Malaysia } \\
\text { (public) }\end{array}$ & & & & $\begin{array}{l}\text { Local and } \\
\text { percentage } \\
\text { higher } \\
\text { management } \\
\text { from home }\end{array}$ & \\
\hline \multirow[t]{2}{*}{$\mathrm{F}$} & Home & $\begin{array}{l}\text { UK } \\
\text { (public) }\end{array}$ & \multirow[t]{2}{*}{$\begin{array}{l}4 \text { yrs. graduate } \\
\text { entry curriculum }\end{array}$} & \multirow[t]{2}{*}{$\begin{array}{l}\text { Similar } \\
\text { degree }\end{array}$} & \multirow[t]{2}{*}{2011} & Local & \multirow[t]{2}{*}{$\begin{array}{l}\text { Lectures and } \\
\text { PBL }\end{array}$} \\
\hline & Host & $\begin{array}{l}\text { Cyprus } \\
\text { (private) }\end{array}$ & & & & $\begin{array}{l}\text { Local and } \\
\text { seconded project } \\
\text { management }\end{array}$ & \\
\hline
\end{tabular}

Analysis of the interview transcripts was four-staged. In the first stage, all transcripts were read to familiarise the authors with the data. During the second stage, the transcripts were open-coded by two independent researchers (DW and AO). That is, for each partnership, sections that were relevant to the study's objective were identified, resulting in an initial coding scheme. The third stage concerned application of this coding scheme to all transcripts using Atlas.Ti. The scheme was then further refined and extended alongside ongoing data collection and analysis. Throughout this process, a research journal was kept to record analytical decisions, code definitions and researchers' notes. Although after eight interviews the coding scheme appeared complete, we continued the final five interviews to verify our scheme. In the fourth stage, three researchers (DW, AO and JF) performed a cross-case analysis to identify relationships and patterns across partnerships. The transparency of the analysis, the involvement of 
two independent researchers who read and compared ideas about transcripts, the discussion on variations of the coding scheme and the search for disconfirming evidence all bolstered the study's trustworthiness. A copy of the analysis' preliminary results was sent to all participants to elicit their comments on the representation of the data. This operation, however, did not result in any content modifications.

\section{Results}

It was found that in order for a CCP to be successful, partners needed to overcome various challenges which can be grouped into four categories. Three of these spring from differences in home and host settings, that is, differences in health care systems, legal and political interference, and teaching and learning environments. The fourth category relates to intra-partnership interactions. The above categorisation should not be interpreted as a strict separation -as they influence one another- but rather as a clustered overview.

\section{Health care system}

Differences in health care systems which posed a challenge to the achievement of curriculum equivalence were twofold: they related to dissimilarities in organisational structure and to diverging health care needs. An example of organisational differences is the system of referral by primary care physicians, such as general practitioners, which was common in all of the home countries, but did not exist to the same extent in the host countries. As host participant 5 explains:

'So, we had a programme in the home country which is much tailored to the structure of the National Health Service, which did not translate. But the outcomes should be the same, so what we did was to work out novel ways in which those outcomes could be met.'

The availability of teaching hospitals is another example. The home institutions' curricula required frequent and close interaction between students and patients, especially during the clinical phase. Whereas home institutions could rely on a large network of clinical placements, in the host institutions' setting such networks were often still in their infancy. Home participant 7 voices this concern:

'One of the issues we face is the availability of clinical placements for our students. This is such a hassle as the private University has to rely on governmental hospitals for the clerkships.'

To overcome these differences, partnerships focused on the envisaged learning outcomes, and consequently adapted the curriculum content and didactic methods to the local possibilities. In the words of host participant 5: 
'Some of those methods were more economic, more efficient and produce better outcomes in terms of student understanding, learning, skills, and performance at the host than at home.'

At the same time, however, participants indicated that these differences remained a continuous point of attention and were sometimes insurmountable. In such cases they had no choice but to compromise and make concessions to the delivery of home institution's curriculum.

The second challenge within the category of Health care system relates to diverging health care needs that complicated the achievement of curriculum equivalence. These could be traced to deviating graduate outcomes in terms of epidemiological knowledge and generic competences. Remarkably, no uniform method appeared to be in place to map and analyse such differences, which, presuming that a fitting of contexts is key to the viability of CCPs, was quite odd. One of the partnerships, however, formed an exception, as they did a thorough two-year feasibility analysis of potential differences in epidemiological knowledge and generic competences. They found that:

'... there was not that much of a difference in the disease profile, ... it was very similar to the home one. Much more so than you would have ever imagined. So there are some epidemiological gaps, but you know, that didn't particularly worry us. So we [home] found a small number of cases, clinical conditions, where we might have to tweak the curriculum or alter it slightly.' (Home participant 6)

The following quote from home participant 3, about the construction of a theoretical PBL case for first-year students, clearly reflects such alterations:

'So I think a good example is sickle cell anaemia which is common in local population in the home country, while thalassemia is very common in population in the host country. So we had a hemoglobinopathy case and we rewrote the objectives up so that students studied both, in fact, sickle cell and thalassemia. So that was an example of changes that we made.'

The effected changes also included more fundamental ones, as the following example from home participant 1 , where the host country needed graduates with advanced research skills, demonstrates:

'So in response, we put introduction to research methods in the first year.

We added statistic courses and other types of things to the home curriculum that supported our research education mission, so that's different than home institution for instance.'

In general, programme directors felt the host countries' needs could be catered for by adding learning materials, assignments or longitudinal courses to the home institution's curriculum. They felt confident that these modifications would adequately prepare host students for practice in the host country's setting. 


\section{Legal and political interference}

The achievement of full curriculum equivalence in both settings often also became undermined by differences in legislation. Some host country governments, for instance, dictated the length and types of clerkships and sometimes also parts of the curriculum contents, as the following quote from host participant 4 makes clear:

'The host law system obliged us to include parasitology and microbiology with public health.'

Such legal and political interference could be stringent and, if in conflict with the objective of curriculum equivalence, have potentially disruptive consequences. This is evidenced, for instance, by a statement from home participant 1, who uttered his concerns over considerations by the host government, instigated by an explosion of medical schools, to implement national knowledge exams, as this would assure quality across all emerging schools:

'So the local folks have created this test. And the test looks a lot like the recitation of the facts that reflect the way that host country would teach. So the test doesn't look like the type of thing we would actually want to create ... So, it influences the very nature of clinical education.... If the host government truly persists and says all students in clinical training should be treated and trained the same way, the home institution ... would become unsatisfied with the partnership.'

Finally, participants indicated that the tenure of legal and political demands was such that modifications to the home institution's curriculum could not be avoided. Hence, to minimize and circumvent this kind of interference, they advised a more diplomatic stance by appointing someone who would act in the host environment and simultaneously safeguard the home institution's interests, opening doors that the home institution's higher management had not been able to open. This is illustrated by the words of home participant 2:

'You need a bridge, somebody from that host environment who is aware of the differences. ... So this key person who has leg in and leg out is of value in any curriculum partnership.'

\section{Learning and teaching environment}

One imminent challenge faced by programme directors was the transplantation of a student-centred home curriculum to the host setting. For host students this meant that they first had to familiarise themselves with the new learning method. Participants concurred that this process was challenging and sometimes required remediation measures such as extra counselling or study skills trainings. Nevertheless, they all had the impression that the influence on the delivery of the programme was a hurdle that could be taken. Their advice was to start off with only a limited number of students, as it would allow staff and students more time to become familiar with the home curricu- 
lum. Similarly, more time would become available for the creation of appropriate learning resources and experiments with programme elements. The following quote from host participant 5 reverberates the aforesaid:

'I think in the first year, our external examiners said the [host] students are somewhat quieter, but by the time they get to year four, they're indistinguishable [from home students].'

What also rendered the achievement of curriculum equivalence more difficult in the eyes of the participants was the divergence in teaching styles. As host institution staff was often trained in more conventional methods and had not been exposed to the home curriculum's student-centred philosophy, their teaching styles differed considerably from those of the home teachers. It appeared not so easy to achieve convergence, especially so in the clinical phase where students were supervised and trained by local physicians who acted as clinical teachers. Most of these clinical teachers were not, or only part-time, employed by the medical school and upheld a philosophy which differed from the one emanated by the curriculum. The following from home participant 1 quote does not leave any doubt:

'They [host institution clinical teachers] believe that having a vast amount of facts is important. So, they will quiz the students, just fire off question after question ... to see how much the students know. We are not trying to teach the students to memorize the rhythm, we actually try to teach them how to think. And how to know and where to get the information and then know what to do with it.'

All partnerships acted on this divergence by introducing continuous staff development programmes especially in the first three years. Despite these efforts, participants recognised that they were not able to change the hearts and minds of all teachers; aligning clinical teaching methods therefore remained a continuous point of attention for partnerships.

Finally, scepticism towards the new curriculum and the professional skills of its graduates, especially among people who were sideways involved in its implementation, constituted a major challenge. Such suspicious attitudes of stakeholders affected curriculum delivery more subtly and indirectly, as home participant 1 points out:

'I think local scepticism put the partnership at risk. It is one of the areas that make it most challenging and time will tell whether the local boots on the ground become convinced. ... But if, over time, we can demonstrate that our students do fine when they graduate, then, slowly but surely, the acceptance at the ground levels will rise.'

To counteract this scepticism, all partners pointed to the importance of unwavering support from the upper management for the partnership and long-term commitment, in addition to raising and promoting host students' learning performances. 


\section{Partnerships}

The fourth category of challenges affecting the achievement of curriculum equivalence was related to the nature of and interaction within the partnership. Transferring education and assessment materials, and the knowledge to use these adequately, lies at the heart of each CCP. Curiously, it was found that coordinated forward planning was largely absent in all partnerships, as a result of which multiple ad hoc solutions and behaviours sprouted. The following quote by home participant 3 illustrates this best:

'I was running around the medical school with a USB stick, getting people's lectures off them to send them over, you know, I didn't even have administrative support for the partnership then.'

As a result, partners found themselves confronted by various unforeseen problems which had its repercussions on the extent to which curriculum equivalence worked out. To name an example:

'The radiologists didn't share any of their films, because they were worried that it might be patient-identifiable, you know. None of the patient data was on the films, but they still had concerns about access because of our Information Governance Policy so we didn't end up sharing films.' (Home participant 3)

Programme directors largely acknowledged that such issues could harm the relationship between partners and should therefore be anticipated. As home participant 2 stresses:

'Clear outline of what the agreement entailed and very clearly communicated to both parties. And what the expectations are of working together. Yeah, that's really important.'

When asked what programme directors would have done differently if they could start anew, they gave answers similar to the following one:

'80 percent of our issues are due to planning weaknesses. If we have to do it one more time then I think we should spend at least a year in thoroughly planning this project. This includes the planning of curriculum, its delivery, the human resource, the other planning aspects of management support, mechanisms, the infrastructure etcetera etcetera.' (Host participant 6).

A second challenge in this context originated from the differences in roles partners naturally assumed: that of architect (home institution) vs receiver (host institution) of the curriculum. This created a tension, sometimes blurring the boundaries of ownership and autonomy. Although all six host institutions - or their governments - had initiated and financed the partnerships, they were curbed in their authority to amend the programme, as they had to act in line with the original intent of the curriculum partnership. Hosts were not so much disturbed by this reduced autonomy provided deci- 
sions were initiated by their own staff and they were treated respectfully. As host participant 3 states:

'The responsibility is shared. ... Like the adaptations that they [host] needed to make, they can contact their home colleagues and explain what is happening, so that we understand and didn't feel like they were just being arbitrary. Although they are finally approved by home, it is principally a decision made by the host.'

It followed that partners minded their language, both in written policies and spoken language, being careful not to use utterances that could inadvertently inflict any sense of inferiority upon the host institutions. The following quote from a home programme director 2 demonstrates the delicate nature of these relationships:

'The Head of host institution Assessment unit once said: Why do we have to double mark? ... We know how to double mark and we're doing it well on our side. Why are you [home institution programme director] still overseeing us by this quality assurance process?' And I said 'We are not overseeing you, we are making sure both cohorts are marked in the same way.' It's mutual alignment. Double marking is about quality alignment, rather than quality assurance, now. So this framing seemed to be acceptable [for our partner].' (Home participant 2)

Another strategy to strengthen intra-partnership relations was to purposively screen the first host teacher recruits for high motivation, out-of-the-box thinking, and excellent communication skills. This was valued more than reputation or academic rank. In some cases, a certain percentage of host institution key figures were appointed by the home institution, an approach that worked, as it decreased the cultural distance between institutions.

The pursuit of curriculum equivalence in two different settings demanded intensified interaction between educators and administrators. This also called for different working procedures in the home setting, which appeared quite challenging to home programme directors, as the following quote from host participant 1 indicates:

'As long as home staff members don't have to do anything differently, the relationship is okay. But if you make them do something different then it is not okay.'

Despite the reluctance to adjust procedures in the home-setting, various forms of collaboration resulted in accordance with the nature of the partnership. For instance, CCPs who graduated students with identical degrees integrated their academic working processes as much as possible:

'We have, in fact, mirrored the roles that exist by doing this, we almost had a pairing amongst colleagues. ... There are countless hours, countless hours of proceedings that are happening via video conferencing. Committee meetings, fitness to practice meetings, student support meetings, 
question assessment meetings, meetings about exam results. ... there is a huge amount of contact.' (Home participant 3)

Interestingly, such efforts yielded several academic advantages, as the following quote suggests:

'We've seen loads of changes in our home programme, because of the feedback from host. Whereas our home staff sometimes couldn't bother giving feedback. So lots of things have improved, lots of suggestions are coming.' (Home participant 2)

Intensified collaboration, however, also had other consequences that should not be overlooked as stressed by home participant 2:

And most importantly, the administrators have had an enormous role and they need to be in contact with each other as much if not more than the academics. Because the administration of this course is very complex. So there has been a lot of administrative training as well and exchange of administrative people from here to there.'

\section{Discussion}

From our study on crossborder medical curriculum partnerships it results that partners are not looking to achieve an exact copy of the home curriculum, as they realise this is neither possible nor desirable. It is not possible because resources or learning opportunities available in the home setting are simply absent or differ from those available in the host setting. Neither is it desirable because partners acknowledge, in line with existing literature on globalisation in medical education that international medical partnerships can potentially lead to a misalignment with local health care needs. ${ }^{19-21}$ In response, partners took to adapt the home curriculum to accommodate differences in health care systems, health care needs, legal interference, and educational environments.

Yet, the very nature of curriculum partnerships calls for comparability of curricula and learning experiences in both locations. Finding a balance between adaptation and equivalence creates an educational tension as the adaptations to local settings are constrained by the intentions of the partnerships. We found that, when resources differed between host and home settings, partners bridged this disparity by focusing on similarity in educational outcomes rather than on using similar methods of instruction. Other adaptations were aimed at accommodating the home curriculum to the host country's health care needs by adding (longitudinal) courses, assignments and exposure to local health care systems. This confirms our initial statement that crossborder curricula are not just carbon copies of home curricula. Some participants expressed their confidence that such revisions adequately prepared host students for practice in both countries. It is important to investigate more closely whether this truly is the case. After all, a CCP is deemed successful when a seamless fit with local needs has been achieved, distinguishing it from 'offshore' medical schools that explicitly cater for the home rather than the host market. ${ }^{3}$ 
We have seen that CCPs not only thrive on revision of the home curriculum, but also on proper management. Interestingly, all partnerships in our study were initiated by senior health care decision-makers and/or policy-makers from the host country. Nevertheless, with knowledge and materials stemming from the home institution, and remuneration from host to home, the relationship between partners of a CCP is inherently unequal, which can complicate collaboration and communication processes. Our findings confirm studies by Heffernan and Poole ${ }^{17}$ and Sidhu ${ }^{22}$ who argue that seeming trivialities, such as timing of joint meetings and perceived impolite communication, can cause harm to the relationship and the quality of curriculum delivery. Furthermore, it remains to be seen whether contextual differences related to clinical teaching culture, students' learning behaviours, and feelings of scepticism among stakeholders can truly be overcome by deliberate management strategies over the longer run. This issue definitely merits to be investigated further as soon as the pioneering partnerships have become more mature.

The present discourse gives rise to a fundamental question, which is: how to define 'equivalence' in the first place, and who determines the extent to which equivalence should be reached in a crossborder curriculum partnership? Although different institutes such as UNESCO have set guidelines for curriculum partnerships, 1, 23, 24 there is currently no internationally agreed accreditation standard by which 'equivalence' can be measured. It therefore remains a grey area, often leaving it at the discretion of both partners to decide. More alarmingly, the absence of an acknowledged judge or institution makes way for other dynamics: financial considerations, for instance, might just prevail over the commitment to assure equal quality of student experiences. ${ }^{9}$

This makes the experiences of home medical schools, such as one of the partnerships in the present study, who guarantee their host students that their final degree is of exact equivalence to the one from the home institution, an interesting object of scrutiny. These partnerships distinguish themselves for involving, as intensely as possible and from the start of the partnership, the host institution's staff in many academic spheres of the home institution. This more collaborative, participatory approach yields greater benefits, such as increased feedback on the home institution's educational materials and assessment papers, and a more profound evaluation of the educational programme. Furthermore, partners report that close integration offers the opportunity to try out educational innovations and new delivery modes, ultimately resulting in joint research ventures. Evidently, this integrative approach has a potentially strong positive effect on the quality of curriculum delivery. This approach might ultimately elevate the notion of CCPs to entail partnerships where teachers conjointly develop materials and establish international medical curricula, and where educational knowledge not only travels from home to host but in both directions. ${ }^{7}$ Eventually, such partnerships could grow to become a fully integrated global university network, as envisioned by Wildavsky ${ }^{25}$ and Knight ${ }^{10}$.

One of this study's merits is that it addresses a relatively young and rather unexplored trend in the ambit of medical education. Another strength is that data were collected first-hand, reflecting the perspectives of programme directors who, from the very beginning, had been overseeing the quality of curriculum delivery on both sides of the partnership. It should be mentioned, however, that the data only reflect one side of 
the story and it cannot be determined to what extent participants were in a position to disclose all their strategic sensitive challenges and partnership experiences. It would therefore be interesting to expand and triangulate the data with teacher and student perspectives.

A second potential restriction of this study is that challenges programme directors encountered were predominantly based on small batches of students and only few partnerships had actually graduated students. We therefore support the suggestion made by Hodges, Maniate, Martimianakis, Alsuwaidan and Segouin ${ }^{21}$ that a broader comparative research programme is needed to examine long-term impacts of CCPs on host country health care systems, their graduates' professional skills and cultural and collaborative aspects.

\section{Conclusion}

Establishing crossborder medical curriculum partnerships is a challenging endeavour due to the educational tension created by opposing inside forces that seek to achieve curriculum equivalence while adapting curricula to local contexts. Home and host settings differ in health care systems, legal and political interference, and teaching and learning environments requiring partners to make concessions to the equivalence objective of CCPs. The experiences of pioneering medical institutions seem to suggest that it is feasible to overcome these differences without harming curriculum equivalence.

From a management perspective it seems that there are not only financial, but also academic advantages to be had for both institutions as long as equal relationships on all institutional levels are deliberately promoted and sustained by modern communication facilities. Lessons on how to integrate academic operations, balance the interactions between staff, and on optimal ways to transfer curriculum materials can be learned from pioneering medical partnerships.

However, before embarking on a crossborder curriculum partnership we strongly recommend institutions to critically reflect on their motives and to factor in ample time for planning. A culturally and locally sensitive partnership with an emphasis on alignment with host country health care needs and addressing the impact on learners and teachers, requires of both partners a profound analysis and hence significant investment from the start. This, however, is worth the effort as it limits the chance of failure and maximises the chance for potential advantages of CCP in the long run.

\section{Acknowledgements}

The authors would like to thank all participants of this study for their time and their openness to share their experiences and perspectives. Furthermore, we would like to acknowledge Angelique van den Heuvel for her help in the preparation of this article. 


\section{References}

1. Karle H. Global standards and accreditation in medical education: A view from the WFME. Acad Med. 2006;81(12):S43-S8.

2. Williams RS, Casey PJ, Kamei RK, Buckley EG, Soo KC, Merson MH, Krishnan RK, Dzau VJ. A Global Partnership in Medical Education Between Duke University and the National University of Singapore. Acad Med. 2008;83(2):122-7.

3. Knight J. Cross-border education: Conceptual confusion and data deficits. Perspect Educ. 2006;24(4):1527.

4. Lane JE. Global Expansion of International Branch Campuses: Managerial and Leadership Challenges. New Dir High Educ. 2011;(155):5-17.

5. Verbik L, Rumbley LE, Altbach PG. The international Branch campus -Models and Trends. 2006. [Report] Available from; Accessed September 2013.

6. Wilson M. Transnational nursing programs: models, advantages and challenges. Nurse Educ Today. 2002;22(5):417-26.

7. Harden RM. International medical education and future directions: a global perspective. Acad Med. 2006;81(12):S22-S9.

8. British Council. The shape of things to come 2. The evolution of transnational education: data, definitions, opportunities and impacts analysis. 2013. [Report] Available from [https://www.britishcouncil.org/education/ihe/knowledge-centre/transnational-education/the-shape-of-things-to-come-2]; Accessed August 2013.

9. Coleman D. Quality assurance in transnational education. J Stud Int Educ. 2003;7(4):354-78.

10. Knight J. Higher Education in Turmoil, vol. 13. Toronto: Sense Publishers; 2008.

11. Shams F, Huisman J. Managing Offshore Branch Campuses: An Analytical Framework for Institutional Strategies. J Stud Int Educ. 2012;16(2):106-27.

12. Sharma Y. US-Malaysia medical school collaboration collapses. 2014. [Internet] Available from [http://www.universityworldnews.com/article.php?story=20140819111911158]; Accessed December 2015.

13. Vinen DG, Selvarajah C. A framework for sustainability of an offshore education program: a systems based approach. Journal of International Business and Economics. 2008;8(2):160-9.

14. Smith L. Sinking in the Sand? Academic Work in an Offshore Campus of an Australian University. HERD. 2009;28(5):467-79.

15. Smith K. Transnational Teaching Experiences: An Under-Explored Territory for Transformative Professional Development. International Journal for Academic Development. 2009;14(2):111-22.

16. Briguglio C. Language and Cultural Issues for English-as-a-Second/Foreign Language Students in Transnational Educational Settings. High Educ Eur. 2000;25(3):425-34.

17. Heffernan T, Poole D. In Search of "The Vibe": Creating Effective International Education Partnerships. HETIJHEEP. 2005;50(2):223-45.

18. Waterval DGJ, Frambach JM, Driessen EW, Scherpbier AJJA. Copy but Not Paste: A Literature Review of Crossborder Curriculum Partnerships. J Stud Int Educ. 2014;19(1):65-85.

19. Bleakley A, Brice J, Bligh J. Thinking the post-colonial in medical education. Med Educ. 2008;42(3):26670.

20. Burgis-Kasthala S, Kamiza S, Bates I. Managing national and international priorities: a framework for lowincome countries. Med Educ. 2012;46(8):748-56.

21. Hodges BD, Maniate JM, Martimianakis MA, Alsuwaidan M, Segouin C. Cracks and crevices: Globalization discourse and medical education. Med Teach. 2009;31(10):910-7.

22. Sidhu R. The 'brand name' research university goes global. High Educ. 2009;57(2):125-40.

23. Stella A. Quality assurance of cross-border higher education. Qual High Educ. 2006;12(3):257-76.

24. Zwanikken PAC, Peterhans B, Dardis L, Scherpbier A. Quality assurance in transnational higher education: a case study of the tropEd network. BMC Med Educ. 2013;13(1):43.

25. Wildavsky B. The great brain Race. New Jersey: Princeton University Press; 2010. 



\section{Chapter 4.}

\section{Connected, attracted, and concerned: A Q study on medical crossborder curriculum partnerships}

Accepted for publication: Waterval DGJ, Frambach JM, Driessen EW, Muijtjens A, Scherpbier AJJA. Connected, attracted, and concerned: A Q study on medical crossborder curriculum partnerships. Medical Teacher. 2018. DOI:

10.1080/0142159X.2018.1431618 


\section{Abstract}

Introduction: A new form of internationalisation has been trending upward in the medical education realm: crossborder medical curriculum partnerships established to deliver the same, or adapted, curriculum to groups of geographically separated students. This study aims to investigate crossborder medical curriculum partnerships by exploring the experiences of teachers at the recipient institution who have a key role in delivering the program.

Method: From 4 pioneering recipient medical schools twenty-four teachers participated in a Q-sort study. Each participant rank-ordered 42 statements about teaching in a crossborder medical curriculum on a scale from -5 (indicating strong disagreement) to +5 (indicating strong agreement). The authors conducted a "by-person" factor analysis to uncover distinct patterns in the ranking of statements, using the statistical results and participants' comments about their $\mathrm{Q}$ sorts to interpret these patterns and translate them into distinct viewpoints.

Results: Three viewpoints emerged, reflecting: 1) a feeling of connectedness with the partner institution, trust in the quality of the curriculum, and appreciation of interinstitutional relationships; 2) the partnership's attractiveness because of the career opportunities it offers; and 3) concerns over the quality of graduates because of doubts about the appropriateness of the didactic model and insufficient attention to local healthcare needs, and over the practical feasibility of such partnerships.

Conclusions: The three viewpoints identified revealed a pallet of views on how host teachers might experience their work. It shows the heterogeneous features of this group and counterbalances reports that they are feeling 'deprived' from their role as teacher. Two viewpoints featured an appreciation of interinstitutional relationships and of the partnership, especially when perceiving a degree of autonomy. Partners can capitalize on all different viewpoints by deploying procedures and policies to raise the quality of education delivery. 


\section{Introduction}

In the last decade a number of medical schools have entered into crossborder curriculum partnerships (CCPs). In such partnerships it is the curriculum, not students or faculty, that crosses borders from the location where it was developed (home) to an institution (host) where it will be delivered. ${ }^{1}$ This transfer of the curriculum can be realized through various legal forms ranging from branch campuses to franchises or delivery agreements with host public or private providers, which of course influence the way the partnership is shaped. However, the overarching communality of these partnerships is to provide a comparable learning experience to students at both institutions. It has been argued that CCPs are a logical next embodiment of globalisation in higher education following the student and teacher exchanges of the previous decades. ${ }^{2}$ According to a report from the British Council ${ }^{3}$, this type of partnership is rapidly expanding and has high-potential growth rates. Key actors in such crossborder medical curriculum partnerships are host teachers as they are expected to deliver a program that has been developed by another institution. Although host staff are typically well qualified and employed full-time, they often have no experience with the program and teaching method of the home institution. ${ }^{4-6}$

Despite the pivotal role host teachers play, only a few studies outside of health care education have spotlighted their experiences and perceptions. What these studies revealed is that host staff could experience little ownership of the program. Programs have been adopted from the home institution and the host teachers have not been involved in the creation of new educational materials in substantial ways. ${ }^{7}$ Teachers were cited to "... just follow the syllabus" and "just [be] here to follow the home institution". ${ }^{8}$ These studies also reported incidences of host staff feeling maltreated by their partners, whom they perceived as being disinterested, ignorant, and feeling superior. ${ }^{7,} 8$ Furthermore, Waterval, et al. ${ }^{9}$ identified that the necessary communication processes in curriculum partnerships between host and home teachers could be perceived as frustrating due to the use of email for correspondence, time zone differences, and large geographic distances.

Although, curriculum partnerships are often initiated by higher management, ${ }^{10}, 11$ the teachers perceptions and enthusiasm for the partnership determines to a large extent the quality of curriculum implementation. The purpose of this study is therefore to canvass host teachers' views on teaching in a crossborder curriculum partnership, thereby contributing to the current debate on the pros and cons of this relatively novel form of internationalisation that is growing in medical education and beyond. ${ }^{12}$

\section{Methods}

\section{Setting}

We purposively selected six medical partnerships that delivered a home institution's curriculum at a host institution across borders, with the aim to provide comparable 
learning experiences to cohorts of geographically separated students. ${ }^{13}$ While two institutions declined due to a lack of time or interest, four responded positively to our email invitation to participate in this study. Appendix 4.1 summarizes the participating partnerships and their characteristics.

\section{$Q$ methodology}

To investigate host teachers' perceptions of teaching in a medical curriculum partnership we used Q methodology. An organized means to identify opinions and priorities among a group ${ }^{14}$ this technique has been effectively used to study a wide range of topics in education and the health sciences. ${ }^{15-21}$ In applying the method, we purposively selected a representative number of participants and invited them to rank-order a set of statements about the research question on a scale ranging from "disagree most strongly" to "agree most strongly." As the method aims to describe a population of viewpoints, and not, as is the case with conventional survey analyses, of people, we did not require a large sample. ${ }^{14}$ Each participant recorded his or her ranking of statements on the score sheet (the Q sort) depicted in Figure 4.1 and consequently participated in a short qualitative interview in which they commented verbally on the statements placed at the $\mathrm{Q}$ sort extremities.

This data collection was followed by a "by-person" factor analysis of participants' Q sorts to discover patterns in the statement rankings. Unlike traditional factor analysis, the objective of which is to identify correlations between variables across a sample of participants, Q methodology aims to detect correlations between participants across a number of variables, in this case statements. Assuming that such correlations indicated similarity of participants' viewpoints, we used the statistical results and qualitative data from the post-Q-sort interviews to interpret these patterns and to translate them into distinct viewpoints.

\section{Development of the $Q$ set}

Critical to Q methodology is the effective development of the research instrument, i.e., the set of statements ( $Q$ set) to be sorted. Although the generation of items does not follow a fixed procedure, an effective $Q$ set should meet two important criteria. First, the statements should adequately represent the discourse on the topic of study, allowing for expression of all possible viewpoints. ${ }^{22,23}$ Hence, they must cover all the ground and be rooted in real existence. ${ }^{23}$ Second, the $\mathrm{Q}$ set should be balanced, ensuring the absence of bias toward any particular viewpoint. ${ }^{22}$

To assemble the pool of statements about teaching in a crossborder curriculum partnership, we drew on two of our previous studies: a literature review of the factors that make or break crossborder curriculum partnerships ${ }^{9}$ and a qualitative study for which we interviewed 13 directors of host and home medical crossborder curriculum partnerships. ${ }^{13}$ In doing so, we specifically focused on the data pertinent to the challenges host teachers face. The initial $Q$ set that resulted comprised 48 statements and was structured around six themes: "ownership of curriculum materials," "communica- 
tion and relationship with home staff," "challenges related to differences in learning styles," "understanding of teaching philosophy of home institution," "fit between adapted home curriculum and local healthcare setting," and "miscellany."

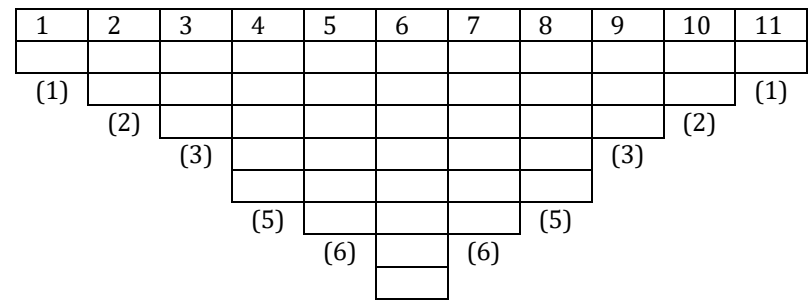

(8)

\title{
$\leftarrow$ DISAGREE MOST STRONGLY
}

\author{
AGREE MOST STRONGLY $\rightarrow$
}

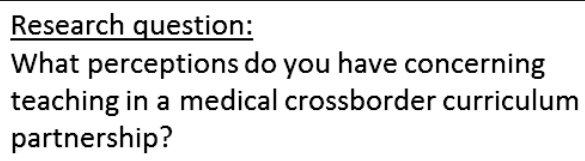

Figure 4.1: The Q-sort grid: Score sheet for the Q sort of 42 statements on host teachers' experiences of teaching in a crossborder curriculum partnership.

* Blue cells pertain to the scoring mechanism and were not visible to participants. Participants placed each statement on one position of the score sheet, representing their level of agreement with the statement (from "disagree most strongly" to "agree most strongly"). Participants placed the statement card they agreed with most strongly in column 11, the two cards eliciting their next -strongest agreement in column 10, and so on. For the 42 statements used in the Q sort, please refer to Table 4.3.

After all authors had reviewed the initial Q set for ambiguity, clarity, and suitability, D.W. made adjustments based on their comments. Research team members E.D., A.M., and J.F. and one host teacher then performed a dry run of the $Q$ set to test its adequacy by completing a $\mathrm{Q}$ sort and critically reviewing the $\mathrm{Q}$ sort instructions and post-Q-sort questions (see Appendix 4.2). A second round of adjustments ensued, resulting in a final set of 42 statements (between $40-50$ is most common). ${ }^{14,}{ }^{23}$ Finally, we randomly numbered the backside of the final statements and printed them on laminated cards for use by participants during their $\mathrm{Q}$ sorts.

\section{Participant recruitment and procedure}

The Q-methodological approach to recruiting participants (the P set) is to select them strategically in accordance with the study's purpose ${ }^{22}$. In our case, and in coordination with the host program directors, we selected 24 participants based on their long-term involvement in the partnership, preferably from the start, and their ability to provide the information sought after. Additionally, we aimed at an even distribution in terms of gender and participants' expertise (basic/social sciences, and clinicians). Table 4.1 presents the final list of teachers who participated. The first author and on one occasion a research assistant visited each participating institution in the period spanning December, 2015, to March, 2016, during which time all participants received written and verbal instructions. After completing the $Q$ sort by placing the 42 cards on the 
score sheet (see Figure 4.1), participants provided comments on the statements they rank-ordered at the extremities. The entire exercise took participants 45 minutes on average to complete.

Table 4.1: P set overview: the 24 participants categorized into gender, partnership, academic background, and viewpoint loadings.

\begin{tabular}{lllll}
\hline Participant & Gender & Partnership & Discipline & Viewpoint loadinga \\
\hline 1 & M & A & Clinician & 2 \\
2 & F & A & Clinician & \\
3 & F & A & Basic scientist & \\
4 & F & A & Clinician & 2 \\
5 & M & A & Clinician & 2 \\
6 & F & A & Basic scientist & 2 \\
7 & F & B & Social scientist & 1 \\
8 & M & B & Basic scientist & 1 \\
9 & F & B & Clinician & 1 \\
10 & F & B & Social scientist & 1 \\
11 & M & B & Social scientist & 1 \\
12 & M & B & Clinician & \\
13 & M & C & Clinician & \\
14 & M & C & Clinician & 2 \\
15 & M & C & Basic scientist & 3 \\
16 & M & C & Social scientist & \\
17 & M & C & Social scientist & 1 \\
18 & M & C & Social scientist & \\
19 & F & D & Basic scientist & \\
20 & M & D & Basic scientist & 2 \\
21 & F & D & Basic scientist & \\
22 & M & D & Clinician & 2 \\
23 & M & D & Clinician & 3 \\
24 & F & D & Clinician & 1 \\
\hline
\end{tabular}

a This column indicates which participant, if applicable, loads significantly on which factor.

\section{Analysis}

We analysed the data using dedicated software (PQMethod 2.11, schmolck.user web.mwn.de/qmethod). A first exploration pointed to different numbers of factors: six when applying the "eigenvalue $>1$ " criterion; two or three based on the scree plot; and three or four when adopting Watts \& Stenner's rule of thumb to employ one factor for each 6-8 $\mathrm{Q}$ sorts. ${ }^{22}$ To find the appropriate solution, we trialed 3 to 5 -factor structures using PCA and varimax. A four-factor solution, combined with a 0.45 significance threshold for the loadings, resulted in a minimum number of confounding $Q$ sorts. After dismissing one of the factors for being associated with only one $Q$ sort, a final, threefactor structure remained.

For each of these factors, using the PQMethod software, we generated an idealized $\mathrm{Q}$ sort - the score pattern over the set of statements - representing how someone teach- 
ing in a medical crossborder curriculum partnership with exactly that viewpoint would have ranked the 42 statements in the sorting grid. In the process, we flagged the statements that for a particular factor were ranked significantly differently $(\mathrm{P}<.05$ or $\mathrm{P}<.01)$ from all other factors as "distinguishing statements." Statements that did not distinguish between any pair of factors (P>.05) were identified as "consensus statements." Finally, D.W and J.F independently interpreted each factor's score pattern and translated them into viewpoints, using the crib-sheet method, ${ }^{22}$ the distinguishing statements, and the comments of participants whose $\mathrm{Q}$ sorts were associated with the respective viewpoint.

\section{Results}

The three viewpoints had respectively seven, seven and two defining Q sorts (i.e., participants statistically significantly associated with the viewpoint). Together, the three viewpoints accounted for $57 \%$ of the variance in the 24 Q-sorts (see Table 4.2 ).

Table 4.2: Distribution of the three emerging viewpoints regarding teaching in a medical crossborder curriculum partnership.

\begin{tabular}{llcc}
\hline Viewpoint & 1: Connected & 2: Attracted & 3: Concerned \\
\cline { 2 - 4 } Characteristic & & & \\
\hline Number of defining participants & & 7 & 2 \\
\% of variance explained by the viewpoint & 25 & 23 & 9 \\
\hline
\end{tabular}

a $O$ the 24 participants, 8 were not uniquely associated with a single viewpoint.

For each viewpoint Table 4.2 presents the levels of agreement on each statement on a scale from -5 to +5 . In the following, we will give a detailed description of each viewpoint based on the statements that were flagged as distinguishing and characteristic of the viewpoint, illustrated by a representative quote from one of the participants. The information in parentheses refers to the statement number listed in Table 4.3 (1 to 42) and the factor score $(-5$ to +5$)$, respectively. 
Table 4.3: The $Q$ set and associated Q-sort values, indicating for each factor the average level of agreement on each statement (on a scale from -5 to +5 ).

Q-sort value for viewpoint $\quad 1: \quad 2: \quad 3$ :

Statement

1 Certain essential diseases in the local context are not included in the learning program $-1^{\mathrm{d}} \quad 1^{\mathrm{d}} \quad 5^{\mathrm{d}}$ of our students

2 A good relationship between host and home staff is essential to the quality of the $\quad 5^{\mathrm{d}} \quad \begin{array}{lll}1 & 1\end{array}$ program delivery

3 Email is an ineffective tool for communicating with home teachers ${ }^{b} \quad-1 \quad-2 \quad-2$

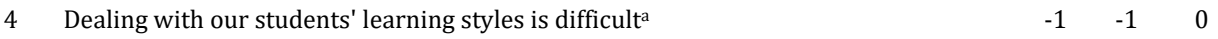

5 Host teachers deliver the program in the exact same way as home teachers do $\quad-1 \quad 0^{\mathrm{d}} \quad-1$

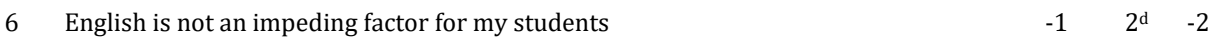

$7 \quad$ My students are able to attain the same learning objectives as home students $\mathrm{do}^{\mathrm{b}} \quad \begin{array}{llll}3 & 4 & 2\end{array}$

8 I am afraid our students are not appropriately trained to work in the local healthcare $\quad \begin{array}{cccc}-2 & -2 & 0^{\text {d }}\end{array}$ setting

9 I can add important local aspects to my teaching, regarding local diseases and the local $\quad \begin{array}{llll}1 & 3 & 4\end{array}$ healthcare system, for example ${ }^{\mathrm{a}}$

10 I appreciate the international community of teachers at this institution ${ }^{a}$

11 I do not like the learning method of the home institution ${ }^{b}$

12 I can teach without interference from my colleagues at the home institution ${ }^{\mathrm{b}}$

13 I feel part of the teaching community of the home institution

14 I feel a strong commitment to this host institution ${ }^{\text {b }}$

15 I find it difficult to work with educational materials that have been constructed by someone else

16 I feel that home teachers treat us as unimportant $\mathrm{t}^{\mathrm{b}}$

17 I have a good relationship with my counterpart in the home institution ${ }^{a}$

18 I fully understand the philosophy behind the home program

19 I sometimes feel a slave because I just follow orders from the home institution

20 I miss creating educational content myself

21 I think more lectures would improve the quality of the program

22 I sometimes feel inferior when communicating with colleagues from the home institution ${ }^{\mathrm{b}}$

23 It gives me a sense of pride to deliver the reputable program of the home institution

24 I would like to interact more with the home teachers ${ }^{b}$

25 My suggestions for improvement of the course are discussed with home teachers

26 Most of our students adapt quickly to the learning style required by the home curriculum $^{\mathrm{a}}$

27 Our students are assessment-driven

28 Our curriculum partnership causes inflexibility because many aspects need to be coordinated with the home institution

29 Our students lack the ability to study independently ${ }^{a}$

30 Our students are better than their home institution counterparts ${ }^{\text {b }}$

31 Our students show responsibility for their own learningb

32 The learning experience of our students is the same as that of home students

33 Teaching in a medical crossborder curriculum partnership creates more red tape because of coordination between institutions

34 Staff from the home institution do not understand the local context

35 Teaching in a medical crossborder curriculum partnership is unattractive 
Q-sort value for viewpoint

37 Thanks to the curriculum partnership the quality of graduates is higher than would have been the case if we had developed all the educational materials ourselves

38 The assessment tools of the home program are not suitable for our students

39 The student-centered methodology does not work in this setting

40 The educational program is relevant to the local healthcare setting

41 Training in how to communicate with staff from the home institution is needed

42 This program will benefit students in their future career

1: 2: 3:

$4^{\mathrm{d}} \quad-1 \quad-1$

$-4^{\mathrm{d}} \quad-1^{\mathrm{d}} \quad 2^{\mathrm{d}}$

$-5^{\mathrm{c}} \quad-2 \quad-1$

$0^{\mathrm{c}} \quad 1^{\mathrm{c}} \quad-2^{\mathrm{c}}$

$\begin{array}{lll}-1 & 1 & 0\end{array}$

$4 \mathrm{c} \quad 2^{\mathrm{c}} \quad 0^{\mathrm{d}}$

* We considered a statement with a factor score of $5,4,-4$, or -5 as characteristic of that viewpoint, while we flagged statements with a score that differed statistically significantly from those of all other viewpoints as distinguishing statements.

a Consensus statement for all viewpoints at $\mathrm{P}>.01$

b Consensus statement for all viewpoints at $\mathrm{P}>.05$

c Distinguishing statement at $\mathrm{P}<.01$

d Distinguishing statement at $\mathrm{P}<.05$

\section{Viewpoint 1: Connected with home institution}

Adherents of this viewpoint had great trust in the curriculum. They felt the partnership produced graduates of higher quality than would have been the case if they had developed all the educational materials themselves $(37:+4)$. More than their peers who embraced the other two viewpoints, they strongly rejected the notion that the studentcentered learning and assessment methodology of the home program would not work in their setting (38: -4, 39: -5). Neither did they believe the program did not cover certain diseases that were essential to the local context (1: -1$)$. In a similar vein, they were more optimistic about the program being of benefit to students' future careers $(42:+4)$, but less so about its relevance to the local healthcare system $(40 ; 0)$.

Another conviction that marks this viewpoint is that good relationships between host and home staff are essential to the delivery of a high-quality curriculum $(2:+5)$. This may be because exemplars of this viewpoint felt more strongly than others that working with educational materials that had been constructed by someone else was difficult (15: 0). As such they felt part of the home institution's teaching community $(13:+2)$. In the words of one clinician (teacher 24, partnership D): "Any collaboration requires collaboration and communication at all levels. It is the glue to success; it helps them stick. Both parties should be interested; that is what makes collaboration and communication more effective."

The Q sorts of seven participants (four females, three males) loaded onto this viewpoint, including four social scientists, two clinicians, and one basic scientist. The majority (5) were teachers from partnership B, while the remaining two participants came from partnership C and D.

\section{Viewpoint 2: Attracted because of career opportunities}

The teachers represented by this viewpoint felt that working in the context of a crossborder curriculum partnership offered many career advantages $(36:+5)$. They strongly disagreed with the statement that teaching in this context was unattractive (35: -4$)$. 
Instead, they were rather proud to share in the reputation of the home institution (23: +4 ). To a slightly lesser degree than the group previously discussed, these teachers also had significant trust in the curriculum and positive attitudes toward the partnership regarding matters of coordination with and involvement of the home institution (42: 2, 5: 0, 19: -5, 33: -1, 34: -2). This optimism was also reflected in teachers' confirmation that the new language of instruction, assessment methods, and required learning style were suitable for their students $(6: 2,38:-1)$.

Despite this optimism, however, teachers in this group were more convinced that the program did not cover certain diseases that were essential to the local context (1: +1 ). Consequently, they were only moderately enthusiastic about the program's relevance to the local healthcare setting (40: 1), favoring a certain amount of independence from their home partners and adaptation of the home curriculum to their context. They did not experience a high level of interference from home teachers (25: -1), and were neutral about feeling part of the home institution's teaching community (13: 0). Although creating educational content themselves was not among their priorities (20: -3), they did appreciate the opportunity to work with the home program and to adapt it. One basic scientist (teacher 20, partnership D) who exemplifies this viewpoint remarked: "Working in such a partnership provides more challenges and opportunities for me as faculty, which I benefitted from. Think of adjusting curriculum materials to the local context. Furthermore, the reputation of this home institution is very attractive and good for my career."

Seven participants (four males, three females) were associated with this viewpoint, including five clinicians, and two basic scientists. Four of them were affiliated to partnership A, one to partnership C, and two to partnership D.

\section{Viewpoint 3: Concerned about appropriateness}

The teachers who espoused this view were more critical of the home program and of its fit with the local healthcare context (40: -2$)$. They were less confident that the program adequately prepared students for practice in the local healthcare setting (8: 0), also because they felt the curriculum lacked coverage of certain essential local diseases $(1:+5)$, which, in turn, translated into a neutral stance toward the program being of benefit to graduates' careers (42: 0). Their critical attitude also extended to the teaching and assessment methods of the home institution, which they did not always consider appropriate for their students (38: 2, 39: -1). Besides believing that students' learning experiences differed between home and host institution (32: -3), these teachers did not appear to fully understand the philosophy of the home institution (18: -1), and certainly did not feel part of its teaching community (13: -5). They were not particularly positive about working in the context of a crossborder curriculum partnership (33: $3,35: 0$ ), and despite the fact that they found it easy to work with educational materials constructed by others (15: -4 ), they missed creating educational content themselves (20: 3, 21:1).

This viewpoint is best captured by teacher 23 (basic scientist, partnership D), who noted that "..adjustments to the local situation are needed, not so much in [terms of] 
quantity, but of quality. Prevalence of certain diseases makes it essential to look for the differences in the local setting and adjust the program locally". Two male teachers loaded onto this viewpoint: one basic scientist from partnership $\mathrm{C}$ and one clinician from partnership D.

\section{Shared perceptions}

As noted earlier, we also identified several consensus statements indicating similarity of viewpoints. For instance, none of the teachers felt inferior when communicating with home partners $(22:-4,-3,-2)$ and all felt they had good relationships with their colleagues abroad (17: 2,1,1). Importantly, they all agreed that their students were able to attain the same intended learning objectives as home students did $(7: 3,2,4)$.

\section{Discussion}

In this study, we have sought to capture the views of host teachers from four different partnerships on teaching in a crossborder medical curriculum partnership. Their viewpoints show that various aspects of the teaching experience are valued differently by host teachers, even if they work in the same context. Concerns expressed by one critical viewpoint echo previous warnings from medical scholars about home programs not being sufficiently adapted to local circumstances. ${ }^{24}$ These findings lend further credence to the assertion that curriculum partnerships may fail to respond to the needs of the local healthcare system. The other two viewpoints show a different, more optimistic side of the teaching experienced which have been less reported in literature.

Some medical host teachers felt proud to deliver the home program and were relatively confident about its quality, as evidenced by the "connected with home institution" and "attracted because of career opportunities" viewpoints. What's more, they enjoyed the opportunity to work with materials from the home institution, as they felt it would enhance their teaching competence and career prospects. They were not dissatisfied with the program content, nor did they feel disempowered or alienated from what was on offer to students.

These first two viewpoints might be in opposition to the more concerned viewpoint, this could also be related to the amount of autonomy perceived by host teachers to be able to adapt and modify the content up to their insights. For instance all viewpoints were positive about the working relationships with home staff. This seems to support findings indicating that feelings of control and ownership among host teachers were shown to be important determinants of job satisfaction. ${ }^{25}$ As such the fact that the curriculum had initially been developed by another institution did not make them feel deprived of their role as teacher. ${ }^{26}$

Although on one occasion a personal distorted relationship between a home and host course coordinator was mentioned as an illustration during the post Q-sort interview, a structural widespread troubled relationship did not emerge from our viewpoint 
analyses. The host teachers in our study did not report feelings of inferiority caused by inappropriate attitudes of home teachers as noted elsewhere. , $^{27}$

Several factors should be taken into account when relating our findings to those of previous studies. First, differences in research context may account for variations, as, to our knowledge, this research was the first to be conducted in the area of medical education. Next, our use of q-sort methodology and associated quantitative analyses may have led to the emergence of main perceptions only, filtering out individual experiences that qualitative interviewing techniques would otherwise have detected. Our pool of statements, though diverse, did not incorporate every possible teaching experience within a crossborder curriculum context, which narrowed the range of possible perceptions to identify. Finally, Q-sorts might have been biased by a perceived lack of confidentiality as they were purposively selected. Although this cannot be excluded, during the performance of the Q-sort and the post Q-sort questionnaire most teachers expressed their thoughts and concerns in a free and open atmosphere. Many expressed an appreciation for the methodology.

Drawing on these insights, we argue that partnership managers on both sides could put these divergent views to constructive use by appropriate policies and procedures. Responding to the concerns raised by adherents of viewpoint 3, for instance, the partnership could commission formal committees to adapt the home curriculum to the local context. Inviting critical teachers to serve on these committees would create a win-win situation: not only would the curriculum become better adapted, it would also remove some of their valid concerns.

Similarly, managers could support the teachers who feel connected and attracted by implementing communication policies and procedures between coordinators, and removing all technical communication barriers from the start. This is likely to foster strong links and facilitate engagement and interaction between teachers from both sides. Keay, May and 0' Mahony ${ }^{26}$, as well as the British quality assurance agency overseeing the quality of crossborder programs, argued that working toward the development of communities of practice, promoting a focus on the quality of the relationship between partners, will enhance the learning experience for host students. In addition, a recent study suggests that strong linkages between partners may also have a positive effect on the levels of commitment and satisfaction among the home teachers within a curriculum partnership. ${ }^{25}$

Unfortunately, present-day medical curriculum partnerships are not so much concerned with establishing communities of practice as with the transfer of knowledge about the curriculum and didactics by fly-in, fly-out home teachers. ${ }^{13}$ In doing so, they overlook host teachers' willingness and preparedness to engage, interact, and form joint course coordinating groups. Communities of practice will not only support host teachers in their daily activities, they will also render a more sustainable partnership. They can serve as principal platforms for the required frequent and effective communication on multiple organisational levels. ${ }^{28}$ As a result, the curriculum partnership can grow to become truly bilateral, such that a "network partnership" may come to evolve that could eventually span other issues of collaboration besides the curriculum. We therefore welcome future research into the factors that promote the establishment of 
effective communities of practice between teachers in a crossborder curriculum partnership.

\section{Ethical approval}

The study was approved by the ethical review board of the Netherlands Association for Medical Education (NVMO-ERB; file number 579)

\section{Acknowledgements}

The authors wish to thank Mohammed Meziani for his assistance in the data collection, Angelique Van den Heuvel for the language editing and helpful comments, and the participants for their contribution to the research project. 


\section{References}

1. Knight J. Higher Education in Turmoil, vol. 13. Toronto: Sense Publishers; 2008.

2. Harden RM. International medical education and future directions: a global perspective. Acad Med. 2006;81(12):S22-S9.

3. British Council. The shape of things to come 2. The evolution of transnational education: data, definitions, opportunities and impacts analysis. 2013. [Report] Available from [https://www.britishcouncil.org/education/ihe/knowledge-centre/transnational-education/the-shape-of-things-to-come-2]; Accessed August 2013.

4. Shams F, Huisman J. Managing Offshore Branch Campuses: An Analytical Framework for Institutional Strategies. J Stud Int Educ. 2012;16(2):106-27.

5. Märzheuser-Wood B, Chatwood R. How Education Providers Are Growing Internationally Through The Strategic Use Of Franchising. 2014. [Internet] Available from [http://www.mondaq.com/x/335030/Franchising/ How+education+providers+are+growing+internationally+through+the+strategic +use+of+franchising]; Accessed September 2014.

6. Verbik L, Rumbley LE, Altbach PG. The international Branch campus -Models and Trends. 2006. [Report] Available from; Accessed September 2013.

7. Smith L. Sinking in the Sand? Academic Work in an Offshore Campus of an Australian University. HERD. 2009;28(5):467-79.

8. Dobos K. "Serving two masters" - academics' perspectives on working at an offshore campus in Malaysia. Educ Rev. 2011;63(1):19-35.

9. Waterval DGJ, Frambach JM, Driessen EW, Scherpbier AJJA. Copy but Not Paste: A Literature Review of Crossborder Curriculum Partnerships. J Stud Int Educ. 2014;19(1):65-85.

10. Wilkins S, Huisman J. The international branch campus as transnational strategy in higher education. High Educ. 2012:64(5):627-45.

11. OECD. Internationalisation and Trade in Higher Education Opportunities and Challenges. Paris: OECD 2004.

12. Kosmutzky A, Putty R. Transcending Borders and Traversing Boundaries: A Systematic Review of the Literature on Transnational, Offshore, Cross-Border, and Borderless Higher Education. J Stud Int Educ. 2016;20(1):8-33.

13. Waterval DGJ, Frambach JM, Oudkerk Pool A, Driessen EW, Scherpbier AJJA. An exploration of crossborder medical curriculum partnerships: Balancing curriculum equivalence and local adaptation. Med Teach. 2016;38(3):255-62.

14. Watts S, Stenner P. Doing Q Methodology: theory, method and interpretation. Qual Res Psychol. 2005;2(1):67-91.

15. Barker JH. Q-methodology: An alternative approach to research in nurse education. Nurse Educ Today. 2008;28(8):917-25.

16. Nikolaus S, Bode C, Taal E, van de Laar MA. Four different patterns of fatigue in rheumatoid arthritis patients: results of a Q-sort study. Rheumatology. 2010;49(11):2191-9.

17. Wallenburg I, van Exel J, Stolk E, Scheele F, de Bont A, Meurs P. Between Trust and Accountability: Different Perspectives on the Modernization of Postgraduate Medical Training in the Netherlands. . Acad Med. 2010;85(6):1082-90.

18. Meade LB, Caverzagie KJ, Swing SR, Jones RR, O’Malley CW, Yamazaki K, Zaas, Aimee K. Playing With Curricular Milestones in the Educational Sandbox: Q-sort Results From an Internal Medicine Educational Collaborative. Acad Med. 2013;88(8):1142-8.

19. Fokkema JP, Scheele F, Westerman M, van Exel J, Scherpbier AJ, van der Vleuten CP, Dorr PJ, Teunissen PW. Perceived effects of innovations in postgraduate medical education: a Q study focusing on workplace-based assessment. Acad Med. 2014;89(9):1259-66.

20. Daniels V, Kassam N. Impact of personal goals on the internal medicine R4 subspecialty match: a $Q$ methodology study. BMC Med Educ. 2013;13(1):1-9.

21. Perz J, Ussher J, Gilbert E. Constructions of sex and intimacy after cancer: Q methodology study of people with cancer, their partners, and health professionals. BMC Cancer. 2013;13(1):1-13.

22. Watts S, Stenner P. Doing Q Methodological Research: Theory, Method and Interpretation. London, UK: SAGE; 2012.

23. Brown SR. Q Methodology and Qualitative Research. Qual Health Res. 1996;6(4):561-7. 
24. Whitehead CR. On gunboats and grand pianos: medical education exports and the long shadow of colonialism. Adv Health Sci Educ Theory Pract. 2016;21(1):1-4.

25. Toohey D, McGill T, Whitsed C. Engaging Academic Staff in Transnational Teaching: The Job Satisfaction Challenge. J Stud Int Educ. 2017;21(4):333-48.

26. Keay J, May H, O' Mahony J. Improving learning and teaching in transnational education: can communities of practice help? JET. 2014;40(3):251-66.

27. Bodycott $\mathrm{P}$, Walker A. Teaching Abroad: Lessons learned about inter-cultural understanding for teachers in higher education. Teach High Educ. 2000;5(1):79-94.

28. Waterval DGJ, Tinnemans-Adriaanse M, Meziani MA, Driessen EW, Scherpbier AJJA, Mazrou A, Frambach JM. Exporting a student-centred curriculum: a home institution's perspective. J Stud Int Educ. 2017;21(3). 


\section{Appendix 4.1: Overview of included partnerships and their characteristics}

\begin{tabular}{|c|c|c|c|c|c|c|}
\hline $\begin{array}{l}\text { Partner } \\
\text { ship }\end{array}$ & & $\begin{array}{l}\text { Country } \\
\text { (private or public } \\
\text { institution) }\end{array}$ & Type of program & Degree & $\begin{array}{l}\text { Launch of } \\
\text { program }\end{array}$ & $\begin{array}{l}\text { Main methods } \\
\text { of instruction }\end{array}$ \\
\hline \multirow[t]{2}{*}{$A$} & Home & $\begin{array}{l}\text { UK } \\
\text { (public) }\end{array}$ & $\begin{array}{l}\text { 5-year undergraduate } \\
\text { curriculum }\end{array}$ & Separate degree & 2006 & \multirow{2}{*}{$\begin{array}{l}\text { Lectures and } \\
\text { small group } \\
\text { tutorials }\end{array}$} \\
\hline & Host & $\begin{array}{l}\text { Egypt } \\
\text { (public) }\end{array}$ & $\begin{array}{l}5+1 \text { year } \\
\text { undergraduate } \\
\text { curriculum }\end{array}$ & & & \\
\hline \multirow[t]{2}{*}{ B } & Home & $\begin{array}{l}\text { UK } \\
\text { (public) }\end{array}$ & $\begin{array}{l}\text { 4-year graduate entry } \\
\text { curriculum }\end{array}$ & Similar degree & 2011 & \multirow{2}{*}{$\begin{array}{l}\text { Lectures and } \\
\text { small group } \\
\text { tutorials }\end{array}$} \\
\hline & Host & $\begin{array}{l}\text { Cyprus } \\
\text { (private) }\end{array}$ & & & & \\
\hline \multirow[t]{2}{*}{$\mathrm{C}$} & Home & $\begin{array}{l}\text { The Netherlands } \\
\text { (public) }\end{array}$ & $\begin{array}{l}\text { 6-year undergraduate } \\
\text { curriculum }\end{array}$ & Separate degree & 2010 & \multirow{2}{*}{$\begin{array}{l}\text { Lectures and } \\
\text { small group } \\
\text { tutorials }\end{array}$} \\
\hline & Host & $\begin{array}{l}\text { Saudi Arabia } \\
\text { (private) }\end{array}$ & $\begin{array}{l}5+1 \text { undergraduate } \\
\text { curriculum }\end{array}$ & & & \\
\hline \multirow[t]{2}{*}{ D } & Home & $\begin{array}{l}\text { USA } \\
\text { (private) }\end{array}$ & $\begin{array}{l}\text { 4-year graduate entry } \\
\text { curriculum }\end{array}$ & \multirow{2}{*}{$\begin{array}{l}\text { Separate degree } \\
\text { with indication of } \\
\text { location }\end{array}$} & \multirow[t]{2}{*}{2002} & \multirow{2}{*}{$\begin{array}{l}\text { Lectures and } \\
\text { small group } \\
\text { tutorials }\end{array}$} \\
\hline & Host & $\begin{array}{l}\text { Qatar } \\
\text { (public) }\end{array}$ & $\begin{array}{l}\text { 2-year pre-medical + } \\
\text { 4-year graduate entry } \\
\text { curriculum }\end{array}$ & & & \\
\hline
\end{tabular}




\title{
Appendix 4.2: Q-sort instructions and post-Q-sort questions
}

\author{
Section 1: Instructions on how to perform the Q-sorting task
}

This present instructions include the following materials:

- 42 statement cards

- A sorting distribution grid

Step 1: Please examine the sorting distribution grid and the 42 statement cards. On top of your sorting area

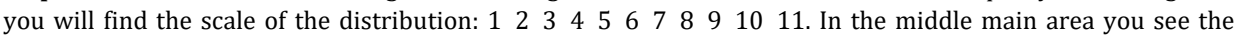
distribution grid. In the lower left corner you will see the research question and in the lower right corner you will have some space to do the pre-sorting, which will be explained in the next step.

Step 2: Read the research question and condition of instruction carefully. The 42 item cards all offer a different answer to the research question. The Q-sorting task requires you to allocate every one of these items, or answers, a ranking position within the sorting distribution provided, based on the strength of your agreement/disagreement with its content. The more you agree with an item, the higher the ranking you are likely to award it. The more you disagree, the lower the ranking. Please note, however, that the final pattern of item ranking MUST BE THE SAME AS the shape of the sorting distribution provided. If you look at the blank sorting distribution, you will see that only ONE item can be given a ranking of 11, TWO can be given a ranking of 10, THREE can be given a ranking of 9 , and so on. Please stick to these rules. There are good reasons for this distribution, which we will be happy to explain. This system is being used because it is the most effective means of capturing your viewpoints for purposes of our study.

Step3: Take the pile of 42 items cards. You need to read each card in turn, one at a time, and provide them into three provisional ranking categories on the lower right of the distribution grid,. This should be done in relation to the research question, so it may be as well to remind yourself of this as you go along. Category 1 should include those items, and hence those responses to the research question, with which you definitely AGREE. Put these items in a single pile towards your right-hand side. Category 2 should include those items with which you definitely DISAGREE. Put these items in a single pile towards your left-hand side. Category 3 should include those items about which you feel INDIFFERENT, UNSURE or which otherwise leave you with MIXED FEELINGS. These items should be placed in a single pile directly in front of you. There are no limits to the number of items that can be placed in any of these three categories. Just be faithful to your own feelings and viewpoint.

Step 4: you should now have three distinct categories (and piles!) of items.. Take the pile of items you definitely AGREE with and spread them out so that you can see them all at once. Your job is now to allocate each of these items a ranking position at the right-hand (or agree) end of the distribution provided. Clearly, the highest rankings should be given to the items with which you agree most strongly. So, in line with the limits imposed by the distribution provided, the ONE item you find most agreeable should be awarded a ranking of 11 . When you've identified this item physically move the relevant item card until it sits just below the card indicating the 11 ranking value. The next TWO most agreeable items should then be given a ranking of 10 the next THREE a ranking of 9, and so on. As you go, continue to physically position the relevant item cards below the appropriate ranking value card. Keep going until ALLL the AGREE items have been allocated an appropriate ranking. At the end of Step 4, your Q-sort will probably look something like the diagram shown here, although the number of items you've ranked and the items you've allocated to the various ranking values will obviously be different!

\begin{tabular}{|c|c|c|c|c|c|c|c|c|c|c|}
\hline 1 & 2 & 3 & 4 & 5 & 6 & 7 & 8 & 9 & 10 & 11 \\
\hline & & & & & & 10 & 35 & 37 & 05 & 16 \\
\hline \multirow[t]{6}{*}{ (1) } & & & & & & 03 & 27 & 09 & 28 & (1) \\
\hline & (2) & & & & & & 02 & 22 & (2) & \\
\hline & & \multirow[t]{4}{*}{ (3) } & & & & & 42 & \multirow[t]{4}{*}{ (3) } & & \\
\hline & & & & & & & 13 & & & \\
\hline & & & \multirow[t]{2}{*}{ (5) } & & & & (5) & & & \\
\hline & & & & $(6)$ & & (6) & & & & \\
\hline
\end{tabular}

(8)

$\leftarrow$ DISAGREE MOST STRONGLY

AGREE MOST STRONGLY $\rightarrow$ 
Step 5: To continue sorting, you now need to follow the same procedure we used for step 4, but this time focusing on the pile of items you definitely DISAGREE with. Spread them out so you can see them all at once. Keep going until ALL the items you disagree with have been allocated an appropriated ranking. Your Q-sort will probably look something like the diagram shown below, although the number of items you've ranked and the items you've allocated to the various ranking values will obviously be different!

\begin{tabular}{|c|c|c|c|c|c|c|c|c|c|c|}
\hline 1 & 2 & 3 & 4 & 5 & 6 & 7 & 8 & 9 & 10 & 11 \\
\hline 23 & 08 & 31 & 26 & & & 10 & 35 & 37 & 05 & 16 \\
\hline \multirow[t]{7}{*}{ (1) } & 12 & 06 & 40 & & & 03 & 27 & 09 & 28 & (1) \\
\hline & \multirow[t]{6}{*}{ (2) } & 35 & 14 & & & & 02 & 22 & \multirow[t]{6}{*}{ (2) } & \\
\hline & & \multirow[t]{4}{*}{ (3) } & 32 & & & & 42 & \multirow[t]{5}{*}{ (3) } & & \\
\hline & & & & & & & 13 & & & \\
\hline & & & (5) & & & & (5) & & & \\
\hline & & & & (6) & & \multirow{2}{*}{\multicolumn{2}{|c|}{ (6) }} & & & \\
\hline & & & & & (8) & & & & & \\
\hline
\end{tabular}

Step 6: All that remains is to complete the Q-sort using the pile of items about which you feel INDIFFERENT.. Keep going until ALL your indifferent items have been allocated an appropriate ranking.

Step 7: Congratulations! You're finished sorting and you should now have a complete Q-sort sitting in front of you. At this stage, have one final look at the whole thing and feel free to make any final adjustments you want to make. Your final Q-sort should look something like the diagram shown below,

\begin{tabular}{|c|c|c|c|c|c|c|c|c|c|c|}
\hline 1 & 2 & 3 & 4 & 5 & 6 & 7 & 8 & 9 & 10 & 11 \\
\hline 23 & 08 & 31 & 26 & 21 & 07 & 10 & 35 & 37 & 05 & 16 \\
\hline \multirow{8}{*}{ (1) } & 12 & 06 & 40 & 34 & 19 & 03 & 27 & 09 & 28 & \multirow[t]{8}{*}{ (1) } \\
\hline & (2) & 35 & 14 & 01 & 38 & 11 & 02 & 22 & \multirow[t]{7}{*}{$(2)$} & \\
\hline & & \multirow[t]{6}{*}{ (3) } & 32 & 15 & 33 & 20 & 42 & \multirow[t]{6}{*}{ (3) } & & \\
\hline & & & 24 & 39 & 25 & 36 & 13 & & & \\
\hline & & & (5) & 17 & 04 & 30 & \multirow[t]{4}{*}{ (5) } & & & \\
\hline & & & & \multirow[t]{3}{*}{ (6) } & 29 & \multirow[t]{3}{*}{ (6) } & & & & \\
\hline & & & & & 18 & & & & & \\
\hline & & & & & $(8)$ & & & & & \\
\hline \multicolumn{6}{|c|}{$\leftarrow$ DISAGREE MOST STRONGLY } & \multicolumn{5}{|c|}{ AGREE MOST STRONGLY $\rightarrow$} \\
\hline
\end{tabular}

Step 8: All that remains for you to do is to complete Section 2 of this material. The researcher will make sure that your responses to all the sections are returned to us in the reply-paid envelope provided. If you have any further questions or problems please contact the researchers via the contact details provided below.

Thank you so much for your help! We really appreciate it. 


\section{Helpful Hints for Sorting}

1. You may find it quite difficult to decide immediately which item should be ranked at 11, particularly if you have a relatively large number of AGREE items. If you do, a possible strategy is to read each item again and to gently slide the ones that generate the strongest feelings of agreement towards the right and those you feel slightly less strongly about towards the left. This process will physically spread the items and it should also create a new sense of distribution within the group.

2. Don't get hung up on the ranking of a specific item. For example, if you find three items (instead of two) you'd like to rank at 10 don't take 10 minutes to decide which one to relegate to 10 . We just need to get a general sense of your likes and dislikes and we promise that this will happen whichever one you relegate.

3. Don't worry if your AGREE items cross over into the low rankings. We won't be assuming that this means you disagree with (or thoroughly dislike!) the item. The ranking system in $\mathrm{Q}$ methodology is relative. When you allocate a 2 ranking, therefore, this indicates only that you probably agree with that item slightly less than the items you ranked at 3 , and slightly more than those you're about to rank at 4 . That's all.

4. The order in which items appear in a particular column or under a particular ranking value is irrelevant. In the diagram above, for example, item 19 appears above item 33 in the 6 column, but it wouldn't matter at all if this order was reversed. In other words, don't try and order your columns! 


\section{Section 2: Demographics and post-sorting questionnaire}

The researcher would like to ask you a few questions regarding your distribution. For data-gathering purposes we would like to record your answers to avoid any misinterpretations. The recordings will be deleted after verbal transcription and will only be used for interpretation purposes of your sorting list. As mentioned in the informed consent your data will be encrypted by a key only accessible to the main researcher, no referral to individual participants will be made in paper.

\section{Post-Sorting Questionnaire}

1. Is there a statement you would like to elaborate on?

2. Why have you chosen this statement at the upper extremes?

3. Why have you chosen this statement at the lower extremes?

4. Are there any topcis you missed in relation to teaching in a crossborder curriculum partnership?

5. Any comments you would like to make?

6. Any further questions 


\section{Chapter 5.}

\section{Crossborder curriculum partnerships: Medical students' experiences on critical aspects}

Accepted for publication: Waterval DGJ, Frambach JM, Scott S, Driessen EW, Scherpbier AJJA. Crossborder curriculum partnerships: Medical students' experiences on critical aspects. BMC Medical Education. 2018. 


\begin{abstract}
Introduction: The past decade has witnessed an upsurge in medical curriculum partnerships established across national boundaries to offer students at the foreign institution (host) a learning experience comparable to that of students at the exporting institution (home). However, since the learning environments and national healthcare contexts differ greatly between institutions, concerns have been raised in the literature about potential low quality of curriculum delivery, inadequate preparation of students to practice in the host country healthcare setting, and a culture shock for host students having to study a home curriculum. The experiences and opinions of medical students related to these concerns have not been investigated. This study takes an explorative approach on key challenges faced by host institution students.
\end{abstract}

Method: 361 host students recruited from 3 partnerships completed a survey about their motives, transition from high school, language, preparedness for practice, future career planning, and general satisfaction. Descriptive statistics of closed-ended items and thematic analysis of open-ended items were performed.

Results: Findings revealed that students generally held positive views of the education they received. Switching to a new language of instruction (English) and learning environment was not perceived as a major obstacle. However, a significant portion of students who as non-nationals did not speak the language of the patient population felt this complicated effective workplace-based learning.

Conclusion: Despite differences in learning experiences, host students felt the partnership afforded opportunities to acquire unique academic competencies and boost their career. Further adaptation of the home curriculum to the host country healthcare system may be beneficial, without losing sight of medical curriculum partnerships' potential to offer graduates an international outlook on global healthcare. 


\section{Introduction}

Worldwide, medical education institutions are establishing crossborder curriculum partnerships. ${ }^{1,2}$ In such partnerships, the curriculum, not students or faculty, crosses borders from the home location where it was developed to a host institution where it is delivered. ${ }^{3}$ Host students expect a learning experience similar to that of their home institution counterparts. However, the learning environments of both institutions differ in terms of teachers, facilities, learning and other resources, and healthcare systems. ${ }^{4,5}$ Consequently, both student cohorts follow their curriculum in different learning and healthcare environments, potentially impacting the comparability of their learning experience.

As this new variety of internationalisation is growing fast, so too the body of literature on this topic ${ }^{6}$, albeit still preliminary ${ }^{7}$, is expanding. Much attention is given to the effectiveness and desirability of this new form of internationalisation based on an investigation of stakeholders' motives and quality assurance frameworks. ${ }^{8}$ However, few studies address the educational challenges crossborder curriculum partnerships face and rarely base their conclusions on students' voices as well. ${ }^{9}$

Concerns have been raised that crossborder curriculum partnerships carry several risks which may impact students' learning experiences, well-being, preparation for practice, and future career. ${ }^{10-12}$ One potential risk is low quality of curriculum delivery. The literature has indeed reported instances of partnerships that have ended or delivered low-quality curricula, also in the medical domain. In contrast, several quantitative survey studies report high levels of satisfaction among business and computer science students at Middle Eastern and Malaysian branch campuses. ${ }^{13-15}$ Yet, students' perceptions of crossborder curriculum partnerships in the medical domain were not included in these studies, and these partnerships face unique challenges related to international differences in healthcare systems.

A second risk is that host students, similar to exchange students, could experience "culture shock" when exposed to the new, foreign learning environment. ${ }^{10,16,17}$ This shock may be caused by a switch to a non-native language of instruction (i.e., English) and to a student-oriented approach to learning. ${ }^{18-21}$ Their secondary education may not have prepared them for the self-directed, student-centered methodologies that are characteristic of many exported medical curricula. Teachers and managers have indeed expressed concerns about the imposition of foreign approaches on host students. ${ }^{21}$ This concern has furthermore been acknowledged by the British quality assurance agency for higher education in their adoption of guidelines that point out the need to consider "the cultural assumptions about higher education learning methods."22 A similar call has been made to international medical educators to be aware of ethnocentricity when exporting ideas and programs. ${ }^{23}$ Unfortunately, little is known about the nature of this potential culture shock and its impact on host institution students.

A final risk is that the curriculum of the host institution does not adequately prepare students for practice in the host labor market, as it mirrors, albeit in a slightly adapted form, the curriculum of the home institution. A large survey outside the medical domain, for instance, noted that graduates of the host institution were highly 
skilled, but that their skills were not necessarily aligned with host country needs. ${ }^{24}$ In such cases curriculum partnerships can be criticized for contributing too little to the host country context. ${ }^{25}$ A related concern is the potential loss of human resources for host country healthcare if only a small proportion of graduates of these programs continue their training and professional career in the host country. ${ }^{26}$

The aforementioned concerns have been recognized by the medical program directors responsible for the implementation and quality of six different medical curriculum partnerships. ${ }^{27}$ Although they acknowledged that these were challenging issues that required continuous attention, they also believed that they generally did not interfere with the overall aims of the curriculum partnership. Strikingly, students' views and experiences about these areas of concern were not solicited. This study explores host students' perspectives on critical aspects of crossborder medical curriculum partnerships. Its outcomes may be useful for university leaders, branch campus managers and educators, policymakers, and other stakeholders. Together with our previous study involving medical program directors ${ }^{27}$, this study contributes to a more comprehensive picture of this phenomenon. Furthermore, by concentrating on students as key stakeholders, this study can contribute to an in-depth understanding of issues and challenges in these partnerships.

\section{Methods}

Our aim was to explore students' experiences of challenges they face in crossborder curriculum partnerships, transcending a singular context. Therefore we used a selfadministered survey consisting of a mix of open-ended and closed-ended items to investigate host students' perceptions. As part of a larger research project, potentially eligible partnerships were identified using a snowballing technique: twelve independent international medical education experts were approached in person or by email, which yielded 22 potential partnerships. By means of an Internet research and email inquiry, this selection was further condensed to six partnerships that deliver a home institution's curriculum at a host institution across borders and intend to provide comparable learning experiences to the geographically separated groups of students. Three institutions responded and participated; the remaining three declined due to a lack of time. Appendix 5.1 provides more details on these included partnerships. In all cases the initiative to establish a partnership originated from the host institution or country and served a domestic purpose. Furthermore, all host institutions offered a preparatory year which aimed to bridge the difference between secondary school and university with regards to content as well as language and study techniques. Host teachers were trained through mutual visits and online sessions about content and didactics.

\section{Research Instrument}

The survey consisted of 31 items which were drawn from a synthesis of literature on curriculum partnerships. Our search for an existing validated instrument that fulfilled 
our research objective and context was unsuccessful. We analysed the articles included in two review studies on crossborder higher education ${ }^{6,9}$ for student-related issues. Six themes emerged from this analysis, specifically: motives, transition from high school, language, preparedness for practice, future career planning, and general satisfaction levels. We consequently structured the survey around these themes.

As we aimed to explore student experiences on all themes and offer them the opportunity to fully describe their experience, we used a mix of 5 Likert scale items, 8 closed-ended items, 11 full open-ended items and 7 structured open-ended items. The latter offered multiple answer options among pre-defined categories and provided the option "other" which students could use to articulate alternative views. The items and pre-defined answer options were based on the literature review. The structure was also designed to reduce survey fatigue.

Finally, five international students originating from the region in which data collection took place and for whom English was their second language pre-tested the survey for language and clarity. Program directors of the participating institutions also checked its face-validity and use of appropriate terminology. Their feedback led to further improvements. The final survey is available upon request.

\section{Data Collection}

Data were collected by using a convenience sampling procedure in order to reach as many host students as possible within each institution in all years of training. We initially set out an e-survey, but due to legal barriers (e.g. storing student data outside the host country) and low completion rate, we switched to a paper-based version. During on-site visits between December, 2015, and March, 2016 (starting period of the $2^{\text {nd }}$ semester), the researcher or a research assistant selected accessible educational sessions in consultation with the host program director, inviting students to participate immediately after their session. Before distributing the survey, the researcher explained the study rationale and objectives, explicitly emphasized confidentiality, and asked participants to sign an informed consent form.

\section{Data Analysis}

We included all surveys that were completed until the final closed-ended item. This criterion led to the exclusion of two surveys, resulting in 361 completed surveys. However, response rates varied per item.

We performed descriptive statistics in SPSS of the closed-ended items and Likert scale items, which was supplemented with bivariate analysis of the variables "partnership," "gender," and "study phase," wherever appropriate.

The responses to the full and structured open-ended items were analysed thematically and categorized with the help of two research assistants. We developed an initial coding template based upon a first set of surveys. Through an iterative process codes were adjusted, refined or extended and all responses were categorized and until consensus was reached. The final categorisation for each item was discussed and agreed 
upon by the research team. Disagreements were resolved by discussion. The results include the number and percentage of participants in case of single answer items and responses and percentage in case of multiple answer items.

\section{Results}

\section{Demographics of Respondents}

Table 5.1 summarizes the demographic characteristics of our sample. We included a total of 361 surveys, representing nearly $50 \%$ of the total student population (740) at the three institutions.

Table 5.1: Demographic characteristics of the sample.

\begin{tabular}{lllll}
\hline & Partnership A & Partnership B & Partnership C Total \\
\hline Sample size & 70 & 201 & 80 & 361 \\
$\begin{array}{l}\text { Population size } \\
\text { Gender }\end{array}$ & 121 & 450 & 169 & 740 \\
$\quad$ No. of males (\%) & $70(100)$ & $83(39)$ & $30(37)$ & $183(51)$ \\
$\quad$ No. of females (\%) & $0(0)$ & $128(61)$ & $50(63)$ & $178(49)$ \\
Age & $21.0(2.5)$ & $20.3(1.8)$ & $22.6(2.1)$ & $21.0(2.1)$ \\
$\quad$ Mean age (SD) & $41(59)$ & $129(61)$ & $47(59)$ & $217(60)$ \\
Study phase & $29(41)$ & $82(39)$ & $33(41)$ & $144(40)$ \\
$\quad$ No. of pre-clinical students (\%) & & & & \\
$\quad$ No. of clinical students (\%) & 11 & 6 & 24 & 31 \\
$\begin{array}{l}\text { Distribution of Nationalities } \\
\text { No. of nationalities }\end{array}$ & $9(13)$ & $121(57)$ & $16(20)$ & \\
$\quad \begin{array}{l}\text { No. of students with host-country nation- } \\
\text { ality (\%) }\end{array}$ & & & & \\
\hline
\end{tabular}

The host student population in partnership A consisted exclusively of male students as they had no female students at that time; nonetheless, the total sample across the three institutions had an equal gender distribution (51\% male, $49 \%$ female). To be able to explore how experience within the program influenced perceptions, we divided students according to their study phase. The ratio of pre-clinical (early years) to clinical students (later years) was approximately 60\%:40\% in all three institutions. The average age of the respondents was 21.

The host student population was heterogeneous in terms of ethnicity and background. We counted a total of 31 different nationalities. In partnership A, a relatively large proportion of respondents came from Syria $(\mathrm{N}=30 / 69 ; 43 \%)$. The majority of students in partnership B were nationals of the host country $(\mathrm{N}=121 / 211 ; 57 \%)$, closely followed by Malaysian students $(\mathrm{N}=82 / 211 ; 39 \%)$. Partnership $\mathrm{C}$ had the most diverse mix of students, with nationals of the host country representing the largest proportion $(\mathrm{N}=16 / 79 ; 20 \%)$. Based on analysis and grouping of the themes resulting from 
the explorative and qualitative data, we present our results clustered in two primary domains: the learning environment and the work environment.

\section{Learning Environment: Teaching Method \& Program Implementation}

Students reported high levels of satisfaction with the study program across all partnerships and study years (Table 5.2). In general, respondents perceived their transition from high school to medical college as a shift to fewer contact hours and more freedom to determine the depth and range of their study. The majority $(\mathrm{N}=231 / 355 ; 65 \%)$ reported they had overcome this transition to a new learning environment, and many $(\mathrm{N}=169 / 208 ; 81 \%)$ indicated having reached this within one year or less. These findings were comparable across partnerships and by gender.

Table 5.2: General satisfaction levels; indicated on a 4-point Likert scale from very dissatisfied (1) to very satisfied (4).

\begin{tabular}{lrll}
\hline & \multicolumn{3}{c}{ How satisfied are you with the study program? } \\
\cline { 2 - 4 } Institution & $\mathrm{N}$ & Mean $(1-4)$ & Std. Deviation \\
\hline Partnership A & 65 & 2.72 & .650 \\
Partnership B & 203 & 2.96 & .566 \\
Partnership C & 78 & 3.14 & .597 \\
Total & 346 & 2.95 & .603 \\
\hline
\end{tabular}

In commenting on the advantages of the program, many students $(\mathrm{N}=192 / 361 ; 53 \%)$, especially those from later years, reported that the program, and in particular the student-centered teaching method, contributed to their academic and professional growth through added self-responsibility, confidence in public speaking, and collaboration with others. One student noted:

"The system is really strong and I have already seen the difference between the students of my college and those of other colleges, regarding their level of education. [...] In this system I have to be much more independent and do everything by myself. Right now this might be a little bit hard, but in the long run it will benefit me a lot." (1st-yr. student, Partnership A, item 28).

Although students did not report major challenges, and their comments were generally constructive and positive, containing suggestions to improve the quality of the program implementation, some students were critical, and a few expressed frustration about the level of integration between the two institutions, for example:

"It needs to be more integrated and the home institution should be more aware of the host institution" (4th-yr. student, Partnership C, item 31).

When asked explicitly about the perceived disadvantages for their learning experience compared to their home counterparts, many students ( $N=161 / 361 ; 45 \%)$ identified differences in learning facilities, differences in the conduct of educational sessions, and 
staff being perceived as less qualified to conduct sessions. The emphasis of these comments varied across institutions. One student described that

"They have more access to libraries, electronic books and websites; they have better health institutions and training; they have more updated knowledge and more wide-minded doctors." (5th-yr. student, Partnership B, item 30).

\section{Learning Environment: Language}

A second issue regarding the learning environment of host students was the use of English as the principal language of instruction. For the vast majority of respondents English was their second language (339/361; 94\%). However, most of them did not consider this as a major impediment to their study $(\mathrm{N}=317 / 355 ; 90 \%)$. Approximately one third of respondents $(\mathrm{N}=102 / 361 ; 28 \%)$ reported that additional activities were needed to address language deficiencies, such as online language courses and deliberate practice with friends and family. A substantial group ( $\mathrm{N}=148 / 343 ; 43 \%)$ indicated some language problems, mostly when answering test items, in group discussions, selfstudy and in understanding teachers for whom English was also a second language:

"The teachers have an excellent command of English, but some have accents that need some time getting used to. English is not used at all in interactions with patients. Since I have a limited command of Arabic, I have limited interactions with patients." (6th-yr. student, Partnership B, item 21).

This comment addresses another language issue which emerged from our data analysis. Due to the international student intake at the host institutions, a large proportion of respondents did not speak the primary language of the host institutions' patient population. As a result, students faced challenges when interacting with patients, especially in the clinical phase of the curriculum. This influenced the learning experiences of many respondents $(115 / 216 ; 53 \%)$ and was mentioned comparably across institutions. Some respondents suggested pragmatic strategies for overcoming the language barrier, such as using student or professional translators, or learning the host country's language. Some reflected that learning to deal with the inability to communicate directly with patients is a valuable skill:

"There is diversity which already prepares me for the diversity of healthcare in the workplace. Interactions are more meaningful when people come from different cultures." (1st-yr. student, Partnership C, item 30).

\section{Work Environment: Match with host country Healthcare System}

Another issue was how students perceived their preparedness for practice in the host country healthcare context. Respondents had already garnered substantial experience 
in the host country healthcare system: the pre-clinical students had made short visits and assignments in the host country healthcare setting, while the clinical students had done rotations. Overall, most students felt either appropriately trained to work in the host country healthcare system or they had a neutral opinion about it (Table 5.3).

Table 5.3: Preparedness for practice on a 5-point Likert scale from very inappropriate (1) to very appropriate (5).

\begin{tabular}{lrll}
\hline & \multicolumn{2}{l}{$\begin{array}{l}\text { How do you feel your current study program prepares you for your experience in the } \\
\text { host country healthcare setting? }\end{array}$} \\
\cline { 2 - 4 } Institution & $\mathrm{N}$ & Mean (1-5) & Std. Deviation \\
\hline Partnership A & 70 & 3.29 & .965 \\
Partnership B & 207 & 3.33 & .824 \\
Partnership C & 79 & 3.96 & .688 \\
Totals & 356 & 3.46 & .866 \\
\hline
\end{tabular}

When asked whether they had missed important topics in their study program in relation to the host country healthcare context, half of the students replied in the affirmative $(\mathrm{N}=150 / 361 ; 42 \%)$. There was strong inter-institutional variation in the curriculum elements that were perceived as missing or not fully implemented. However, students $(\mathrm{N}=46 / 150 ; 31 \%)$ in all institutions expressed the need for more information about the host country's healthcare and legal system, ethical values, and appropriate behaviour. For example,

"The health system of the host country requires an understanding of many different cultures as well as of languages, issues which I feel weren't particularly addressed although we did have lectures about these issues, we still face problems of this kind in the local (host) health setting." (1st-yr. student, Partnership C, item 12).

This suggests that while theoretical lectures about the home or host context may be helpful, they may not sufficiently address language and culturally appropriate clinical behaviours.

A smaller proportion of students $(\mathrm{N}=85 / 348 ; 24 \%)$ perceived certain curriculum content as irrelevant to the host healthcare setting. Their remarks concentrated on information and data that seemed relevant only in the home country, such as epidemiological, social and cultural aspects, and facts on certain topics that were not applicable to their host contexts. For example:

"We learn about the prevalence of diabetes in the home country, with its geographical distribution. I do not believe it is relevant to study this in our setting which is thousands of miles away. Most of the graduates will practice medicine in this country and not in the home [country]. Consequently, I think we should learn more about here. It's good to learn about the situations in other countries but not in such detail." (1st-yr. student, Partnership A, item 12).

At the same time, however, students also highlighted the potential benefits of acquiring more knowledge about the home country, as the following quote illustrates: 
"Being in the host country and taking a home program, there are some things in a cultural perspective that don't relate so much to our society ... However, studying medical conditions that are more relatable to the home country can help us to learn about it if we want to work there in the future." (5th-yr. student, Partnership B, item 14)

This revealed a two-sided picture: While some students, logically, did not like being exposed to blunt copying and pasting of irrelevant curriculum materials, others did value learning about professional practice and diseases in the home country, as this broadened their perspective.

\section{Work Environment: Future Career Path}

Students seemed very aware of their unique profile and potential career paths. Many students (N=192/361; 53\%) mentioned that studying as a host student in their partnership would bring specific advantages to their future careers, such as more academic and professional growth. A few were able to compare their education with that of conventionally trained friends and expressed confidence in their own level of training. 87 of these 192 students felt that an internationally oriented profile was an explicit advantage:

"[...] it will make me a good doctor and help me to travel abroad in order to do some more research on medicine. It will help me to communicate with other best doctors from all over the world and to gain some of their experience." (2nd-yr. student, Partnership B, item 28)

For many, the international profile of the institution was a specific reason to choose the program. Although students reported several other reasons, many were attracted by the international reputation of the home institution $(170 / 357 ; 48 \%)$ and by the prospect of continuing or spending part of their study at the home institution. Nearly all participants were aiming for specialty training as the next step in their medical careers. The UK and the US $(\mathrm{N}=81 / 269 ; 23 \%$ and $\mathrm{N}=104 / 360 ; 29 \%$, respectively) were cited as the leading target destinations, followed by Asia ( $\mathrm{N}=50 / 360 ; 14 \%)$, the Middle East $(\mathrm{N}=35 / 360 ; 10 \%)$, and Europe $(\mathrm{N}=29 / 360 ; 8 \%)$.

Table 5.4 lists for each partnership the proportion of students that indicated a desire to pursue studies in the student's country of origin, home institution's country, host institution's country, or other country, respectively. It should be noted that the categories overlap, hence we should be cautious while making inferences. While a large proportion of students in partnership $\mathrm{C}$ indicated interest in training in the country of the home institution, students in the other partnerships were more divided. The data showed that a relatively small proportion of students $(\mathrm{N}=25 / 241 ; 10 \%)$ had intentions to stay in the host country for postgraduate training; they either wanted to return to their country of birth or had international ambitions. 
Table 5.4: Country of destination after graduation.

\begin{tabular}{|c|c|c|c|c|c|c|}
\hline & & \multicolumn{4}{|c|}{ Country of destination after graduation } & \multirow[t]{3}{*}{ Total } \\
\hline & & \multicolumn{2}{|c|}{$\begin{array}{l}\text { Country of Country of } \\
\text { birth/ethnicit home }\end{array}$} & \multirow{2}{*}{$\begin{array}{l}\text { Country of } \\
\text { host } \\
\text { institution }\end{array}$} & \multirow[t]{2}{*}{ Other } & \\
\hline & & $\mathrm{y}$ & institution & & & \\
\hline \multirow[t]{2}{*}{ Partnership A } & Count & 3 & 3 & 7 & 15 & 28 \\
\hline & $\%$ within institution & $10.7 \%$ & $10.7 \%$ & $25.0 \%$ & $53.6 \%$ & \\
\hline \multirow[t]{2}{*}{ Partnership B } & Count & 56 & 66 & 7 & 47 & 176 \\
\hline & $\%$ within institution & $31.8 \%$ & $37.5 \%$ & $4.0 \%$ & $26.7 \%$ & \\
\hline \multirow[t]{2}{*}{ Partnership C } & Count & 7 & 63 & 11 & 4 & 85 \\
\hline & $\%$ within institution & $8.2 \%$ & $74.1 \%$ & $12.9 \%$ & $4.7 \%$ & \\
\hline \multirow[t]{2}{*}{ Total } & Count & 66 & 132 & 25 & 66 & 289 \\
\hline & $\%$ of total & $22.8 \%$ & $45.7 \%$ & $8.7 \%$ & $22.8 \%$ & $100.0 \%$ \\
\hline
\end{tabular}

A number of students ( $N=63 / 161 ; 39 \%)$ shared concerns that they would have difficulty securing postgraduate training or other positions in their future work context. They believed that they might not be considered "good-quality graduates" with a worthy degree, due to the lack of a positive or established reputation of graduates from international medical programs. One pre-clinical student noted that

"[it will be] harder to find a residency program and it [will be] difficult for all programs to be aware of who we are." (2nd-yr. student, Partnership C, item 28)

Although most of them were positive about the quality of their training, they felt a sense of "distrust" of the outside world. As these partnerships are relatively young, many partnerships do not have a body of alumni to 'promote' the host institution. Even in partnership B, which has existed since 2006, students felt that the relatively young program, despite its collaboration with a reputational foreign institution, still faced suspicion within the host country.

\section{Discussion}

This study sought to explore medical host students' perceptions of a number of educational concerns raised in the literature about cross-border curriculum partnerships. Students' overall levels of satisfaction were high and comparable to those reported outside the medical domain. ${ }^{13-15,28}$. Students particularly valued the home program for its student-centered teaching method, its international profile, and higher career prospects compared to local alternatives available to them. This latter observation is an important factor for students who are unable to leave their home region or have no intention to do so. ${ }^{29}$ Moreover, students shared medical program directors' view that most of them needed only a few months to adapt to English as the main language of instruction and to student-centered education. ${ }^{27}$ Some students even flagged these two aspects as clear advantages. Although students did identify many areas for improvement, they also realized that exact similarity of their learning experience compared 
with home students would be unattainable, as Coleman was already keen to point out. ${ }^{30}$ In all, this study seems to suggest that although an alleged "culture shock"10, 16, 17 could indeed be observed in these medical curriculum partnerships, its consequences were of manageable magnitude.

Nevertheless, our findings do to some extent confirm the validity of concerns about students' preparedness for practice. ${ }^{11,19}$ The fact that host institutions attracted students from different nationalities, for instance, created situations in which some of the host students did not master the language of the host country's patient population. Such hurdles represent a serious threat not only to deliver comparable quality but also to prepare students to work in the host context. Potential ways for institutions to anticipate such problems, for instance, are to include compulsory host-language instruction in the pre-clinical years or to organize a binary clinical placement system whereby students who speak the host language see host country patients, and those who do not encounter English-speaking patients. ${ }^{13-15,27,28}$

A fundamental issue to students' preparedness for practice is the observation that students often pursue their professional careers in contexts other than the ones they were trained in. Our study's student population had diverse career plans and international ambitions, while their planned destinations differed across partnerships. This leads to the question: is the partnership's aim to train students for the local context, home context or to prepare them for an international career? The answer to this question will affect decisions about curriculum content, implementation, and delivery, determining how and to what extent the home program should be adapted to the context of the host institution, and ultimately shaping students' learning experiences and preparedness for their desired practice.

Answering this question, however, is no easy feat, as ethical issues should be considered. The WHO, for instance, urges medical institutions to be socially accountable to their host country contexts and to address the needs of the host population. ${ }^{31}$ In a similar vein, scholars have warned against a copy-paste approach to curriculum partnerships, stressing the need to adapt the home program to the host context as much as possible. ${ }^{25,30}$ Yet, we have seen that students often aspire to future careers outside the host country healthcare setting, hence an overemphasis on curriculum adaptations to fit the host context may not be in their best interest. Not only the respondents in this survey voiced this concern, but also host students who were interviewed in depth elsewhere did so. ${ }^{28}$ These considerations would support an adaptation of the home institution's curriculum to make it more globally oriented.

It can be argued that international curriculum partnerships are in a unique position to offer such globally oriented learning experiences. Upon entering the program, host students are immersed in an international learning community and are taught an (adapted) foreign medical curriculum by teachers from different countries. In comparison to their home counterparts, host students have a more heterogeneous background ${ }^{17}$, as was the case in our study. The healthcare system they are trained in is different from the system in their country of origin and destination. These features offer opportunities to develop students' adaptability to new working contexts and to colleagues and patients with diverse backgrounds, which might be an essential attribute of internationally oriented health professionals, and perhaps even of health profes- 
sionals in any context. The challenge for medical educators lies in framing and positioning the diversity that exists within these programs in a way that is meaningful and attractive to students, while simultaneously doing justice to the host context.

Students in this study mentioned they missed important host country healthcarerelated topics in their program and felt certain topics were irrelevant to the host context, although they did appreciate the benefits of the latter for their future international career. Efforts to cultivate adaptability by integrating host country and international topics into the curriculum can yield meaningful learning activities for a wide range of students. An example could be to engage medical students in host context-related patient and physician narratives and have them reflect on the implications for professional practice in both the host context and elsewhere. ${ }^{32}$ By engaging students and possibly other relevant stakeholders in meaningful locally prioritized issues, such an approach would also allow institutions to become more socially accountable to their host contexts.

If partnerships seize the opportunity to distinguish themselves this way, they might establish a reputation as institutions for global-local learning in medical education, rather than being viewed with suspicion by other players in the field, something the students in this study feared. Future research could explore these possible avenues of adaptation and their implications, including the perceptions of graduates of these programs a number of years after graduation to identify their career paths and the role of the curriculum partnership.

The aim of this study was neither to assess the quality of the learning experience of host students nor to make any judgements on particular partnerships. This would require more in depth case-specific investigation, as well as involving other stakeholders, such as teachers. Questions that could be asked are for example: How do teachers work with the materials coming from the home institution? This study is part of a larger research project in which data from different stakeholders, i.e. medical programme directors, ${ }^{27}$ host medical students (this study), host medical teachers, ${ }^{33}$ a case study from a home perspective, ${ }^{34}$ and a literature review including insights from outside the medical domain ${ }^{9}$ are collected. Together they form a comprehensive picture of this complex and challenging form of internationalisation.

One of this study's merits is that it garnered the perceptions of a rather unexplored group of stakeholders in this new form of internationalisation in medical education. Their comments provide meaningful insights into the way host students attend to concerns voiced in the academic field. It should be noted, however, that our conclusions are explorative as the survey instrument has not been validated in an international setting and its items may be subject to different interpretations by participants. Notwithstanding, we feel the survey construct and opportunity to ask questions about the content while completing the survey ensures that the instrument fits the explorative aim of the study.

Another limitation of this study is that all partnerships' host institutions were located in the same region, the Middle East. Since the cultural norms and nature of the local healthcare setting in this region undoubtedly affected host students' responses, the findings cannot be automatically transferred to other contexts. Finally, the partnerships we included varied in their setup and collaboration intensity, potentially influenc- 
ing the results, which we attempted to remedy by concentrating our analysis on the overarching themes and perceptions. We see this survey as a first step in exploring the experiences and challenges faced by students in medical curriculum partnerships. Further research could address particular topics in this survey in greater detail such as the cultural and ethical aspects of implementing curricula across contexts.

\section{Conclusion}

Host students felt that medical curriculum partnerships offered a valuable learning experience. Despite organisational differences between partnerships, institutions shared several similarities in terms of host students' perceptions of the quality of their education, transition to student-centered education, learning in a second language, and match between the home curriculum and the host country healthcare system. Yet, the international mix of students posed additional challenges such as the language barrier between students and the patient population available for clinical training, which called for specific and timely remediation measures. Medical curriculum partnerships that capitalize on the international learning environment of host institutions and create a meaningful synergy between globally and locally oriented adaptations may contribute to the wide spectrum of medical graduates and doctors needed worldwide.

\section{Declarations}

Ethical considerations: The study was approved by the ethical review board of the Netherlands Association for Medical Education (NVMO-ERB; file number 384). Approval was also sought and granted by the Deans and program directors of the participating institutions. Furthermore, partnership $\mathrm{C}$ had an institutional review board in place that approved this study. All participants signed the consent form prior to the survey. Available upon request.

\section{Acknowledgments}

The authors wish to acknowledge the respondents and program directors of the three included partnerships for their contribution to the research project. We also wish to extend our gratitude to Ilse van de Wijgert and Anne van Dijk for their contribution to coding and interpreting the qualitative data. Our thanks also go to Mohammed Meziani for distributing the survey as research assistant. Finally, the authors thank Angelique van den Heuvel for her editing of the language and helpful comments. 


\section{References}

1. Knight J. International Universities: Misunderstandings and Emerging Models? J Stud Int Educ. 2015;19(2):107-21.

2. Lane JE. Global Expansion of International Branch Campuses: Managerial and Leadership Challenges. New Dir High Educ. 2011;(155):5-17.

3. Knight J. Higher Education in Turmoil, vol. 13. Toronto: Sense Publishers; 2008.

4. Heffernan T, Poole D. In Search of "The Vibe": Creating Effective International Education Partnerships. HETIJHEEP. 2005;50(2):223-45.

5. Altbach PG, Knight J. The Internationalization of Higher Education: Motivations and Realities. J Stud Int Educ. 2007;11(3-4):290-305.

6. Kosmutzky A, Putty R. Transcending Borders and Traversing Boundaries: A Systematic Review of the Literature on Transnational, Offshore, Cross-Border, and Borderless Higher Education. J Stud Int Educ. 2016;20(1):8-33.

7. Böhm A, Follari M, Hewett A, Jones S, Kemp N, Meares D, Pearce D, Van Cauter K. Vision 2020 Global student mobility. 2004. [Report] Available from [https://www.britishcouncil.org/sites/default/files/vision2020.pdf]; Accessed September 2016.

8. Zwanikken PAC, Peterhans B, Dardis L, Scherpbier A. Quality assurance in transnational higher education: a case study of the tropEd network. BMC Med Educ. 2013;13(1):43.

9. Waterval DGJ, Frambach JM, Driessen EW, Scherpbier AJJA. Copy but Not Paste: A Literature Review of Crossborder Curriculum Partnerships. J Stud Int Educ. 2014;19(1):65-85.

10. Pimpa N. Learning problems in transnational business education and training: The case of the MBA in Thailand. Int J Train Dev. 2009;13(4):262-79.

11. British Council, German Academic Exchange Service (DAAD). Impacts of transnational education on host countries. 2014. [Report] Available from [https://www.britishcouncil.org/sites/default/files/tne_study_ final_web.pdf]; Accessed August 2015.

12. Kassim SS, McGowan Y, McGee H, Whitford DL. Prepared to practice? Perception of career preparation and guidance of recent medical graduates at two campuses of a transnational medical school: a crosssectional study. BMC Med Educ. 2016;16(1):56.

13. Wilkins S, Balakrishnan MS. Assessing student satisfaction in transnational higher education. Int J Educ Manag. 2013;27 (2):143 - 56.

14. Ahmad SZ. Evaluating student satisfaction of quality at international branch campuses. Assess Eval High Edu. 2015;40(4):488-507.

15. Miliszewska I, Sztendur EM. Australian Transnational Education Programmes in South East Asia: Student Satisfaction with the Learning Environment. AUR. 2012;54(2):12-21.

16. Chapman A, Pyvis D. Dilemmas in the Formation of Student Identity in Offshore Higher Education: A Case Study in Hong Kong. Educ Rev. 2006;58(3):291-302.

17. Pyvis D. Culture shock and the international student 'offshore'. J Res Int Educ. 2005;4(1):23-42.

18. Gregory VL, Wohlmuth SR. Planning for the Internationalization of a Postgraduate Professional Degree Programme in Library and Information Science. High Educ Eur. 2002;27(3):261-68.

19. Wilson M. Transnational nursing programs: models, advantages and challenges. Nurse Educ Today. 2002;22(5):417-26.

20. Castle R, Kelly D. International Education: quality assurance and standards in offshore teaching: exemplars and problems. Qual High Educ. 2004;10(1):51-7.

21. Dobos K. "Serving two masters" - academics' perspectives on working at an offshore campus in Malaysia. Educ Rev. 2011;63(1):19-35.

22. Quality Assurance Agency for Higher Education. Code of practice for the assurance of academic quality and standards in higher education. Section 2. Collaborative provision and flexible and distributed learning (including e-learning). 2010. [Report] Amplified version of the second edition 2010. Available from [http://www.bbk.ac.uk/linkinglondon/resources/apel-creditresources/pub_Nov2010_QAA_COP_section_2_HE_guidance.pdf]; Accessed August 2017.

23. Whitehead CR. On gunboats and grand pianos: medical education exports and the long shadow of colonialism. Adv Health Sci Educ Theory Pract. 2016;21(1):1-4.

24. Knight J, McNamara J. The impact of transnational education in receiving countries. International Higher Education. 2015;(82):3-5. 


\section{Chapter 5}

25. Wilkins S. Ethical issues in transnational higher education: the case of international branch campuses. Stud High Educ. 2015:42(8):1385-400.

26. Stilwell B, Diallo K, Zurn P, Vujicic M, Adams O, Dal Poz M. Migration of health-care workers from developing countries: strategic approaches to its management. Bulletin of the World Health Organization. 2004;82:595-600.

27. Waterval DGJ, Frambach JM, Oudkerk Pool A, Driessen EW, Scherpbier AJJA. An exploration of crossborder medical curriculum partnerships: Balancing curriculum equivalence and local adaptation. Med Teach. 2016;38(3):255-62.

28. Hoare L. Transnational Student Voices: Reflections on a Second Chance. J Stud Int Educ. 2011;16(3):27186.

29. Wilkins S, Balakrishnan MS, Huisman J. Student Choice in Higher Education. J Stud Int Educ. 2012;16(5):413-33.

30. Coleman D. Quality assurance in transnational education. J Stud Int Educ. 2003;7(4):354-78.

31. Frenk J, Chen L, Bhutta ZA, Cohen J, Crisp N, Evans T, Fineberg H, Garcia P, Ke Y et al. Health professionals for a new century: transforming education to strengthen health systems in an interdependent world. Lancet. 2010;376(9756):1923-58.

32. Charon R. Narrative medicine: A model for empathy, reflection, profession, and trust. JAMA. 2001;286 (15):1897-902.

33. Waterval DGJ, Frambach JM, Driessen EW, Muijtjens A, Scherpbier AJJA. Connected, attracted, and concerned: A Q study on medical crossborder curriculum partnerships. 2017. Under review

34. Waterval DGJ, Tinnemans-Adriaanse M, Meziani MA, Driessen EW, Scherpbier AJJA, Mazrou A, Frambach JM. Exporting a student-centred curriculum: a home institution's perspective. J Stud Int Educ. 2017;21(3). 


\section{Appendix 5.1: Included partnerships}

Table 5.1: Partnerships' codes and characteristics

\begin{tabular}{|c|c|c|c|c|c|}
\hline $\begin{array}{l}\text { Partnership's } \\
\text { code }\end{array}$ & $\begin{array}{l}\text { Country of home } \\
\text { institution }\end{array}$ & $\begin{array}{l}\text { Country of host } \\
\text { institution }\end{array}$ & Type of program & $\begin{array}{l}\text { Start first } \\
\text { batch }\end{array}$ & $\begin{array}{l}\text { Main methods of } \\
\text { instruction }\end{array}$ \\
\hline A & The Netherlands & Saudi Arabia & 6-year undergraduate & 2010 & PBL and Lectures \\
\hline B & United Kingdom & Egypt & 6-year undergraduate & 2006 & PBL and Lectures \\
\hline $\mathrm{C}$ & United States & Qatar & 4-year postgraduate & 2002 & PBL and Lectures \\
\hline
\end{tabular}




\title{
Appendix 5.2: Survey
}

\author{
Students' perceptions of crossborder curriculum partnerships
}

Dear student,

We would like to invite you to participate in this survey on "Students' perceptions of crossborder curriculum partnerships" in the medical domain. As you are aware, the medical program that you are following is the result of a curriculum partnership between your institution and a foreign institution in the West. The goal of our research is to better understand these medical partnerships and develop implementation guidelines. Therefore we are eliciting perceptions and experiences from various medical schools around the world. Your perspectives are therefore of great value to the scientific community. We would like to emphasize that this survey is not a quality review or evaluation of the program that you are following.

\section{Terminology}

In this survey, the foreign partner university is called the "home institution," and its students are called "home students." Your own university is called the "host institution" and you are a "host student."

Type of Research Intervention

This research will involve your participation in a paper-based survey consisting of closed- and open-ended questions. The survey will take about 20 minutes to complete.

\section{Participant Selection}

You are being invited to take part in this research because you are a registered student among one of the 6 institutions worldwide that are participating in our research. All of these students are being invited to share their perspectives.

\section{Confidentiality}

Participation is strictly anonymous, and we will not ask any personal information. You are invited to leave your email address at the end in case you would like to be informed about the final results, but this is voluntary. The data will be stored according to the rules of the School of Health Professions Education, Maastricht University, for a period of 5 years and will only be accessible by the research team.

Risks

Besides the time investment, there are no reasonable foreseeable risks or discomforts to participate.

\section{Benefits}

There will be no direct benefit to you, but your participation is likely to help us find out more about how to create sustainable crossborder curriculum partnerships that ensure a similar learning experience to students at both home and host institutions.

\section{Right to Refuse or Withdraw}

Refusal to participate and/or discontinuity will involve no penalty or loss of benefits in any way.

This research proposal has been reviewed and approved by the Ethical Review Board of the NVMO (Netherlands Association for Medical Education) If you wish to find out more about the NVMO, contact Ms. M. Sterman, secretariaat@nvmo.nl, telephone: +31(0)88 7559911.

\section{Who to Contact}

XXX 
Informed Consent

I have read the information for participant in the introduction to the survey. I was able to ask the researchers additional questions. My questions were adequately answered. I had sufficient time to decide whether to participate.

I am aware that participation is completely voluntary. I know I can quit at any particular moment in time without providing a reason and without incurring any penalty or loss.

I know that the research team mentioned on the introduction page of the survey has access to the data.

I consent to the use of my data for the purpose mentioned in the introduction page of the survey.

I understand the rationale and setup of this survey.

Therefore, I agree to participate in this survey.

Yes

No (please don't proceed with the survey unless you can state yes.) 


\section{Chapter 5}

The following items tell us about you:

1. What is your gender?

Male

Female

2. What is your age?

3. What is your nationality?

4. In which institution are you following your medical study program?

Partnership A

Partnership B

Partnership C

5. In which year did you start this study program?

2009

2010

2011

2012

2013

2014

2015

Other, please specify

6. Why did you choose this study program?

(you can tick multiple answers)

Because I wanted to continue my studies at this specific partnering (home) institution

Because I satisfied the entry criteria

Because of the international reputation of the (home) study program

Because of the PBL system

Because of the proximity of my institution

Other, please specify

7. Which year are you currently in? (Please count from when you entered the educational program at your institution.)

1st year (i.e., premedical curriculum year 1 )

2nd year

3 rd year (i.e., medical curriculum year 1 )

4 th year

5 th year

6th year

Preparatory year 
THE FOLLOWING ITEMS TELL US MORE ABOUT THE MATCH BETWEEN YOUR STUDY PROGRAM AND LOCAL HEALTHCARE SYSTEM

8. In your study program, what experience did you have of the local healthcare setting (meaning the healthcare system of the country you are currently in - the host country)?

(You may tick multiple answers)

I have experience because I worked in the local healthcare system before

I did some rotations/internships

I have made visits to healthcare centers

I have made (short) assignment(s) that took place in the local healthcare setting: for example interviewing patients

Other, please specify

9. How much time have you spent on average in the local professional healthcare setting? Please write your answer in the following format:

No. hours per week for no. months.

10. How do you feel your current study program prepares you for your experience in the local healthcare system?

(please select the option that most applies to your situation)

Very Inappropriately Inappropriately Neutral Appropriately Very Appropriately

I feel it prepares me

11. When thinking about your experiences in your healthcare setting, is there any topic (e.g., medical knowledge, skills, or attitudes) in the study program that you missed because in your experience it was needed in the host (your) healthcare setting?

Yes

No

12. If yes, please indicate which topics, i.e., knowledge, skills or attitudes, that were not covered during the study program but according to your experiences are relevant in the host (your) healthcare setting;

13. Do you think that you have studied topics (medical knowledge, skills, or attitudes) in the (home) program that are not relevant in the host healthcare setting?

Yes

No

14. If yes, please indicate which topics, i.e., knowledge, skills, or attitudes, that are included in the study program but according to your experiences are not relevant in the host healthcare setting:

THE FOLLOWING ITEMS TELL US MORE ABOUT YOUR TRANSITION FROM HIGH SCHOOL TO UNIVERSITY

15. How would you describe the amount of contact hours and freedom to determine depth and range of study in your high school experience and in your current study program?

(please select the option that most applies in each situation)

\begin{tabular}{llll}
\hline $\begin{array}{l}\text { A lot of contact hours } \\
\text { and no freedom to } \\
\text { determine depth and }\end{array}$ & $\begin{array}{l}\text { Many contact hours } \\
\text { and a little bit of } \\
\text { freedom to }\end{array}$ & $\begin{array}{l}\text { Little contact hours } \\
\text { and some freedom to and a lot of freedom } \\
\text { determine depth and study }\end{array}$ & $\begin{array}{l}\text { determine depth and to determine depth } \\
\text { range of study }\end{array}$ \\
& range of study & & and range of study
\end{tabular}

High school

Current program

16. Do you feel you have overcome this transition (between your high school experience and your current study program)?

Yes 


\section{Chapter 5}

No

Not sure

17. If yes, how much time did it approximately take you to overcome this transition?

18. What kind of activities helped you to cope with the transition to your current academic program? (you may tick multiple answers)

Individual coaching and mentoring

Studying by myself

Study skill courses

No specific activities

Other, please specify

THE FOLLOWING ITEMS TELL US MORE ABOUT LANGUAGE ISSUES

19. Please indicate whether English is your:

Mother tongue

Second language

Other, please specify

20. Do you find it difficult to study medicine in English? (please select the option that best applies to you)

\begin{tabular}{cccc}
\hline Strongly Disagree & Disagree & Agree & Strongly Agree \\
\hline
\end{tabular}

I find it difficult to study

medicine in English

21. At this point of time in my studies, my competency in English language is hindering the level and depth of my:

(you can tick multiple answers)

Answering of test questions

Discussion in group sessions

Interaction with patients

Self-study

Understanding of teachers

None

Other, please specify

22. Do you feel that your proficiency in English has a negative impact on the quality of your learning experience? (please select the option that best applies to you)

Strongly Disagree Disagree $\quad$ Neither Agree nor Agree Strongly Agree Disagree

My English

language skills

have a negative

impact on the

quality of my

learning

experience

23 Have you undertaken any activities to overcome language difficulties?

Yes

No

24. If yes, please specify which activities, and what has been the effect of these activities?

25. Which language is spoken by the majority of the patients you encounter? How does this affect communication? 
THE FOLLOWING ITEMS TELL US MORE ABOUT YOUR FUTURE CAREER

26. What are your plans after graduation?

Apply for specialty training

Do not know yet

Other, please specify

27. In which country are you planning to apply for specialty training?

UK

USA

Host country I am living in now

Country of birth

Other country, namely

No idea yet

28. Do you feel that there are specific advantages and/or disadvantages for finding and carrying out your future job, due to the fact you will graduate from a crossborder medical study program? Please specify the advantages and/or disadvantages.

THE FOLLOWING ITEMS TELL US MORE ABOUT OTHER ISSUES

29. How satisfied are you with the study program?

\begin{tabular}{llll}
\hline \multicolumn{1}{c}{ Very Dissatisfied } & Dissatisfied & Satisfied & Very Satisfied \\
\hline How satisfied are you & & \\
with the study & & \\
program? & & \\
\hline
\end{tabular}

30. In which way do you think your learning experience differs from the learning experience of home students? (i.e., students of the partnering institution)

31. Do you have any other remarks about this survey or your experiences with your crossborder medical study program?

Thank you for your participation!

We would be pleased to send you a summary of the survey results. If you wish to receive this summary, please state your email address. Your email address will only be used for this purpose and will be treated confidentially. For any questions feel free to contact: d.waterval@maastrichtuniversity.nl 

Chapter 6.

\author{
Exporting a \\ student-centred curriculum: \\ a home institution's perspective
}

Published as: Waterval DGJ, Tinnemans-Adriaanse M, Meziani MA, Driessen EW, Scherpbier AJJA, Mazrou A, Frambach JM: Exporting a student-centred curriculum: a home institution's perspective. Journal of Studies in International Education. 2017, 21(3):278-90. 


\begin{abstract}
Introduction: Numerous, mainly Anglo-Saxon, higher education institutions have agreements with foreign providers to deliver their curricula abroad. This trend is gradually making inroads into the medical domain, where foreign institutions undertake to offer their students learning experiences similar to those of the home institution. Not an easy feat, as the national health care contexts differ greatly between institutions. In a bid to export the curriculum, institutions risk compromising their financial resilience and reputation.
\end{abstract}

Method: This article presents an instrumental case study of a home institution's perspective on the establishment of a crossborder student-centred curriculum partnership.

Results: It provides the reader with a practical discourse on dimensions that need to be bridged between home and host contexts, and on new working processes that need to be integrated within the home institution's existing organisational structure.

Discussion: We describe advantages and disadvantages based on our experiences with a centralized organisational approach, and advocate for a gradual move towards decentral inter-faculty communities of practice. 


\section{Introduction}

Many higher education institutions worldwide are forming crossborder curriculum partnerships, ${ }^{1}$ the essence of which is to transpose the 'curriculum', not students or faculty, from the location where it was developed (home) to the institution where it will be delivered (host). ' 'Curriculum', in this context, refers to the ensemble of content, assessment and didactics. Although on one end these international partnerships are mushrooming in areas such as languages, ICT, business and management, ${ }^{3}$ on the other end we find partnerships on the brink of collapse. ${ }^{2,4}$ Such occurrences are, to say the least, detrimental to the institutions' reputation, financial liability and efforts devoted by faculty. While the body of research into this novelty is expanding, its focus has hitherto stayed largely confined to partnerships' motives and quality assurance processes. ${ }^{5-}$ 7 Previous studies have indicated that, for partnerships to be sustainable, home and host institutions must bridge a wide range of differences. ${ }^{8}$ Other studies have reported that partnership sustainability is also contingent upon the formal set-up of the partnership and intra-partnership relations. ${ }^{9}{ }^{10}$ In this discourse, however, the institutional perspective on the educational, managerial and strategic processes required to render these types of partnerships successful and sustainable has received scant attention, probably due to the sensitivity of the topic. ${ }^{5}$

In a bid to address this gap, the present study describes, analyses and reflects on the experiences of a home institution that exported its medical student-centred curriculum to a host institution. Its purpose is to provide institutions who consider entering or who have entered a crossborder curriculum partnership with a deeper understanding of the possible challenges, approaches and implications. By focusing primarily on the home institution's perspective, we were able to probe more deeply into the issues faced by the home party. This does not alter the fact that a study into the host institution's perspective would have yielded equally valuable insights and would complement this research, as the issues identified in the current study cannot be bridged without constructive actions and measures on either side. ${ }^{11}$

\section{Methods}

\section{Design and Setting}

This study was set in the context of a medical undergraduate curriculum partnership between Maastricht University in the Netherlands (the home institution) and a newly established medical college in Saudi Arabia (the host institution). It spans a period of seven years, from the first cohort of students entering their preparatory year until their graduation. We used an instrumental case study approach to address the aforementioned research objective. Essentially, such methodology uses a particular case to gain insight into an issue or phenomenon. ${ }^{12}$ In this paper we chose to explore Maastricht University's experiences as a home institution (case) to illustrate and support our understanding of the process of transposing a medical curriculum (general 
phenomenon). ${ }^{13}$ Ethical approval was obtained from the Netherlands Association for Medical Education Ethical Review Board (NVMO file number 629).

\section{Research Team}

The first, second and third author are employed full-time as international project officers by the home institution and jointly responsible for managing this partnership. They have detailed knowledge of the home institution's curriculum, expertise in studentcentred learning, and relevant work experience in the host country. It is through the lens of their experiences that this case study unfolded. Additionally, the first author is pursuing a PhD on crossborder curriculum partnerships and has developed an overview of existing literature that serves as a framework for reflection. ${ }^{6}, 8$ The fifth and sixth authors were involved in the partnership's set-up as deans of the home and host institution, respectively. The remaining two authors are medical education researchers specialised in internationalisation, who are affiliated to the home institution but had no role in the partnership.

\section{Data Collection and Analysis}

In the first phase of the data collection and analysis process, the three project officers collected all project documentation to perform a chronological document analysis guided by the research objective. The output of these sessions, that stimulated the collective memory of the case, were consequently discussed in the entire research team. In the next stage, the management of the host institution verified whether the description and analysis resonated with their experiences.

On the basis of these findings and the literature, we developed a three-dimensional framework presenting the distances that both institutions needed to bridge, from the home institution's standpoint, in order for the partnership to be successful. The next sections will elaborate on these dimensions, specifically 'relational/cultural', 'geographical' and 'educational', describing why they were an issue, how we tackled them and what we learnt. Our findings will then be discussed in light of the existing literature. First, however, we will briefly expound on the partnership's key characteristics and its inception.

\section{Results}

\section{How it Started}

In 2009, the founding dean of a then yet-to-be-established university in Saudi Arabia approached Maastricht University with the idea to initiate a curriculum partnership. He deliberately chose Maastricht University as an academic partner because of its reputation, global rankings and experience with problem-based learning (PBL). The founding dean strongly favoured student-centred education, which he believed would bolster 
the quality of graduates in his context. ${ }^{14}$ At first, Maastricht University was hesitant to accept the proposal due to its unfamiliarity with the type of partnership and the host country. Although these types of curriculum partnerships are quite common in AngloSaxon countries, they are rather uncharted territory for higher education institutions in the rest of Europe, especially in the field of medicine. ${ }^{3}$ Mutual visits and background research, however, slowly but gradually helped to build trust and relationships between higher management. Eventually, the home institution decided to join in for various reasons, including the opportunity to bridge cultures that are at times in tension with each other, to export student-centred education to places where it is in demand, to earn a profit that could be invested in the quality of educational delivery at home, to 'pilot' this form of internationalisation, and to expand the university's international network. Research found a similar myriad of reasons. ${ }^{15,}, 16$

By the end of 2009, both partners signed a contract governing the period from 20092020, in which they stipulated that the host institution should function independently according to the model of the home institution's curriculum by September 2020. For this purpose, the host institution was to use Maastricht University's 6-year undergraduate medical curriculum (content, didactics and assessment) as the foundation for its own. The home institution committed itself to providing training to the management and teaching faculty of the host institution tasked with implementing the curriculum and adapting it to the local context. In addition, the home institution was to oversee the quality of the curriculum, for instance during review visits. Although the ultimate object of the agreement was to offer host students a learning experience comparable to that of home students, the home institution is not entitled to award a Maastricht University degree upon graduation pursuant to restrictions imposed by Dutch law. As an alternative, the home institution issues a supplement to the host institution's degree, testifying the quality of the programme and its implementation signed by the highest authority of the home university. To sustain the partnership, the home institution created a project office, consisting of the three officers previously described who developed work processes, facilitated the exchange of materials, and had close links with decision-makers. Although we were unaware of this at the time, the literature recommends a similar strategy of creating a small, dedicated team vested with powers to take prompt decisions so as to avoid time-consuming committee decision-making. ${ }^{17,18}$

\section{Bridging Relational and Cultural Distances}

Institutional and personal relations at all levels can make or break a curriculum partnership. ${ }^{9}$ This holds true not only for interfaculty relations between home and host institution, but also for the relations within the home institution which must be strengthened to ensure and boost the commitment of home faculty. ${ }^{19}$, 20 Cultural differences between both contexts shine through in these relationships, and can complicate as well as enrich encounters. In our case, the cultural and religious distances between the Netherlands and Saudi Arabia were quite large and impacted relationships on many levels. Beyond that, the idea that the home institution, as a publicly funded research institution, embarked on this large-scale venture for reasons which were in part com- 
mercial created an air of suspicion among home institution faculty. This was reinforced by the fact that it was the first time educational services were used as substantial revenue stream. As a result, these faculty members did not list the collaboration as their number-one priority, a response identified as typical of home faculty in the literature. ${ }^{20 \text {, }}$ ${ }^{21}$ This situation posed a serious threat to the partnership, as our project office relied heavily on the support, input and involvement of our colleagues for the transfer of knowledge and materials to the host institution.

To bridge relational distances and to foster a supportive culture among faculty members of the home institution, the project office regularly provided them with partnership updates by issuing newsletters, annual reports, and presenting at meetings. In addition, the project officers made sure to register and generously reward every effort, big or small, and to relieve home faculty as much as possible by answering all host institution's questions not related to content, regarding structure, didactics and logistics of the curriculum, for example. Most important of all measures, however, was the emphasis on personal encounters. Whenever the involvement of home institution faculty was requested, a project officer would meet these faculty members and brief them on the content and rationale of the collaboration as well as on cultural aspects. While in literature ${ }^{17,22,23}$ a more formal faculty induction programme is advocated by some ${ }^{17,22}$, 23 , we preferred a personal approach, which was highly valued and sometimes served as the gentle prod faculty needed to become involved and reduce their anxiety. In the end, cultural distance constituted no real impediment to participation for the vast majority of home faculty, both male and female. On the contrary, considering the open attitude of faculty members towards new experiences, this cultural distance induced many of them to become involved in the collaboration.

The relational and cultural distance between partners existed not only on faculty level, but also on the level of higher and project management. As noted in literature, these relations are the 'grease' of the partnership and eventually determine success or failure to a large extent. $9,10,17,24$ It was with ups and downs that we learned about this. We soon realized that creating strong links meant 'doing the little things' on multiple levels e.g. between faculty, project officers and higher management, as emphasized by Heffernan and Poole ${ }^{10}$. At the level of project management for instance, the project office adopted the policy to respond to questions within 24 hours also during weekend. We noticed how much this was valued by our counterparts and how this prevented frustrations and misunderstandings especially since our contract only listed main issues, while governing an 11-year period. Therefore, good relationships and communication were indispensable to continuously negotiate details of the collaboration.

Despite these efforts, it was inevitable that relational and cultural distances manifested themselves variously in online and offline communication, which could easily have triggered stereotyping as other studies have warned for.9, 23, 24 A survey among faculty of transnational programmes revealed the magnitude of this issue, with over 50 percent of respondents reporting communication styles as a challenge in the delivery of crossborder education. ${ }^{25}$ Since cultural context and communication strongly influence one another, Keay, May and 0' Mahony ${ }^{25}$ champion the intensification of efforts to ensure that information is exchanged and that both parties understand its meaning. Our way of dealing with this potential threat was to involve project officers in most interac- 
tions between home and host faculty, especially in the initial phase, to explain the background of questions and act, if necessary, as intermediary between faculty members. This strategy appeared beneficial as the number of incidents stayed limited to isolated events - e.g. an individual teacher's disappointment with an unmet agreement that did not influence the overall partnership relations.

\section{Bridging Geographical Distances}

Besides relational distances, the geographical distance between the two partners further complicated overseas implementation of the curriculum. Not only did differences in time and space between the institutions affect the partnership, but also the physical transfer of learning materials, the pivot of the partnership, proved to hold several unforeseen pitfalls. For an extensive account of challenges similar to the ones we faced, though derived from different settings, we refer to the work by Lane ${ }^{1}$ and Lim $^{26}$. At the start, we realised that transfer of the home curriculum, which comprised a variegated range of educational sessions and materials owing to its multidisciplinary, integrated and competency-based nature, required an equal amount of different approaches. Subsequently, we discovered that it was difficult to lend transparency to all aspects of the curriculum, as much content appeared to be hidden with faculty members running their sessions based on implicit and tacit knowledge and experience.

Another bottleneck presented itself when the project office undertook its first mission to gather and prepare all formal documentation intended to explicitly guide the implementation process: various learning tools that were embedded in the home curriculum, such as software programmes and access to the electronic or home-based library, were actually owned by third parties and had not been identified upfront. We therefore had to make separate arrangements with each individual third-party owner, leading to differences in the availability of these learning tools between home and host institution, especially in the first years. Other case studies by Castle and Kelly ${ }^{18}$ and Wilson ${ }^{27}$ have reported similar challenges.

Further preventing a smooth transfer of materials was the fact that both institutions relied on different e-learning environments, which made direct transfer impossible. We learnt that in order for the transfer and synchronisation of the curriculum to run smoothly, both sides need expertise on how to structure the learning environment as well as a basic understanding of how to use the educational materials.

A final hurdle was the realisation that the transfer of materials, rather than being an isolated activity, was a continuous process, as the curriculum was updated and adjusted on a yearly basis. With home and host curricula running simultaneously and parts of assessment materials being identical, this synchronisation needed to be on time and accurate. In their case studies, Dobos ${ }^{9}$, Dunworth ${ }^{28}$ and $\mathrm{Lim}^{26}$ also warned that the scope of continuous synchronisation is easily underestimated, an oversight that can have major repercussions. In our experience, synchronising the curriculum so far has been no easy feat, not only in terms of content, but also logistically, with national holidays, working days and weekends differing across both institutions. Therefore, we found that mutual investment of time and effort in long-term advance planning and 
coordination, at least one year ahead, was crucial and prevented surprises that were most unexpected and their associated consternation.

\section{Bridging Educational Distances}

Physical transfer of curriculum materials did not automatically result in transfer of the curriculum, that is, its local fit, acceptance and understanding of curriculum content, didactics and assessment by the host institution's stakeholders, such as students, faculty, management, parents, hospitals and patients. The different educational traditions on both sides created an educational distance between home and host contexts that needed to be bridged. Although host faculty were generally dedicated and eager to learn, they had a background in teacher-centred lecturing, which approach was scarcely reconcilable with the student-centred educational concept that represented the backbone of the home institution's curriculum. Other institutions have reported similar experiences, ${ }^{29}, 30$ while some authors have signalled potential problems in implementing student-centred curricula developed in Western contexts in other settings. ${ }^{31}$ Yet other authors have denounced such ventures altogether for their ingrained and often unquestioned cultural assumptions. ${ }^{32}$ Aligning the educational cultures of home and host institution has indeed been a challenge, to which we responded by seeking to explicate assumptions on both sides. Fostering student-centred education was an explicit goal of our agreement, which we sought to achieve by paying a number of training visits and a review visit each year, based on a mutual needs analysis initiated by the host institution. We also launched a University Teaching Qualification programme at the host institution: a longitudinal certified training programme aimed to train host faculty in their various teaching roles, to equip them with a theoretical foundation for learning and to establish a culture of peer review. We are in the process of developing a medical education department at the host institution, which may eventually assume responsibility for faculty development that is currently resting with the home institution. However, the challenge to align both different traditions remains a constant, especially when viewed in the light of literature findings emphasising that training does not automatically cause faculty to gain a deep understanding and apply a new educational philosophy. ${ }^{10,26,33}$

Another explicit objective of the agreement was to adapt home curriculum content as much as possible to the host context. Hodges et al. have warned against the inherent risk of imported curricula not responding to the host country's health care needs. ${ }^{34}$ Although in the first two years the host programme ran entirely on home curriculum content, it gradually came to incorporate local adaptations, such as the introduction of host-designed elective courses. In the third year, contextualisation of the curriculum occurred almost automatically, as the programme was largely patient-based, with host students being exposed to the local health care setting and prevailing diseases.

Differences in educational contexts became especially pronounced with the introduction of home-invented assessment methods into the host setting. Our experience is echoed in the work by other researchers who point out that potential differences in assessment cultures and national legislation influence the delivery of the curriculum. ${ }^{29}$, 35, 36 In our case, the host institution had to comply with the national accreditation 
standards for education and assessment, which place a strong emphasis on summative knowledge testing. This contrasted considerably with our aforementioned studentcentred philosophy that favoured the provision of formative feedback to students rather than marks only. Despite initial efforts to implement and explain the rationale of the home institution's assessment programme, we soon realised it was a bridge too far. Therefore, the host institution, in consultation with the home institution, eventually developed its own assessment programme, which included additional items, tutorial assessments, different weightings of exam components and more formal assessment moments in the clinical phase. This strategy gave the host institution more control over its assessment and is illustrative of the pragmatic stance we adopted: one of being open to and influenced by each other, which has also been promoted in literature. ${ }^{37}$ As a corollary, we now have two curricula that are far from identical, yet comparable in terms of their essential features and intended learning outcomes. In the long run, it will be interesting to investigate the impact of the more intensive and summative assessment system on host students' learning behaviours, considering the strong relation between assessment and learning. ${ }^{38}$

\section{Discussion}

In the previous section we have recounted the challenges faced and the working procedures adopted by a home institution that established a student-centred medical curriculum partnership. Looking back in hindsight on the last seven years, we can say that the partnership has developed in accordance with the initial agreements and to the satisfaction of both partners. Although distances seemed daunting at face value, we managed to overcome the main obstacles and to have two comparable student-centred medical curricula run simultaneously in two different countries. Transfer of studentcentred principles appeared viable, indeed, as evident from the appreciation host students repeatedly expressed during review visits. Other studies have reported similar experiences. ${ }^{39-41}$ Moreover, equivalent standardised summative knowledge tests administered in the first years yielded comparable student results in both curricula, while the first batch of host graduates passed their national licensing exam, the gateway to medical practice and specialty training. These are strong positives ascribable to both partners, which bolster confidence in the robustness of the implementation. On a more individual level, many home faculty members reported that their visits to the host country and meetings with students and staff had positively changed their beliefs and ideas about the host country's culture.

Although we successfully managed the said distances, they keep requiring our constant attention as the influx of new faculty on both sides may spark new cultural miscommunications and differences in expectations. In addition, since the home institution's curriculum is regularly updated, efforts must continue to be channelled into maintaining close relationships between faculty and project office. For these reasons we shifted the focus of our faculty development strategy away from individual teachers' behaviours towards organisational policies, structure and culture: a persistent 
effort that will determine the sustainability of the curriculum in the long run. Now that the first batch of students has graduated and the partnership is maturing, we are entering a new phase; one in which flow of ideas and information between home and host institution will be transformed from a unilateral direction (until now the host institution relied heavily on input and guidance from the home institution) towards a more bilateral flow (in which host faculty provide feedback and suggestions for curriculum improvement).

The present case study provides an example of a partnership in which management is centralised in one project office tasked with the initiation, channelling, and management of nearly all flows of communication and materials between partners. Preconditions for the success of this type of management included having a core team of officers well versed in the context of both institutions with good connections with key faculty to ensure the parallel and timely delivery of curricula. This construct has helped the home institution to overcome the aforementioned 'distances', by accelerating the decisionmaking process, addressing cultural differences, being easily accessible to host faculty, reducing workload for home faculty, and serving as a reference point for home faculty who are unfamiliar with the new work processes. On the other hand, the project office may risk becoming an isolated entity within the organisation. Being heavily reliant on the central project office, home faculty members might be less inclined to take ownership of the partnership. As a result, the flow of information from home to host institution may stay largely confined to updates, home decisions and home products. ${ }^{42}$

A decentralised alternative to the centralised-management approach is to establish direct linkages and communication lines between faculty in all echelons of the home and host institutions. Such approach requires a substantial adaptation of home faculty's roles and responsibilities. Tasks and responsibilities such as organising online meetings with geographically separated faculty, for instance, must become institutionalised in the faculty role descriptions. The management will need not only a strategy to coordinate these numerous meetings, but also a 'disintegration strategy' or plan B when partners digress because of diverging interests. Inevitably, such joint enterprises will tax the cultural competences of the faculty members involved and increase the risk of miscommunications and misunderstandings compared to a partnership based on a mediating project office. In the long run, however, the decentralised approach which enhances collaboration and joint development between members of home and host faculty could facilitate the implementation of updates and adaptations on both sides. Keay, May and 0' Mahony ${ }^{25}$ argue that such bilateral inter-faculty communities of practice that develop educational products together could improve the quality of curriculum delivery. By creating a stronger network, they provide opportunities for research collaboration and other positive spin-offs. They also redress the imbalance of power between home and host faculty in terms of knowledge and feelings of curriculum ownership and offer a platform for the host faculty to make suggestions for improvement of the delivery and quality of the home institution's curriculum.

Which management approach would best suit such partnerships depends on several conditions, such as the availability of faculty, financial endowment, long-term strategic objectives, and the prevailing cultural and geographical distances. The two management approaches we have outlined can be considered as two extremes on a contin- 
uum. Depending on the type of partnership and its stage of maturity, we encourage a move along this continuum: from a more centralised approach, which increases the likelihood of the partnership being rooted in the home organisation, towards a more decentralised approach to reap the educational benefits of an equal relationship between faculty members of both institutions. We welcome further studies into these flexible approaches to manage curriculum partnerships.

This case study has a number of limitations. First, several members of the research team assumed the dual role of researcher and informant, which may have led us to give an overly optimistic presentation of the partnership, its challenges and outcomes. To minimise this bias, we included two authors who were outsiders to the curriculum partnership and explicitly addressed the possibility of bias during our reflections and discussions with all authors. Notwithstanding these considerations, the inclusion of project officers as authors allowed us to collect rich data and detailed insights into the challenges and the strategies to overcome them.

A second, even more important limitation is that this case study only reflects one side of the partnership. We strongly encourage host institutions to conduct comparable research on managerial processes and strategies to disclose their views. Together with the present study, such reports will offer a comprehensive picture of this revolutionary trend in the internationalisation of education, medical or otherwise.

\section{Acknowledgements}

The authors would like to thank all participants of this study for their time and their openness to share their experiences and perspectives. Furthermore, we would like to acknowledge Angelique van den Heuvel for her help in the preparation of this article. 


\section{References}

1. Lane JE. Global Expansion of International Branch Campuses: Managerial and Leadership Challenges. New Dir High Educ. 2011;(155):5-17.

2. Knight J. Higher Education in Turmoil, vol. 13. Toronto: Sense Publishers; 2008.

3. British Council. The shape of things to come 2. The evolution of transnational education: data, definitions, opportunities and impacts analysis. 2013. [Report] Available from [https://www.britishcouncil.org/education/ihe/knowledge-centre/transnational-education/the-shape-of-things-to-come-2]; Accessed August 2013.

4. Skidmore M, Longbottom J. The future of transnational education. 2011. [Internet] Available from [http://www.obhe.ac.uk/newsletters/borderless_report_november_2011/future_transnational_educatio n]; Accessed November 2011.

5. Lane JE, Brown II, Christopher M, Pearcey MA. Transnational campuses: Obstacles and opportunities for institutional research in the global education market. New Directions for Institutional Research. 2004;2004(124):49-62.

6. Waterval DGJ, Frambach JM, Driessen EW, Scherpbier AJJA. Copy but Not Paste: A Literature Review of Crossborder Curriculum Partnerships. J Stud Int Educ. 2014;19(1):65-85.

7. Kosmutzky A, Putty R. Transcending Borders and Traversing Boundaries: A Systematic Review of the Literature on Transnational, Offshore, Cross-Border, and Borderless Higher Education. J Stud Int Educ. 2016;20(1):8-33.

8. Waterval DGJ, Frambach JM, Oudkerk Pool A, Driessen EW, Scherpbier AJ. An exploration of crossborder medical curriculum partnerships: Balancing curriculum equivalence and local adaptation. Med Teach. 2015:1-8.

9. Dobos K. "Serving two masters" - academics' perspectives on working at an offshore campus in Malaysia. Educ Rev. 2011;63(1):19-35.

10. Heffernan T, Poole D. In Search of "The Vibe": Creating Effective International Education Partnerships. HETIJHEEP. 2005;50(2):223-45.

11. Knight J, McNamara J. The impact of transnational education in receiving countries. International Higher Education - Center for International Higher Education. 2015;82.

12. Stake RE. The art of case study research. Thousand Oaks, Californa: Sage Publications; 1995.

13. Baxter P, Jack S. Qualitative Case Study Methodology: Study Design and Implementation for Novice Researchers. McMaster University, West Hamilton, Ontario, Canada. 2008;13 (4 ):544-59.

14. Summum. Maastrichtse' faculteit in Saoedi-Arabië begint september. In: Summum; magazine voor het azM en de UM-faculteiten geneeskunde en gezondheidswetenschappen. vol. 86. Maastricht: Stafdienst Communicatie azM, Maastricht; 2010.

15. OECD. Internationalisation and Trade in Higher Education Opportunities and Challenges. Paris: OECD 2004.

16. Zhang L, Kinser K, Shi Y. World Economies and the Distribution of International Branch Campuses. International Higher Education. 2014;8(77):8-9.

17. Smith L. Sinking in the Sand? Academic Work in an Offshore Campus of an Australian University. HERD. 2009;28(5):467-79.

18. Castle R, Kelly D. International Education: quality assurance and standards in offshore teaching: exemplars and problems. Qual High Educ. 2004;10(1):51-7.

19. Sidhu R. The 'brand name' research university goes global. High Educ. 2009;57(2):125-40.

20. Shanahan P, McParlane J. Serendipity or strategy? An investigation into entrepreneurial transnational higher education and risk management. Horizon. 2005;13(4):220-8.

21. Coleman D. Quality assurance in transnational education. J Stud Int Educ. 2003;7(4):354-78.

22. Chapman A, Pyvis D. Quality, Identity and Practice in Offshore University Programmes: Issues in the Internationalization of Australian Higher Education. Teach High Educ. 2006;11(2):233-45.

23. Seah WT, Edwards J. Flying in, flying out: Offshore' teaching in higher education. Aust J Educ. 2006;50(3):297-311.

24. Dunn L, Wallace M. Australian academics and transnational teaching: An exploratory study of their preparedness and experiences. HERD. 2006;25(4):357-69.

25. Keay J, May H, O' Mahony J. Improving learning and teaching in transnational education: can communities of practice help? JET. 2014;40(3):251-66. 
26. Lim FCB. Do Too Many Rights Make a Wrong? A Qualitative Study of the Experiences of a Sample of Malaysian and Singapore Private Higher Education Providers in Transnational Quality Assurance. Qual High Educ. 2010;16(3):211-22

27. Wilson M. Transnational nursing programs: models, advantages and challenges. Nurse Educ Today. 2002;22(5):417-26.

28. Dunworth K. Ideas and realities: Investigating good practice in the management of transnational English language programmes for the higher education sector. Qual High Educ. 2008;14(2):95-107.

29. McBurnie G, Ziguras C. Transnational education: Issues and trends in offshore higher education: Routledge; 2007.

30. Ziguras C. Educational technology in transnational higher education in South East Asia: the cultural politics of flexible learning. Educational Technology \& Society. 2001;4(4):8-18.

31. Frambach JM, Driessen EW, Chan LC, van der Vleuten CP. Rethinking the globalisation of problem-based learning: how culture challenges self-directed learning. Med Educ. 2012;46(8):738-47.

32. Bleakley A, Brice J, Bligh J. Thinking the post-colonial in medical education. Med Educ. 2008;42(3):26670.

33. Shams F, Huisman J. Managing Offshore Branch Campuses: An Analytical Framework for Institutional Strategies. J Stud Int Educ. 2012;16(2):106-27.

34. Hodges BD, Maniate JM, Martimianakis MA, Alsuwaidan M, Segouin C. Cracks and crevices: Globalization discourse and medical education. Med Teach. 2009;31(10):910-7.

35. Eldridge K, Cranston N. Managing Transnational Education: Does National Culture Really Matter? J High Educ Pol Manag. 2009;31(1):67-79.

36. Miliszewska I, Sztendur E. Critical Success Attributes of Transnational IT Education Programmes: The Client Perspective. Journal of Information Technology Education. 2011;10:123-37.

37. Djerasimovic S. Examining the discourses of cross-cultural communication in transnational higher education: from imposition to transformation. JET. 2014;40(3):204-16.

38. Schuwirth LW, Van der Vleuten CP. Programmatic assessment: From assessment of learning to assessment for learning. Med Teach. 2011;33(6):478-85.

39. Koh GC, Khoo HE, Wong ML, Koh D. The effects of problem-based learning during medical school on physician competency: a systematic review. CMAJ : Canadian Medical Association journal = journal de l'Association medicale canadienne. 2008;178(1):34-41.

40. Jippes M, Majoor GD. Influence of national culture on the adoption of integrated and problem-based curricula in Europe. Med Educ. 2008;42(3):279-85.

41. Khoo HE. Implementation of problem-based learning in Asian medical schools and students' perceptions of their experience. Med Educ. 2003;37(5):8-.

42. British Council, German Academic Exchange Service (DAAD). Impacts of transnational education on host countries. 2014. [Report] Available from [https://www.britishcouncil.org/sites/default/files/tne_study_ final_web.pdf]; Accessed August 2015. 



\section{Chapter 7.}

\section{Twelve tips for crossborder curriculum partnerships in medical education}

Accepted for publication: Waterval DGJ, Driessen EW, Scherpbier AJJA, Frambach JM. Twelve tips for crossborder curriculum partnerships in medical education. Medical Teacher. 2018. DOI: 10.1080/0142159X.2018.1429585 


\section{Abstract}

Crossborder curriculum partnerships are a relatively new and fast-growing form of internationalisation in which the curriculum that has been developed by one institution (the home institution) crosses borders and is implemented in another institution (the host institution). These partnerships aim to provide students in both institutions comparable learning experiences and are driven by a variety of motives, such as strengthening international networks, increasing financial gains and stimulating research spinoffs.

Although popular, crossborder curriculum partnerships are also criticised for their potentially low educational quality, failing to address fundamental differences in teaching and learning between the home and host institutions, and not addressing the educational needs of the host country health care system.

Our aim is to provide guidance to those considering or engaged in designing, developing, managing and reviewing a crossborder curriculum partnership or other forms of international educational partnerships in medical education. Drawing from research, personal, and institutional experiences in this area, we listed twelve tips categorized into four themes that contribute to the establishment of sustainable partnerships that can withstand the aforementioned criticism. 


\section{Introduction}

Crossborder curriculum partnerships are a growing form of internationalisation in higher education. ${ }^{1}$ By 2012 for example, Australia had set up 394 crossborder partnership programmes in higher education ${ }^{2}$, and by the same year, UK universities had set up 1,395 crossborder partnerships in addition to 73 overseas campuses. In a crossborder curriculum partnership, a curriculum developed in one institution (the home institution) is transferred across borders and also implemented in another institution (the host institution). ${ }^{3}$ The partners offer their curriculum simultaneously and aim to provide comparable learning experiences to both groups of students. This definition includes partnerships that award the same degree to students in both locations, as well as host institutions that issue their own degree. This form of internationalisation enjoys popularity for the benefits it brings to both partners in terms of an expanded network, international reputation, research collaborations and finances. . $^{4-6}$

However, crossborder curriculum partnerships are not an easy internationalisation strategy, especially in the medical domain, due to many differences in context that need to be bridged. ${ }^{7}$ Most medical curricula, for instance, are highly intertwined with the local healthcare system through assignments, projects, and visits. This interconnection increases in the clinical phase as the learning environment shifts from the university to healthcare practice, and classroom teaching is replaced by learning that includes interacting with patients. This interconnection requires a careful and deliberate adaptation to balance the home programme with what is feasible in the host situation, while preserving a comparable learning experience. Furthermore, there may be differences between the home and host institutions' legal and political context, for instance a country might determine length and even content of medical programmes affecting comparability. Additionally it is challenging to address differences in teaching and learning environment and to fulfil the healthcare needs of the host country. ${ }^{8,9}$

In this article, we provide 12 tips for designing and implementing crossborder curriculum partnerships in medical education. These tips are distilled from personal experiences with crossborder curriculum partnerships and based on our experience with a larger research project on challenges and strategies of crossborder medical curriculum partnerships. All authors were part of the research team and conducted a literature review and four field studies that involved perspectives from programme directors, students, teachers and management. Because we were interested in non-case specific challenges and strategies, we included multiple partnerships in each study design. These crossborder medical curriculum partnerships had been identified at the start of the research project in 2012. The inclusion criterion was that the partnership aimed to provide comparable learning experiences to students in both settings by delivering equivalent curricula. Furthermore, we selected partnerships that existed for a period of at least three years and had at least one batch of graduates. A total of six partnerships participated in the project, with home institutions located in the US, the UK and the Netherlands, and host institutions in Egypt, Saudi-Arabia, Qatar, Singapore, Malaysia and Cyprus. 
Although the research context did not include any specific North-South or SouthSouth partnerships, we do believe that our tips have relevance for other contexts as well. The tips are categorized into four interrelated themes: (1) Governance, (2) Curriculum, (3) Learning environment and (4) Relationship management. Our aim is to provide guidance to those involved in planning, managing or reviewing crossborder curriculum partnerships and other forms of international educational partnerships in medical education.

\section{Theme 1: Tips on governance}

\section{Tip 1: Develop a master plan to govern the collaboration}

Curriculum partnerships share many commonalities with large-scale projects and can therefore be managed accordingly, that is, by performing regular SWOT analyses, describing new work processes, responsibilities and duties, and by comprehensive time planning. This can be daunting for educational organisations as they may not be used to such a business-like approach. ${ }^{10}, 11$ Successful partnerships are those that explicate major decisions upfront in legal contracts. ${ }^{12,13}$ Decisions need to made on the following topics:

- responsibilities for hiring faculty and recruiting students;

- growth strategy for recruiting students;

- methods of transferring and updating educational materials;

- third-party licenses of educational instruments used within the home curriculum;

- collaboration with respect to assessment policies and instruments;

- intellectual property rights on materials during and after the partnership;

- legal status of the degree awarded to host students.

By reaching agreements on the aforementioned and other topics, partners can prevent future disappointments that arise from tacit expectations. ${ }^{12-14}$ However, any curriculum partnership per definition spans multiple years, and many aspects cannot be foreseen at the start of the project. Therefore, it is desirable that the partners avoid placing each other inside a straitjacket, as a determining factor for success in such long-term partnerships is the ability to be flexible and to seize and adjust to unforeseen opportunities that might occur along the way.

\section{Tip 2: Adopt a robust internal system for quality control}

The UK is leading in the crossborder delivery of programmes, as many UK universities are offering overseas programmes and degrees. ${ }^{2}$ In recent years, these programmes have been monitored - perhaps even more than national programmes - by British accreditation agencies. In contrast to these recent efforts in the UK, there are many home and host countries whose accreditation systems are not yet sufficiently robust and/or well-developed to address this form of internationalisation. ${ }^{15}$ 
In any case, we urge partnerships to establish a robust internal quality assurance mechanism aiming to monitor the educational quality of the delivery of the programme. This internal system should scrutinize the process through which the philosophy of the home programme can be preserved given the inevitable differences in context that need to be bridged. As Boteju and Burnapp ${ }^{16}$ stated, there is a possibility that all those concerned (including staff, students and quality assurance managers) may setup programmes and learning activities which really only mimic the intended features of a specific culture of education but do not actually replicate that system in its essential features. Evaluation outcomes should be discussed among partners and used to sustain a continuous cycle of quality improvement. Furthermore, such an internal quality assurance system should link with the required external (national) system and at the same time offer sufficient flexibility to tackle issues within the context of the host institution. Apart from an adequate internal quality system, we would encourage partners to regularly plan external reviews of the crossborder programme. ${ }^{17}$

An illustration might originate from one partnership where the home institution initiates and executes bi-yearly 'mock' accreditation visits to the host, which served as an opportunity for host staff to practice for their host country national accreditation process. At the same time, the 'mock' accreditations provided valuable information about the quality of the implementation process to the home institution.

\section{Tip 3: Prepare the home faculty as well}

Managers of crossborder programmes tend to direct their activities at setting up the host organisation and therefore may neglect to foster and cultivate appropriate conditions within the home institution. Most academics in the home institution will be unfamiliar with curriculum partnerships. Studies report that they might be sceptical about such international projects and reluctant to adjust their behaviour, whereas these partnerships require additional actions and changing work responsibilities. ${ }^{18,} 19$ To enhance the commitment of home faculty, it is therefore crucial that the home institution communicates frequently and as early as possible about the partnership's rationale, potential benefits and long-term strategy.

In addition, the home institution needs to organize the interactions and responsibilities at the project management level and to think about how to organize the project office and its place within the organisation. ${ }^{20}$ Finally, a crossborder curriculum partnership requires the integration of new working processes into the existing ones. Various tasks and responsibilities must become institutionalised, ranging from organising online meetings to creating joint exam papers in cooperation with a geographically distant faculty. 


\section{Theme 2: Tips on curriculum}

\section{Tip 4: Adapt the content of the home curriculum to the host's local context}

The original home curriculum of most medical partnerships was not designed to be exported overseas. The programme is usually interconnected with the home health care system in terms of intended competencies/learning outcomes as well as workplace learning activities. Furthermore, the learning materials are often developed from the perspective of the home context and of the home students. ${ }^{7}$ These features make a medical curriculum unsuitable for exact replication across borders. Therefore, we suggest that partners adapt the learning materials at three levels.

First, change original names, places, and circumstances to descriptions that are more recognisable to host students. Although this seems trivial and might be perceived as window dressing, it does contribute to contextual learning and it increases motivation and feelings of ownership among staff and students of the host institute. We have come across cases where the context of the home learning materials had been placed in a Western context involving e.g. drugs, alcohol, sex or combination. Such learning materials might not only be difficult to relate to for host students, they could also be perceived as culturally offensive for host country teachers, students or parents. Here we do not mean the intended learning objectives, but the context in which learning materials are offered to students.

Second, delete elements that are not relevant to the learning outcomes of the host students, e.g. curriculum elements that are too home specific. Examples might be the prevalence of certain diseases in the home country or a detailed elaboration of a characteristic element of the home country health care system.

Third, adapt and add learning activities as necessary or legally required in the context of the host institution, such as additional courses on child delivery or tropical diseases. These adaptations are aimed at developing competences relevant for the host country's healthcare system.

Adapting the curriculum to the context of the host institution raises the issue of who is responsible or who should take the lead for these adaptations. We encountered different approaches; however, the participation of host country stakeholders, e.g. students, teachers, representatives of the healthcare system, seems indispensable, as they are the ones most capable of determining their needs and the required competencies and of designing materials that fit the host context. We often encountered that a lack of clarity on this responsibility prevented actions within the partnerships.

\section{Tip 5: Address technical and logistical barriers}

An often neglected issue within curriculum partnerships is the actual transfer of all curriculum materials. ${ }^{21}$ Although it can be considered the core of the partnership, an interview study among medical crossborder programme directors revealed that there often was no clear working plan for the transfer of curriculum materials. ${ }^{7}$ As a consequence, many challenges with respect to transfer, synchronisation, and updates of the 
curriculum were faced along the way. This led, for instance, to programme directors running around with USB-sticks to collect home institutions' lectures.

These technical and logistical barriers can be overcome but require deliberate ontime planning and coordination between both sides. We advise institutions to map all curriculum elements, including whether or not third-party licenced software is used, and to devise transfer strategies accordingly. In cases where this had not been done upfront accurately, promises and unspoken expectations were made between partners to exchange materials, while the materials legally were not owned by the home institution.

\section{Tip 6: Capitalize on the unique global learning community at host institutions}

A unique learning environment exists within many host institutions that offers opportunities for a global perspective on the curriculum's content and objectives. In comparison to their home counterparts, host students often have a more heterogeneous background, ${ }^{22}$ and they study a foreign, albeit adapted medical curriculum delivered by teachers from different countries. In host institutions, one can easily find students who were born in Malaysia and study a medical programme in Saudi Arabia that was developed by Dutch teachers and adapted to the Saudi healthcare context. They study together with colleagues from India, Jordan, Egypt and are taught by American, Saudi, Pakistani and Egyptian teachers. In our view, the adaptation of the home curriculum to the host institution's context (see tip 4) should be directed at optimising an international approach that does justice to the international learning environment in these institutions. This might, for instance, include designing learning activities in which students are exposed to different healthcare systems around the world and to different ways of approaching patients or dealing with colleagues in order to familiarise them with a global mind-set regarding healthcare issues.

\section{Theme 3: Tips on learning environment}

\section{Tip 7: Manage the culture shock for host students}

Host students often experience a 'culture shock' with respect to the new academic learning environment and the required study behaviour, especially in the first months. Some authors argue that the student-centred didactic model that is characteristic of many home curricula needs to be moulded or adapted to fit with the host students learning style, ${ }^{23,24}$ as the majority of host students have been exposed to a more teacher-oriented didactic approach. ${ }^{22,25}$

Others, including programme directors, teachers and students, argue against this adaptation and indicate that after a transition period, students adapt well to the difference in required learning behaviour. ${ }^{20}$ Interestingly, the resulting didactic model will likely never be a carbon copy of the model applied in the home institution and will develop naturally in a way that fits the host context, as Frambach, et al. ${ }^{26}$ showed that 
there is a continuous interaction and influence between students, culture and learning model.

Therefore, we would argue that efforts should not be geared to a predesigned adaptation but to developing and implementing an additional safety net and remedial programme for those students who need support and coaching in developing self-directed learning competences.

\section{Tip 8: Address language issues}

In most partnerships, English is used as instructional language, and for most students, English is their second language. Similarly, for teaching staff at the host institution, English is often the second or third language. ${ }^{27}$ Not surprisingly, teachers and programme directors as well as students report that especially in the beginning, a proportion of students face language problems that interfere with their study results and behaviour. For these students, additional remedial measures are needed. However, it is not necessary to make any structural adjustments to the programme and its instruction methods, as students with help of some support structures seem to pick up their English language skills. ${ }^{28}$

A greater challenge with respect to language is the potential mismatch that host students experience in the clinical phase between English as the language of instruction and the local language of the patient population. This can be a bottleneck for those medical partnerships where the host institution's patient population does not speak English and the student population is very heterogeneous. A possibility for institutions might be to offer two parallel clinical tracks: one offered to students who have mastered the language of the local patient population by additional efforts in their preclinical years and another track with predominantly English-speaking patients.

\section{Tip 9: Invest in staff development}

Host teachers play a crucial role in the quality of the actual delivery of the programme. However, these teachers usually were not involved in the development of the curriculum materials. Furthermore, it is likely that most of them are educated in a teacheroriented didactic system, and hence they will be relatively unfamiliar with the studentoriented didactical model. This means that continuous and intensive faculty development activities are required for full-time host teachers as well as for clinicians who are involved in teaching in the clinical phase. ${ }^{7}$ These activities aim to involve staff members who are unfamiliar with the content and didactics of the curriculum and bring them in this aspect up to par with their colleagues at the home institution.

We would urge partnerships to map out a comprehensive professional development plan regarding the main educational and management roles in the curriculum. In the initial phase, the emphasis will lie on the transfer of basic knowledge and on understanding the didactics of the programme. This can be achieved via short mutual training visits, online or face-to-face educational workshops and formal medical educational training for a selection of key members of the host staff. In the next phase, the focus 
might shift from knowledge and understanding to 'showing how'. This can be achieved by host staff members setting up their own training department and delivering, first in collaboration with the home institution, the didactical training. In the ultimate phase, this competency development plan would involve interacting with home staff members at an equal level within communities of practice, which is further specified in tip 10.

Besides the teaching staff employed by the host institution, the partnership's professional development plan also needs to include the staff members of the affiliated hospitals who supervise the students during the clinical phase of their education. Reaching out to these professionals is particularly challenging because teaching is often a small part of their job and it is therefore difficult to get in contact with them for training and to familiarise them with the principles of the curriculum. ${ }^{7}$ Increasing awareness of this risk and taking extra efforts, for instance by inviting them from the start to all types of faculty development sessions is recommended. In our experience, this group offers most resistance, which is echoed in often voiced remarks such as: "..we are doing this for so many years, are we not trained as good doctors?" It could be that these teachers feel most threatened by host students, who are educated in a different way.

\section{Theme 4: Tips on relationship management}

\section{Tip 10: Establish communities of practice}

Although most crossborder curriculum partnerships start with a unilateral flow of ideas, materials, and experts from home to host, in the longer run sustainable partnerships require that the exchange of educational expertise becomes more bi-lateral and preferably of equal strength. Programme directors and medical teachers in host institutions voiced frustrations that it was often difficult to communicate their ideas for improving the curriculum - resulting from their experiences of working with home materials - to the home institution due to a lack of appropriate channels of communication. ${ }^{7}$ To quote one programme director: “They (the home institution) sometimes couldn't possibly imagine good comes out of here (the host institution)."

A possible route to solving this issue is to establish 'communities of practice' at an early stage of the partnership. Communities of practice consist of teachers who are jointly responsible for the development, implementation, assessment and evaluation of the curriculum components. ${ }^{29}$ of course, host staff members first have to become acquainted with the curriculum, but in due time, a mutual exchange of ideas and experiences within these communities of practice can serve as a mechanism for quality improvement. Communities of practice also have other benefits; for instance, they can contribute to an increased sense of commitment among host teachers ${ }^{30}$ and provide a fertile soil for joint research projects. 


\section{Tip 11: Foster cultural intelligence at all levels}

Many authors have specifically emphasized the importance of cultural intelligence within crossborder curriculum partnerships. ${ }^{31-33}$ In curriculum partnerships, interactions between institutions are taking place at multiple moments and at various levels. Consequently, the people involved will encounter different approaches and ways of doing things, which may potentially create 'little annoyances', misunderstandings, or even frustrations. ${ }^{20}$ Due to differences in time zones and culture between partners, these feelings, which might arise at both sides, may jeopardise the sustainability of the partnership in the long run, as they impair interpersonal relationships.

A helpful approach to this dilemma might be the framework of 'cultural intelligence' developed by Early and Ang ${ }^{34}$. Fostering cultural intelligence implies that partners suspend their judgement about a particular experience until enough information becomes available to adequately describe and act on the situation and the people involved. Cultural intelligence, defined as "a person's capability for successful adaptation to new cultural settings" comprises three components: (meta)cognition (Do I know what is going on?), motivation (Am I motivated to act?) and behaviour (Can I act appropriately and effectively?) (Early \& Ang 2003). Strategies to promote the cognitive element of cultural intelligence include, for instance, striving for a better understanding of the working context of both partners, as this helps to frame experiences in a more constructive and collaborative way. To increase motivation, partners could for instance spend time on reflecting on the cultural aspects of experiences after visits or interactions. In terms of behaviour, even teachers who generally adopt a respectful and curious attitude might, in times of small conflicts, be inclined to put energy into blaming and looking for the source or cause of a conflict. Although understandable, this is counterproductive. Instead, a strong problem-solving attitude at the project management level, which deliberately avoids blaming and shaming, is perhaps key to a partnership's success and sustainability. Although there are no quick fixes, fostering and promoting cultural intelligence on these three aspects is vital. Heffernan, Morrison, Basu and Sweeney ${ }^{24}$ and Smith ${ }^{35}$ strongly advocated that a focus on cultural intelligence should already inspire the screening and selection of suitable project officers and key teachers.

\section{Tip 12: Communicate, communicate, communicate}

Last but certainly not least, a tip that should be considered as a foundation for all other tips for success is to create open, easily accessible channels of communication. Communication was identified as a crucial factor in partnerships. ${ }^{36,} 37$ A review distinguished three levels of communication: between teachers, between project officers and between members of upper management, each of which has its own strategy and pitfalls. $^{38}$ These open channels of communication might not be so easy to establish due to differences in time zones and working days. The use of new technologies such as WhatsApp, Facebook groups or online meeting platforms might provide some solutions but also has its downsides. Relying too much on a virtual environment will not do the trick, as collaborators also need to see each other to develop a personal relationship. 
During mutual visits, a balance between social and work related activities is advised. A number of studies tackled this specific issue and encouraged teachers to do "the little things", 27 for instance make an effort to filter out irrelevant information upfront when transferring educational materials from home to host or showing genuine interest in personal and social issues.

All communication and contact will gradually build upon a degree of 'trust' between partners. This trust is vital because the long-lasting nature of crossborder curriculum partnerships means that unanticipated opportunities and threats may occur that can only be solved on the basis of trust and with good communication.

\section{Conclusion}

Although the number of crossborder curriculum partnerships in medical education is expected to grow, they are by no means easy endeavours. Such partnerships require deliberate planning and informed decision-making during the design, implementation and operational phase in order to guarantee a comparable and high quality learning experience for students at both locations. We provided 12 tips that address some of the critiques to this form of internationalisation and contribute to establishing sustainable partnerships. A partnership where there is a bilateral flow of educational ideas.

\section{Acknowledgements}

The authors would like to thank all students, teachers and programme directors who participated in our previous studies on crossborder curriculum partnerships, which helped us to gain a better understanding of the challenges and strategies for this phenomenon. 


\section{References}

1. Harden RM. International medical education and future directions: a global perspective. Acad Med. 2006;81(12):S22-S9.

2. British Council. The shape of things to come 2. The evolution of transnational education: data, definitions, opportunities and impacts analysis. 2013. [Report] Available from [https://www.britishcouncil.org/education/ihe/knowledge-centre/transnational-education/the-shape-of-things-to-come-2]; Accessed August 2013.

3. Knight J. Cross-border education: Conceptual confusion and data deficits. Perspect Educ. 2006;24(4):1527.

4. Healey NM. Is higher education in really 'internationalising'? High Educ. 2008;55(3):333-55.

5. Lim FCB, Shah M. An examination on the growth and sustainability of Australian transnational education. Int J Educ Manag. 2017;31(3):254-64.

6. Kosmutzky A, Putty R. Transcending Borders and Traversing Boundaries: A Systematic Review of the Literature on Transnational, Offshore, Cross-Border, and Borderless Higher Education. J Stud Int Educ. 2016;20(1):8-33.

7. Waterval DGJ, Frambach JM, Oudkerk Pool A, Driessen EW, Scherpbier AJJA. An exploration of crossborder medical curriculum partnerships: Balancing curriculum equivalence and local adaptation. Med Teach. 2016;38(3):255-62.

8. Altbach P. Franchising-The McDonaldization of Higher Education. In: The International Imperative in Higher Education. Edited by Altbach P. Rotterdam/Boston/Tapei: SensePublishers; 2013: 111-3.

9. Hodges BD, Maniate JM, Martimianakis MA, Alsuwaidan M, Segouin C. Cracks and crevices: Globalization discourse and medical education. Med Teach. 2009;31(10):910-7.

10. Olcott Jr D. Global Connections to Global Partnerships: Navigating the Changing Landscape of Internationalism and Cross-Border Higher Education. J Cont High Educ. 2009;57(1):1-9.

11. McBurnie G, Pollock A. Opportunity and risk in transnational education-issues in planning for international campus development: an Australian perspective. High Educ Eur. 2000;25(3):333-43.

12. Heffernan T, Poole D. "Catch Me I'm Falling": Key Factors in the Deterioration of Offshore Education Partnerships. J High Educ Pol Manag. 2004;26(1):75-90.

13. Davies JL. A Revolution in Teaching and Learning in Higher Education: The Challenges and Implications for the Relatively Traditional University. High Educ Eur. 2001;26(4):501-14.

14. Wilkins S, Huisman J. The international branch campus as transnational strategy in higher education. High Educ. 2012:64(5):627-45.

15. Wilkins S. Ethical issues in transnational higher education: the case of international branch campuses. Stud High Educ. 2015:42(8):1385-400.

16. Boteju D, Burnapp D. Chapter Three: Quality Assurance in International Collaborative Courses. In: The strategic implications of different forms of international collaboration in Higher Education. Edited by Burnapp D. Northampton: The University of Northampton; 2011: 35-53.

17. Lim FCB. Do Too Many Rights Make a Wrong? A Qualitative Study of the Experiences of a Sample of Malaysian and Singapore Private Higher Education Providers in Transnational Quality Assurance. Qual High Educ. 2010;16(3):211-22.

18. Coleman D. Quality assurance in transnational education. J Stud Int Educ. 2003;7(4):354-78.

19. Shanahan P, McParlane J. Serendipity or strategy? An investigation into entrepreneurial transnational higher education and risk management. Horizon. 2005;13(4):220-8.

20. Waterval DGJ, Tinnemans-Adriaanse M, Meziani MA, Driessen EW, Scherpbier AJJA, Mazrou A, Frambach JM. Exporting a student-centred curriculum: a home institution's perspective. J Stud Int Educ. 2017;21(3): 278-90.

21. Lane JE. Global Expansion of International Branch Campuses: Managerial and Leadership Challenges. New Dir High Educ. 2011;(155):5-17.

22. Pyvis D. Culture shock and the international student 'offshore'. J Res Int Educ. 2005;4(1):23-42.

23. Chapman A, Pyvis D. Quality, Identity and Practice in Offshore University Programmes: Issues in the Internationalization of Australian Higher Education. Teach High Educ. 2006;11(2):233-45.

24. Heffernan T, Morrison M, Basu P, Sweeney A. Cultural Differences, Learning Styles and Transnational Education. J High Educ Pol Manag. 2010;32(1):27-39.

25. Pimpa N. Learning problems in transnational business education and training: The case of the MBA in Thailand. Int J Train Dev. 2009;13(4):262-79. 
26. Frambach JM, Driessen EW, Chan LC, van der Vleuten CP. Rethinking the globalisation of problem-based learning: how culture challenges self-directed learning. Med Educ. 2012;46(8):738-47.

27. Dobos K. "Serving two masters" - academics' perspectives on working at an offshore campus in Malaysia. Educ Rev. 2011;63(1):19-35.

28. Green JA. The effect of English proficiency and ethnicity on academic performance and progress. Adv Health Sci Educ Theory Pract. 2015;20(1):219-28.

29. Keay J, May H, O' Mahony J. Improving learning and teaching in transnational education: can communities of practice help? JET. 2014;40(3):251-66.

30. Keevers L, Lefoe G, Leask B, Sultan FKPD, Ganesharatnam S, Loh V, Lim JSY. 'I like the people I work with. Maybe I'll get to meet them in person one day': teaching and learning practice development with transnational teaching teams. JET. 2014;40(3):232-50.

31. Heffernan T, Poole D. In Search of "The Vibe": Creating Effective International Education Partnerships. HETIJHEEP. 2005;50(2):223-45.

32. Seah WT, Edwards J. Flying in, flying out: Offshore' teaching in higher education. Aust J Educ. 2006;50(3):297-311.

33. Eldridge K, Cranston N. Managing Transnational Education: Does National Culture Really Matter? J High Educ Pol Manag. 2009;31(1):67-79.

34. Early PC, Ang S. Cultural Intelligence Stanford, California: Stanford University Press; 2003.

35. Smith L. Sinking in the Sand? Academic Work in an Offshore Campus of an Australian University. HERD. 2009;28(5):467-79.

36. Dunworth K. Ideas and realities: Investigating good practice in the management of transnational English language programmes for the higher education sector. Qual High Educ. 2008;14(2):95-107.

37. Stella A. Quality assurance of cross-border higher education. Qual High Educ. 2006;12(3):257-76.

38. Waterval DGJ, Frambach JM, Driessen EW, Scherpbier AJJA. Copy but Not Paste: A Literature Review of Crossborder Curriculum Partnerships. J Stud Int Educ. 2014;19(1):65-85. 

Chapter 8.

Discussion 



\section{Introduction}

This discussion chapter begins with an outline of the main findings in relation to existing research gaps on crossborder medical curriculum partnerships. Subsequently, it elaborates upon three existing debates, including whether crossborder medical curriculum partnerships are a welcome phenomenon in the medical domain. The section thereafter discusses the consequences of our work for the theory and practice of crossborder curriculum partnerships. Suggestions for future research are provided throughout this chapter. The chapter concludes with an overview of the main limitations of this dissertation and a view on the future of crossborder medical curriculum partnerships.

Rq 1: What are the main challenges when establishing and maintaining a crossborder medical curriculum partnership?

Rq 2: How do crossborder medical curriculum partnerships balance standardisation and adaptation?

Rq 3: What are the strategies for establishing and maintaining a sustainable crossborder medical curriculum partnership?

\section{Main findings}

The research questions introduced in the first chapter were examined from five different angles: scientific literature, crossborder medical programme directors, host students, host teachers, and the home institution. The context of all studies was medical curriculum partnerships that explicitly aim for an equivalent learning experience for students at both institutions.

For a comprehensive overview of the main challenges of establishing and maintaining a crossborder medical curriculum partnership (Rq 1), the dissertation begins with a review of the available academic literature. The review outcomes were captured in a framework that identified 13 challenges clustered into four domains (Chapter 2). Three domains are related to the learning environment, i.e., students, teachers, and the curriculum content. The fourth domain, labeled "hard" and soft project management, includes the collaboration and communication processes between partners at various levels. Challenges for students were clustered according to differences in: i) learning behaviour, ii) entry level, and iii) language. Teacher-related challenges were identified due to differences in: i) content and didactical approaches and ii) feelings of ownership. The domain of curriculum challenges was related to differences in: i) local context, ii) attitudes and approaches towards assessments, iii) access to learning resources and support systems, and iv) times zones and work weeks. The challenges identified for general management were: i) relationship and communication between partners, ii) internal commitment at the home institution, iii) contract and business approaches, and iv) quality assurance procedures. Each challenge was analysed along with potential strategies offered in the literature. Furthermore, this review showed that there were 
barely any papers that described this phenomenon in the medical domain. We questioned whether these challenges are also applicable to the medical domain and whether there are additional challenges, and if so, which strategies pertained to crossborder medical curriculum partnerships.

To explore these questions, 13 programme directors from both home and host institutions were interviewed (Chapter 3). On one hand, these interviews confirmed the challenges identified in the literature review. At the same time, programme directors presented a nuanced view of some of the challenges, as they were perceived as less problematic in practice. For instance, programme directors almost uniformly indicated that adapting to the more student-centered learning style as well as the use of English as the language of instruction used in the home curriculum was not a major challenge for the majority of host students. On the other hand, during the interviews, three challenges that specifically pertained to the medical domain were identified. First, the (significant) differences in healthcare systems between the home and host countries created a necessity for many different types of adaptations because the healthcare systems and curriculums are interlinked through assignments, visits, and rotations. Second, programme directors discussed the difficulty of reaching out to clinical teachers who are responsible for workplace-based learning and assessments at the various affiliated hospitals. More specifically, familiarizing them with the teaching philosophy of the home curriculum was a challenge. Third, the interviewees indicated that due to governmental interference on the format, duration, and sometimes content of medical curricula, further adaptations had to be made. These three challenges complicated a comparable learning experience for home and host students in a medical curriculum partnership in addition to the challenges identified by the literature review presented in chapter 2. Despite these additional challenges, programme directors viewed the attainability of medical curriculum partnerships positively, providing that timely and appropriate measures were taken; however, this raised questions regarding to what extent participants were in a position to disclose all their strategically sensitive challenges and experiences. Therefore, the next two studies aimed to expand and triangulate the findings based on teacher (Chapter 4) and student perspectives (Chapter 5).

Host medical teachers play a crucial role in the delivery of the home curriculum. The main teacher-related challenges identified in the framework described in Chapter 2 were: i) although host teachers are not involved in the construction of the materials, they are supposed to deliver it in a similar way; ii) they must adjust to the required teaching philosophy of the home curriculum; and iii) they must communicate and collaborate effectively with their home counterparts. These challenges can impact their feelings of ownership and the way they perceive their roles as teachers. The study presented in chapter 4 revealed the diversity of opinions that host teachers have regarding job responsibilities within crossborder medical curriculum partnerships. The three perceptions among host clinicians and basic science teachers confirmed and also expanded on the teacher-related challenges. For instance, some teachers testified that working with curriculum content from the home institution was not easy but that it exposed them to new ways of teaching, which made it appealing. Other teachers explicitly expressed pride and interest in working with materials from a reputable counterpart. A third group emphasized that some curriculum elements were less suitable for 
the host context. The study did not reveal a structurally "distorted relationship" in the medical partnerships, but it did confirm the importance and complexity of interinstitutional relationships in these partnerships. The results seemed to indicate that host teachers working with new materials were eager to be connected and intertwined with their home counterparts.

In the fourth study (Chapter 5), a survey was distributed to 361 host medical students studying in three host institutions to capture a broad spectrum of experiences. Despite the unavoidable variations in opinions and experiences due to the unique settings, the overall perspective was positive regarding their learning experiences at the host institutions. The vast majority of students felt they were able to adapt within a few months to the different learning style as well as to English as the language of instruction. This finding corresponds with the experiences of teachers and programme directors. On the other hand, the students also identified several opportunities to increase the comparability between the curricula.

One new challenge was mentioned by a large group of students. Many host students indicated that they did not speak the language of the host country and therefore could not communicate easily with host patients. Although there were several attempts to bridge this language barrier, such as the use of translators and intermediating peers, these students felt this significantly impacted the quality of their learning experience, especially during clinical rotations. As the international student community was a common feature of the host institutions' learning community, this is a fourth additional challenge that specifically affects medical curriculum partnerships in addition to the three challenges identified by medical programme directors (Chapter 3) and the general challenges summarized in the framework (Chapter 2).

The fifth study (Chapter 6) zoomed in on the role and organisation of the home institution. This case study provided an illustration of some of the challenges of crossborder curriculum partnerships at the operational level, e.g., managing differences in time zones and work weeks, ensuring internal commitment at the home institution, and establishing relationships and communication channels between partners. This case study showed that each challenge has many facets and requires case-specific remediation strategies. The chapter also suggests ways the home institution could organise its internal project office. For instance, if there is a large cultural distance between partners, the home institution can adapt a more centralised organisation model, and a more decentralised organisation model can be adapted for small cultural distances. Each organisation model has its own benefits and challenges. The decentralised model has a stronger impact on the working procedures and cultural collaboration competences of the home staff, while it potentially increases the changes of miscommunications.

During this research project, it became clear that establishing a crossborder curriculum partnership requires planning, preparation, and multiple strategic decisions for a large range of domains during the different stages of the partnership. By no means should the aforementioned overview be regarded as all-inclusive due to the specificity of the cases; however, addressing these challenges is likely to contribute to a greater comparability and understanding between the two programmes and institutions. 
The second research question, which is related to the ways crossborder medical curriculum partnerships can achieve a balance between standardisation and adaptation, was investigated in all studies. Although the literature reports cases in which the host curriculum is almost an exact replica of the home institution, ${ }^{1}$ according to most scholars, it is an unwise and often unattainable strategy. Medical programme directors as well as teachers emphasized that delivering identical programs was not the aim, although both stakeholders indicated many similarities in medical content and student learning behaviours in both programs. Terms they often used were "equivalence" and "comparability" between home and host curricula. In practice, this refers to the modifications and adaptations in the content of the programme made by host teachers. For instance, written home materials were contextualized to the host context by changing names, places, and assignments. More fundamental examples of adding host country information to the curriculum included additional medical topics as extra cases or complete longitudinal courses. Teachers and programme directors discussed the additional burden in terms of the workload involved for host students, as they sometimes had to study additional information compared to their home-institution counterparts.

Two different student views on the balance between standardisation and adaptation could be distinguished. A number of students expressed that extremely specific home-related learning materials were inappropriate for their careers, while others indicated that the process of adaptation should not be exaggerated. Some host students stated that they liked that educational materials were placed in the context of the home institution and that they experienced little trouble in transferring them to their own context. In general, students preferred learning experiences that were as similar as possible in terms of study facilities and opportunities for the future. They often deliberately chose the host institution for these reasons. It seemed that students were not bothered so much that materials were sometimes offered in a home context, while at a content level, some adaptations to the host context were highly valued.

Interestingly, during the research project, no "red buttons" were encountered that would pinpoint what was regarded as sufficiently comparable. Programme directors in particular emphasized the process of moving towards more comparability each year instead of meeting a selection of hard-cut criteria at a specific point in time. Becoming more comparable is mostly related to student support mechanisms, study resources, learning facilities, and certain non-standardised learning activities within the home curriculum. With respect to curriculum content, there was a movement towards more adaptation each year in a local context. To guide institutions in this standardisation and adaptation process, all partnerships had some type of external review mechanism in place, either a formal quality assurance body or an informal external review body, which offered guidance and identified short-term modifications or adaptations. The general view was quite unilateral: attaining a sufficient degree of comparability seems feasible provided careful planning and proactive measures are taken across multiple domains.

During this research project, the concept of standardisation versus adaptation was gradually questioned as the most suitable framework to guide the curriculum adaptation process within a host institution. In addition to adaptations to the host context and to maintaining a standardised curriculum, a third option emerged. The third approach 
involves the adaptation of the home curriculum being less oriented to the host context and local competences and more oriented to an international context and global competences. An international, more global perspective would be suitable for the more heterogeneous student and teacher population within the host institution that was found in all partnerships. An international medical programme could use the home programme as a foundation and build on the home curriculum content in alternative and complementary ways based on the host's practices. The curriculum context can be contrasted and/or augmented with equivalent practices from other places using the international community of peer students and teachers as fertile soil to produce meaningful learning activities. To return to the analogy of McDonalds (Chapter 1, pg 16): why not make the McWrap and the McBaguette also available to, let's say, Dutch consumers, which is periodically done? By doing so, host institutions would educate graduates who could potentially serve global healthcare.

This third approach resonated with the ambitions of some of the partnerships investigated, but it requires further investigation in terms of the competences that an international medical curriculum should or could aim to develop. This is not an easy route because as Moufahim and Lim $^{2}$ reported in 2014, "the internationalisation of curricula remains extremely rare," and few programmes include non-Western cultural issues and topics within courses ${ }^{3}$; however, given the unique international learning environment within host institutions of crossborder curriculum partnerships, it is a valuable route to explore.

The answers to the third research question (what are the strategies for establishing and maintaining a sustainable crossborder medical curriculum partnership) are mostly found in chapter 7 , which summarizes the findings in 12 concrete tips. Furthermore, chapter 2 lists specific remediating measures for each challenge included in the framework.

\section{Ethical side of crossborder medical curriculum partnerships}

Until now, crossborder curriculum partnerships have been discussed from a pragmatic perspective: analysing challenges and potential strategies to establish a curriculum partnership. The ethical side has been neglected thus far. Establishing a crossborder partnership involves ethical issues that should be addressed. Reflecting on ethical issues is complex because different stakeholders hold different views for what is, or is not, ethical. Furthermore, what is ethical in one country might be unethical elsewhere. ${ }^{4}$ It is beyond the scope of this dissertation to discuss all aspects in greater detail. The work of Wilkins ${ }^{4}$ provides a more elaborate ethical framework in the context of branch campuses. The next sections briefly describe three ethical debates that are particularly related to crossborder medical curriculum partnerships and discuss them in reference to the main dissertation findings. 


\section{Education as a tradable good}

A fundamental argument against the international delivery of education is posited by those who view education as a governmental good. According to this principle, education should be kept outside the whims of the free market because it is primarily viewed as a tool to educate a country's population. ${ }^{5}$ The crossborder provision of education does have a mixed reputation in terms of quality. There are examples of institutions, especially private institutions that operate under the umbrella of crossborder partnerships, whose main interests were short-term gains instead of educational quality. As such, they failed to meet the needs of the host population. ${ }^{6-9}$ According to those who oppose the view of education as a tradable good, education should be excluded from any profit-maximizing behaviour.

On the other hand, proponents of this view stress the potential advantages of crossborder education delivery to host countries and their populations. For example, the Organisation for Economic Cooperation and Development (OECD) and the World Bank advise low and middle-income countries to import tertiary education to fill the gap in quantity and quality that might not be met in the short-term by local institutions. ${ }^{10,11}$ Other authors have argued that the establishment of host institutions not only diversifies the educational system ${ }^{12}$ but also has a presumed positive effect on the quality of existing local providers. ${ }^{13}$ Crossborder providers increase competition, which is expected to lead to higher educational quality as well as to provide a source of educational inspiration. Recently, stakeholders within host countries explicitly stated that the potential positive effects of crossborder curriculum partnerships, such as more choice and increased quality of higher education in the host country, outweigh the potential risks. ${ }^{15}$ Furthermore, proponents assert that existing voluntary codes and guidelines at regional and global levels protect students and other stakeholders from low-quality provisions and disreputable providers as well as encourage the development of quality crossborder higher education that meets human, social, economic, and cultural needs. ${ }^{14}$

The concerns regarding rogue providers have become minimal, as more countries are establishing frameworks that close the jurisdictional mazes of the net of this relatively new phenomenon. Initially, the crossborder provision of education was neglected by host and home quality assurance agencies. Recently, McBurnie and Ziguras ${ }^{15}$ argued that crossborder providers are often even more regulated and reviewed than domestic providers. This issue was also voiced by one of the programme directors. Ruling out curriculum partnerships based on concerns of potential low-quality education seems a bit rash; however, long-term follow-up studies on the alleged advantages are highly recommended. Hodges, et al. ${ }^{16}$ suggestion that a broader comparative research programme is needed to examine long-term impacts on host country healthcare systems, and their graduates' professional skills should be supported. Furthermore, it would be worthwhile to investigate the claim that the crossborder provision of education has a positive impact on existing local providers.

In any case, curriculum partnerships should be cautious and prudent in their marketing and communication approaches. For instance, presenting an overly positive image of the partnership, especially when host students' learning experiences (still) 
differ considerably from those of home students in terms of learning resources and support facilities, can be an unethical way to attract students. This should be acknowledged rather than being concealed by skilful marketing and recruitment announcements.

\section{Dangers of ethnocentricity}

The internationalisation of education has been criticized, as it has been noted to give dominance to Western academic perspectives, knowledge creation, and language.17, 18 Crossborder curriculum partnerships can even be regarded as a form of neocolonialism when Western home institutions export their educational expertise to a non-Western setting. ${ }^{19-21}$ This may lead to a process of uniformity in educational formats worldwide and to the spread of educational principles that is not matching with local learning behaviours.

Other scholars take a more pragmatic stance. They do not reject internationalisation at face value but caution against what is referred to as the dangers of ethnocentricity in curriculum partnerships. ${ }^{22}$ Similar warnings are expressed in the medical domain, where diseases, prevalence, and the cultural approach to patients, for example, might differ globally. ${ }^{16}$ Medical educators should be aware of this pitfall, especially in the context of a crossborder curriculum partnership. ${ }^{23}$ Interestingly, these criticisms are only voiced by Western authors.

Globalisation is not new; it has occurred throughout history, and cultures have always been influenced and adapted by others. Djerasimovic ${ }^{24}$ argued that relationships in educational partnerships should be perceived as fluid, with both sides using the partnership to meet their objectives. Also, in medical education, Frambach, et al. ${ }^{25}$ showed that there is an inevitable constant interaction between the learning model used and the cultural environment. Hoare ${ }^{22}$ found that the host students of a curriculum partnership were "tacitly decontextualizing the course content for themselves. This was occurring both individually and during in-class discussions, sometimes independent of lecturer intent or realisation (p.282)." This research seems to indicate that crossborder education cannot simply be viewed as a form of cultural or ideological imperialism.

During the studies of this dissertation, the impression was developed that students, staff, and programme directors were aware of the dangers of uncritically replicating the partner's institute. They claimed to assess the materials based on the merits it had to the host context. In this regard, it is relevant to note that all included partnerships were initiated by host actors. Furthermore, the host institutions mainly employed local academic faculty for both curriculum management and teaching. Therefore, to reject crossborder curriculum partnerships based on the argument of ethnocentricity would assume incompetence among host decision makers. It would also imply that Western countries are better able to decide what would be best for receiving countries and that receiving countries would be "blind" to the dangers and simply assimilate to whatever is provided by their Western partner. 
The fear of ethnocentricity might also be partly relieved if the assumption that curricula should be identical is replaced with comparability. Comparability entails the possibility of differentiation due to cultural and/or contextual differences. It provides an imaginary space to substantially adapt a home curriculum to the host context. Nevertheless, medical educators should be cautious because ethnocentricity is a pitfall that can easily be overlooked, as it plays out in details. This issue deserves further research, such as studies on the potential impact of English as a second language and on cultural differences in the comparison of assessment papers between institutions.

\section{Dangers of brain drain}

Another ethical dilemma related to crossborder curriculum partnerships is the issue of brain drain. Brain drain is the emigration of highly trained or qualified people from a particular country. According to estimates of the World Health Organisation (WHO), the world faces a shortage of approximately 4.3 million healthcare workers. ${ }^{26}$ Consequently, there is a movement of health professionals from low and middle-income countries towards Western countries. This flow is cultivated by "pull factors," including targeted recruitment efforts by wealthy destination countries, in combination with "push factors", such as low wages, unstable working environments, and weak public health systems in source countries. ${ }^{26}$

Crossborder curriculum partnerships potentially contribute to brain drain because host students often explicitly choose the host institution based on the reputation and curriculum of the home institution. If the home country has a deliberate "under-supply" of medical professionals, there is a risk that these types of partnerships merely serve to fulfil a need for doctors in the home country. By doing so, crossborder curriculum partnerships may not contribute to and could even weaken the host country's healthcare system. Therefore, the WHO adopted a voluntary code of practice, including ethical norms and legal and institutional arrangements, to prevent brain drain. This code forbids deliberate pull activities. ${ }^{27}$

Although a proportion of graduates might pursue a (temporary) international medical career outside the host country, the provision of high-quality education to "glocals"-individuals with global aspirations and local experiences ${ }^{28}$ - would at the same time prevent some host country students from studying in Western countries. ${ }^{29}$ Furthermore, any partnership that educates high-quality graduates for the host country leads to an increase supply of doctors that would most likely dampen the pull-effect on medical professionals from lower-income neighboring countries to the host country. Other arguments made to counterbalance the dangers of brain drain point to the longterm effects of curriculum partnerships, such as increased clinical research endeavours that are expected to benefit the local healthcare system.

In this research project, a substantial part of the students expressed the ambition to continue their careers in the home country or in another Western country, while another substantial group of students from the host country intended to stay. A third group, most of whom were not born in the host country, expected to return to their region of birth. Overall, a diversified picture emerged that deserves follow up research 
on the future career development of crossborder curriculum graduates. The brain drain argument is highly case-specific because its impact and validity depend on the countries/regions involved in the particular partnership and their (expected) shortage or surplus of medical graduates. Decision makers on both sides play a role, and they should investigate this concern. ${ }^{9}$

\section{Towards sustainable partnerships}

If conditions for the high-quality provision of education are met, such as those presented in this dissertation, and if ethical considerations are taken into account, there seems to be a future for crossborder curriculum partnerships in the medical domain. Any sustainable crossborder partnership would not only have comparable learning facilities and student support structures, but also an aligned understanding of the underlying principles of the curriculum. Reaching this deeper understanding is complex. In this regard, Boteju and Burnapp ${ }^{30}$ noted that all those concerned (including staff, students, directors and quality assurance managers) may create programmes that do not actually incorporate that system in its essential features." This concern resonated with the remarks from respondents in the studies of this research project; especially reaching out into the hearts and minds of host teachers, managers, and parents is an ongoing challenge.

Quality assurance bodies play an important role in stimulating and guiding partnerships in a more balanced direction. The current practice has been to establish standards and guidelines that navigate partners and ensure a minimum threshold of quality; however, quality is notoriously difficult to define. Assuming a shared definition of quality existed, Coleman ${ }^{31}$ pointed to the disadvantages of this approach, as standards and guidelines offer little room for legitimate differences among institutions' resources and cultural values and practices. To ensure high-quality learning experiences for all students, attention needs to be paid to the process: the way in which partners interact and engage collaboratively over time, to achieve the best possible outcomes for students. According to the Higher Education Academy's research findings, the ongoing reciprocal interactions between home and host staff, between staff and students, and between students inevitably shape a partnership and thus contribute to its success or failure. ${ }^{32} \mathrm{~A}$ quality assurance framework should examine ways in which teachers, directors, and higher management interact and seek contextually appropriate solutions. In other words, the quality assurance framework should focus more on the means rather than on the ends. ${ }^{33}$

In recent years, studies have begun to focus on promoting collaboration between teachers in the crossborder provision of education. Less than a decade ago, flying faculty from the home to the host institution was the main model, but this is now firmly in decline, giving way to partnerships that build local capacity. ${ }^{34}$ The concept of communities of practice can be used as a framework to further develop collaborative partnerships. Keay, et al. ${ }^{35}$ argued that bilateral inter-faculty communities of practice that collaboratively develop educational products could improve the quality of curriculum 
delivery. Based on this perspective, these communities offer a platform for the host faculty to make suggestions for the improvement of the delivery and quality of the home institution's curriculum. Through these communities of practice, the unbalanced division of knowledge regarding the curriculum could be resolved. Future research could focus on how these new models can take shape and how to create teams of host and home teachers.

\section{Strengths and limitations}

This dissertation has a number of strengths and limitations. First, a merit of this study is that it addresses a relatively new and rather unexplored trend in medical education. The explorative approach used to focus on challenges that were mentioned for all institutions in a research context provided a comprehensive overview of challenges and strategies that might occur in medical partnerships; however, case-specific circumstances must be taken into account when assessing the impact of a challenge and the applicability of a strategy. Furthermore, the partnerships differed in their setups and collaboration intensities, which potentially influenced the findings.

The results provide guidance for those embarking on comparable types of partnerships. The identified challenges and strategies are by no means all-inclusive. Although five different angles are included, some factors remain unexplored, such as the experiences of host graduates or management challenges faced within the host organisation. Furthermore, each challenge deserves a further in-depth investigation on the potential educational impacts. Therefore, these studies should be considered a first step in exploring the experiences and challenges faced by students and staff in medical curriculum partnerships.

Second, regarding the study's generalisability, it should be noted that the majority of the data were collected from the same region, the Middle East. Because the cultural norms and the nature of the local healthcare setting in this region undoubtedly affected participants' responses, caution is advised when applying the findings to other contexts.

Finally, as a researcher and a project manager of a crossborder medical curriculum partnership, an overly optimistic presentation of crossborder curriculum partnerships and their challenges and outcomes may be proposed. To minimise this bias, authors were included who were not directly involved with curriculum partnerships, and the possibility of bias was explicitly addressed during interpretation and writing up of the results, and reflection and discussion sessions with all authors. On the other hand, the practical experience with crossborder curriculum partnerships added to the triangulation of perspectives and contributed to a rich identification and conceptualisation of the issues at hand when establishing and maintaining a crossborder curriculum partnership in the medical field. 


\section{A view on the future}

A promising future for the crossborder provision of education begins with a strong vision on internationalisation from the highest management levels. Do university leaders consider themselves, as most do now, an institution rooted in one geographic location that offers academic programmes to travelling students? Or do they view themselves as providers of high-quality products that should be made available to any interested student population? Though understandable based on the past, the former view might not be a sustainable strategy given the possibilities in the near future in the area of communication technology and an increasing globalised and interconnected world. For the latter view, a university should fundamentally re-evaluate its internationalisation strategy in which currently most leaders focus on internationalisation at home by means of a pull-theory of attracting students to the home campus. Leaders could simultaneously develop a push-strategy, where high-quality education is provided to the world. This shift in "raison d'être" also entails a shift from viewing curriculum mobility as a source of revenue to considering it an integrated core mission of the institution.

Likewise, curriculum partnerships may be viewed as the first stepping stone that may further develop into multi-campus university models. ${ }^{36}$ At a multi-network university, there is no distinction between home or host institutions but rather a network of global centers for research and education. ${ }^{37}$ In this form of internationalisation, curricula are developed, delivered, and evaluated by an international group of teachers offered to an international group of students. Thus, what began as a unidirectional model from a home to a host institution would become a linked, networked global experience involving multiple partners. 


\section{References}

1. Kinser K, Lane JE. Managing the oversight of international branch campuses in higher education. HEMP. 2014;24(3).

2. Moufahim M, Lim M. The other voices of international higher education: an empirical study of students' perceptions of British university education in China. Glob Soc Educ. 2014:1-18.

3. Bennett R, Kane S. Internationalization of U.K. University Business Schools: A Survey of Current Practice. J Stud Int Educ. 2011;15(4):351-73.

4. Wilkins S. Ethical issues in transnational higher education: the case of international branch campuses. Stud High Educ. 2015:42(8):1385-400.

5. Tilak JBG. Higher education: a public good or a commodity for trade? PROSPECTS. 2008;38(4):449-66.

6. Gerson J. Inflation of grades is widespread, study says. 2010. [Internet] Available from [https://www.thenational.ae/uae/education/inflation-of-grades-is-widespread-study-says-1.490104]; Accessed January 2017.

7. Altbach PG. Franchising-The McDonaldization of Higher Education. Internation Higher Education. 2012;66:7-8.

8. Burgis-Kasthala S, Kamiza S, Bates I. Managing national and international priorities: a framework for lowincome countries. Med Educ. 2012;46(8):748-56.

9. OECD, World Bank. Cross-border tertiary education a way towards capacity building. 2007. [Report] Available from [http://hdl.handle.net/10986/6865]; Accessed February 2012.

10. Scherrer C. GATS: long-term strategy for the commodification of education. Rev Int Polit Econ. 2005;12(3):484-510.

11. Worldbank. Constructing Knowledge Societies: New Challenges forTertiary Education. 2002. [Report] Available from [http://siteresources.worldbank.org/INTAFRREGTOPTEIA/Resources/Constructing_Knowledge_ Societies.pdf]; Accessed January 2017.

12. Gottlieb EE, Yakir R. Extensions of Foreign Universities in Israel: Transnational Education, a Form of Privatization? Internation Higher Education. 1998;11:13-4.

13. van der Wende MC. Globalisation and Access to Higher Education. J Stud Int Educ. 2003;7(2):193-206.

14. Vincent-Lancrin S, Pfotenhauer S. Guidelines for Quality Provision in Cross-Border Higher Education: Where Do We Stand? 2012. [Report] Available from [http://www.oecd-ilibrary.org/education/guidelinesfor-quality-provision-in-cross-border-higher-education_5k9fd0kz0j6b-en]; Accessed September 2013.

15. McBurnie G, Ziguras C. Global Trends in Quality Assurance for Transnational Education. In: Quality Assurance of Transnational Higher Education The Experiences of Australia and India. Edited by Stella A, Bhushan S. Delhi: National University of Educational Planning and Administration; 2011.

16. Hodges BD, Maniate JM, Martimianakis MA, Alsuwaidan M, Segouin C. Cracks and crevices: Globalization discourse and medical education. Med Teach. 2009;31(10):910-7.

17. Bashshur M. Observations from the Edge of the Deluge: Are We Going Too Far, Too Fast in Our Educational Transformation in the Arab Gulf? In: Trajectories of Education in the Arab World: legacies and challenges. Edited by Abi-Mershed O. New York: Routledge; 2010: 247-72.

18. Rostron M. Liberal arts education in Qatar: intercultural perspectives. Intercult Educ. 2009;20(3):219-29.

19. Bleakley A, Brice J, Bligh J. Thinking the post-colonial in medical education. Med Educ. 2008;42(3):26670.

20. Schapper JM, Mayson SE. Internationalisation of curricula: an alternative to the Taylorisation of academic work. J High Educ Pol Manag. 2004;26(2):189-205.

21. Schwarz MR. Globalization and medical education. Med Teach. 2001;23(6):533-4.

22. Hoare L. Transnational Student Voices: Reflections on a Second Chance. J Stud Int Educ. 2011;16(3):27186.

23. Whitehead CR. On gunboats and grand pianos: medical education exports and the long shadow of colonialism. Adv Health Sci Educ Theory Pract. 2016;21(1):1-4.

24. Djerasimovic S. Examining the discourses of cross-cultural communication in transnational higher education: from imposition to transformation. JET. 2014;40(3):204-16.

25. Frambach JM, Driessen EW, Chan LC, van der Vleuten CP. Rethinking the globalisation of problem-based learning: how culture challenges self-directed learning. Med Educ. 2012;46(8):738-47.

26. Taylor AL, Hwenda L, Larsen B-I, Daulaire N. Stemming the Brain Drain - A WHO Global Code of Practice on International Recruitment of Health Personnel. NEJM. 2011;365(25):2348-51. 
27. Kupfer L, Hofman K, Jarawan R, McDermott J, Bridbord K. Strategies to Discourage Brain Drain. Bulletin of the World Health Organization. 2004;82(8):616-9.

28. Choudaha R. The rise of 'glocal' students and transnational education. 2012. [Blog] Available from [https://www.theguardian.com/higher-education-network/blog/2012/jun/21/opportunities-intransnational-education]; Accessed August 2014.

29. Ziguras C, Gribble C. Policy Responses to Address Student “Brain Drain”. J Stud Int Educ. 2015;19(3):24664.

30. Boteju D, Burnapp D. Growth of transnational education. In: The strategic implications of different forms of international collaboration in Higher Education. Edited by Burnapp D, Zhao W, Boteju D, Jament J, Feng Y, Li S, Powis C, Klimes C, Mallam-Hassam Y. Northampton: The University of Northampton; 2011: 22-34.

31. Coleman D. Quality assurance in transnational education. J Stud Int Educ. 2003;7(4):354-78.

32. O' Mahony J. Enhancing student learning and teacher development in transnational education. 2014. [Report] Available from [https://www.heacademy.ac.uk/system/files/resources/enhancingtne_final_080414.pdf]; Accessed February 2017.

33. Quality Assurance Agency for Higher Education. Code of practice for the assurance of academic quality and standards in higher education. Section 2. Collaborative provision and flexible and distributed learning (including e-learning). 2010. [Report] Amplified version of the second edition 2010. Available from [http://www.bbk.ac.uk/linkinglondon/resources/apel-credit-

resources/pub_Nov2010_QAA_COP_section_2_HE_guidance.pdf]; Accessed August 2017.

34. Beer J. We need a new type of internationalisation in education. 2016. [Internet] Available from [https://www.timeshighereducation.com/blog/we-need-new-type-internationalisation-education]; Accessed December 2016

35. Keay J, May H, O’ Mahony J. Improving learning and teaching in transnational education: can communities of practice help? JET. 2014;40(3):251-66.

36. Wildavsky B. The great brain Race. New Jersey: Princeton University Press; 2010.

37. Skidmore M, Longbottom J. The future of transnational education. 2011. [Internet] Available from [http://www.obhe.ac.uk/newsletters/borderless_report_november_2011/future_transnational_educatio n]; Accessed November 2011. 

Chapter 9.

Summary 

Chapter 1 introduces the main concept of this thesis: crossborder curriculum partnerships (CCP). The essence of a CCP is to transpose a curriculum from the location where it was developed (the home institution) to another, crossborder location where it will be delivered (the host institution). Crossborder curriculum partnerships can take different legal forms, ranging from a brand-new physical campus to an agreement with an existing institution in the host country. A common feature is that both partners aim to deliver the same learning experience to students at the home and the host institution.

This specific form of internationalisation is widespread in the English-speaking world and is rapidly becoming more popular. In addition, a growing number of institutions in emerging economies, such as India and China, are establishing crossborder curriculum partnerships elsewhere in the world.

The rapid growth of CCP has been fuelled by advances in IT and the accessibility of international air travel, which has made it much easier to establish international collaboration. Another factor behind the rise of CCP is the urgent demand, particularly in Southeast Asia, for top quality education that does not require students to leave their native region.

CCPs are challenging from a pedagogical perspective, because their purpose is to ensure that the curriculum in the host institution is as similar to the curriculum in the home institution as possible, despite differences in legislation, organisational environment, resources, and teaching and learning cultures. The partners seek to strike a balance between standardisation on the one hand - to ensure that the learning experience is close to identical - and adaptation on the other - to respect the aforementioned local factors as much as possible. The second challenge, and one that influences the student learning experience, is to manage the unequal dissemination of knowledge across the curriculum. After all, the curriculum is developed by the home institution but it is taught and organised by the host teachers and programme directors, and that may affect the way in which it is implemented.

The fact that these pedagogical challenges have largely been ignored in the literature and the lack of research on CCP in the medical domain have raised the following three research questions: What are the main challenges when establishing and maintaining a crossborder medical curriculum partnership? How do crossborder medical curriculum partnerships balance standardisation and adaptation? What are the strategies for establishing and maintaining a sustainable crossborder medical curriculum partnership?

Chapter 2 examines the first and third research questions in greater depth and describes the methods and results of a literature review focusing on the challenges and strategies associated with establishing and managing a crossborder curriculum partnership. The terms 'crossborder education', 'transnational education' and 'offshore education' were used to search all publications issued up to 2012 in Web of Science, Google Scholar, ERIC, PubMed and PsycInfo.

The articles that emerged were then subjected to an iterative coding process in order to analyse the pedagogical challenges and any useful strategies leading to a successful crossborder curriculum partnership. The result was summarised in a theoretical framework consisting of 13 factors grouped into four domains: (i) student-related 
challenges, (ii) teacher-related challenges, (iii) challenges related to curriculum transposition and (iv) management challenges.

The study's conclusion is that simply copy-pasting the home institution's curriculum into the host institution is a recipe for failure. Overcoming the above-mentioned challenges requires a package of preventive measures within the various domains. A crossborder curriculum partnership also demands a culturally sensitive implementation strategy.

Chapter 3 explores the extent to which the theoretical framework applies to crossborder medical curriculum partnerships. It therefore supplements the findings described in Chapter 2. Six crossborder medical curriculum partnerships were identified in which a home institution's curriculum was implemented at a host institution. Interviews were conducted with the programme directors of each of these institutions (both home and host) using a questionnaire based on the theoretical framework.

The results revealed four context-related differences that must be overcome in a CCP: differences in health care systems, differences in political and legislative systems, differences in the teaching and learning environments, and the interaction between the partners at varying levels. Many of the factors identified in the theoretical framework (Chapter 1) also reappeared. This study makes three main contributions to the literature. To begin with, it shows that additional regulatory measures issued by the host country's government make it difficult for the host institution to offer a medical curriculum with a length and content comparable to those of the home institution's. Second, the programme directors noted that the home curriculum was closely intertwined with the home country's national health care system. This required the host institution to make extra adjustments to the teaching methods and activities. Third, it was especially challenging to influence the host teachers' teaching style, given that clinical teachers in medical curricula tend to be practising physicians, most of whom have only limited time available for teaching.

None of the partnerships studied aimed to have identical curricula in both institutions; instead, they allowed for integration of the host country's national health care system by changing, expanding or adding cases, or by adding an additional longitudinal course.

The three medicine-specific challenges described above made it especially difficult for the partners to deliver an equivalent learning experience. Nevertheless, the programme directors indicated that a crossborder medical curriculum partnership is certainly possible if the right measures are put into place.

Chapter 4 focuses on the role of the teacher at the host institution in a crossborder curriculum partnership, building on the findings discussed in Chapters 2 and 3. The previous two studies revealed a number of potential teacher-related challenges. For example, it became clear that for a partnership to be successful, the teachers at the host institution must have a sense of ownership. Because they are not involved in developing the curriculum material, their sense of ownership may in fact be weaker. Host teachers also have less autonomy because they rely on the support of the home institution and its willingness to cooperate. Finally, the teachers at the host institutions are expected to adapt their teaching style to the student-centred educational philosophy 
typical of the home institutions. All these challenges may affect the quality of education at the host institution.

A Q-sort performed as part of the study revealed three viewpoints prevalent among host teachers. The first confirmed that host teachers often find it difficult to work with material provided by home institutions because it is unfamiliar to them. At the same time, host teachers find it gratifying to work with new teaching methods. The second viewpoint emphasises pride and the desire to work more closely with teachers at the home institution. The third viewpoint reflects feelings of concern about the applicability and suitability of the home curriculum in de host context.

These viewpoints attest to the importance and complexity of inter-institutional relationships in these partnerships. The findings further appear to suggest that, besides throwing up challenges, the partnerships also offer opportunities because the host teachers are determined to maintain their connection to and stay in touch with the community of home teachers.

Chapter 5 builds on the observed student-related challenges in crossborder medical curriculum partnerships. It is notable how little research has been conducted into student experiences in this form of internationalisation. After all, students can offer insights into the degree of equivalence between the learning experience on both sides (RQ 2) and how they perceive the challenges inherent in this type of partnership (RQ 1).

The student-related challenges that emerged in the previous studies were integrated into a questionnaire consisting of 31 items covering six domains. The six domains are: transition from secondary school, language, occupational suitability, reasons for selecting host institution, career planning and general level of satisfaction.

The findings of this study indicate that students do not find it problematical to have English as the language of instruction. They also do not see the transition to a studentcentred educational concept as difficult. Their views are consistent with those of the programme directors in Chapter 4. Most host students are satisfied with and feel positive about their learning experience. They also identified ways to improve their learning experience.

A noteworthy finding of this study was that the host institution's heterogeneous student population, the result of the unique appeal of crossborder curriculum partnerships, can lead to difficulties in workplace learning. More specifically, some students did not speak the language of the host country, making it impossible for them to communicate directly with patients and/or staff. This was a serious challenge that each of the partnerships resolved in its own way.

Chapter 6 offers a detailed description of the pedagogical and organisational challenges involved in a CCP from the vantage point of the home institution. The chapter uses a case study to identify various practical challenges. Examples include the transfer of the curriculum material, in particular material that teachers had not committed to writing; third-party ownership of e-learning tools embedded in the curriculum; and the challenge of synchronising the two curricula despite frequent major and minor changes and updates.

The study shows that transferring material and providing pedagogical training does not automatically cause host teachers to internalise and apply the philosophy behind 
student-centred teaching methods. For example, it is difficult to align a student-centred assessment system that places considerable emphasis on feedback and formative assessment with the requirements of local quality assurance boards or with the expectations of local teachers and students, who tend to set great store by summative marks.

The study also describes the new working processes that the home institution must integrate into its own organisational structure. It introduces two models situated at opposite ends of a continuum. At one end is a centralised model in which a core team of project managers coordinates and initiates most of the communication and information flows. At the other end is a decentralised management model in which many direct lines of communication run between the two institutions. The advantage of the decentralised model is that home institution staff quickly get involved, updates and changes can be communicated directly, and a platform emerges for channelling pedagogical concepts and suggestions of greater and lesser significance back to the home institution. The disadvantages of this management model are that it has implications for the home staff's roles and makes heavier demands on intercultural communication and cooperation skills. The chapter argues that a centralised management model is likely to be more successful when there are major cultural differences between the partners, but nevertheless advocates a gradual move towards a decentralised management model.

Chapter 7 focuses on the third research question posed in this thesis. It offers 12 tips for creating lasting crossborder medical curriculum partnerships. These tips, the product of synthesising the foregoing studies, are clustered into four domains: governance, curriculum, learning environment and relationship management.

In the first domain, we advise developing a master plan in the preparatory phase to steer cooperation in the right direction. The master plan should outline the expectations and responsibilities of both partners in the various contexts. The second tip is to set up a robust internal quality assurance system that monitors the aims of the partnership and allows for changes where necessary. The third tip is to prepare the home institution's staff and organisation for the partnership, in addition to the host institution staff.

In the second domain, the curriculum, the first tip is to tailor the content to the context of the host institution by making small contextual changes, adding context specific cases and integrating host-specific learning pathways. The second tip is to deal systematically with the technical and logistical factors involved in transposing, updating and monitoring the curriculum content. A medical curriculum generally consists of many different teaching formats and incorporates tools that the home institution does not own. The third tip is for partnerships to capitalise on the host institution's unique international learning environment by developing an educational approach that helps students acquire international competencies.

There are several tips on how to enhance the learning environment. One is to manage the inevitable culture shock that some students will experience upon transitioning to the new educational concept. Another is to pay close attention to the transition to English as the language of instruction and to any language barrier between students and patients in the clinical phase. The final tip highlights the importance of a robust 
competency training programme for all staff members and outlines what such a programme might entail.

The first tip for managing the partnership relationship is to set up communities of practice as soon as possible allowing teachers to communicate with each another and share pedagogical concepts. We also recommend minimising inevitable misunderstandings during the many instances of intercultural cooperation by promoting cultural intelligence. The third tip stresses the importance of voluminous communication between project coordinators, subject teachers and senior management.

Chapter 8 begins with a summary of the research questions formulated in Chapter 1. Subsequently, the focus is shifted to three ethical issues that play a role in crossborder medical curriculum partnerships but have not been addressed thus far: education as a commodity, the hazards of ethnocentrism and the risks of 'brain drain'. The chapter then considers a future in which crossborder medical curriculum partnerships place greater emphasis on an equivalent bilateral flow of information, with pedagogical advantages for both institutions. Curriculum partnerships of this kind could spearhead a genuinely international university. The chapter concludes with a summary of the main limitations of this dissertation and suggestions for further research taking the ethical issues, limitations and future projections into account. 

Chapter 10.

Samenvatting 

Hoofdstuk 1 introduceert crossborder curriculum partnerschappen (CCP), het centrale concept van dit proefschrift. Een CCP is gedefinieerd als de overdracht van een curriculum van de locatie waar het is ontwikkeld - het home instituut - naar een andere, grensoverschrijdende, locatie, waar het curriculum wordt onderwezen -het host instituut. Er bestaan verschillende (wettelijke) constructies en manieren waarop een crossborder curriculum partnerschap kan worden vormgegeven, variërend van het opzetten van een nieuwe fysieke campus tot een overeenkomst met een reeds bestaand instituut in het host land. Het gemeenschappelijke element is dat beide partners streven naar een gelijkwaardige leerervaring voor zowel home als host studenten.

Deze vorm van internationalisering is wijdverspreid in Angelsaksische landen, en sterk groeiende. Daarnaast zijn er steeds meer voorbeelden van instituten in economisch opkomende landen zoals India en China die crossborder curriculum partnerschappen opzetten elders in de wereld.

De sterke groei van CCP wordt mogelijk gemaakt door de vooruitgang in informatie, communicatie technologie en de toegankelijkheid van het internationale luchtverkeer, waardoor internationale samenwerkingen veel gemakkelijker zijn geworden. Een andere stimulans voor CCP is de enorme toename van de vraag, in het bijzonder vanuit Zuidoost Azië, naar hoogwaardig onderwijs waarvoor studenten hun geboorteregio niet hoeven te verlaten

CCP's zijn uitdagend vanuit een onderwijskundig perspectief, omdat zij ervoor moeten zorgen dat het curriculum in het host instituut zoveel mogelijk lijkt op het curriculum in het home instituut, terwijl ze tegelijkertijd te maken kunnen hebben met een verschillende wetgeving, organisatorische omgeving, resources, leercultuur en doceercultuur. Partners zoeken hierin een balans tussen enerzijds standaardisatie, om de leerervaring zo identiek mogelijk te maken, en anderzijds adaptatie, om de voornoemde lokale factoren zoveel mogelijk te respecteren. Een tweede uitdaging, die van invloed is op de leerervaring van studenten, is het managen van de ongelijke verdeling van kennis over het curriculum. Het curriculum is immers ontwikkeld door het home instituut, maar wordt onderwezen en georganiseerd door host docenten en programma directeuren, dit heeft mogelijk een uitwerking op de wijze waarop het curriculum wordt geïmplementeerd.

Het weinig aandacht schenken aan deze onderwijskundige uitdagingen in de literatuur en het ontbreken van onderzoek naar CCP in het medisch domein, hebben geleid tot de volgende drie onderzoeksvragen: Wat zijn de voornaamste uitdagingen bij het opstarten en implementeren van een crossborder medisch curriculum partnerschap? Hoe gaan crossborder medische curriculum partnerschappen om met de balans tussen standaardisatie en adaptatie? Welke strategieën zijn er om een van een crossborder medisch curriculum partnerschap op te starten en te managen?

Hoofdstuk 2 gaat dieper in op de eerste en derde onderzoeksvraag en beschrijft de werkwijze en de resultaten van een literatuuronderzoek naar uitdagingen en strategieen bij het opzetten en managen van een curriculum partnerschap. De databases Web of Science, Google Scholar, ERIC, PubMed, en PsycInfo zijn onderzocht op de termen 'crossborder, transnational en offshore education' tot 2012. 
De geincludeerde artikelen zijn via een iteratief coderingsproces geanalyseerd op onderwijskundige uitdagingen en eventueel bruikbare strategiën voor een succesvol crossborder curriculum partnerschap. Het resultaat is samengevat in een theoretisch raamwerk dat bestaat uit 13 uitdagingen, verdeeld over 4 domeinen: (i) student en (ii) docent gerelateerde uitdagingen, (iii) uitdagingen met betrekking tot de overdracht van het curriculum en (iv) management uitdagingen.

De conclusie van dit onderzoek is dat het eenvoudigweg kopieren van een curriculum van een home instituut naar een host instituut een recept blijkt voor falen. Het overwinnen van de hierbovengenoemde uitdagingen vereist een pakket aan preventieve maatregelen binnen de verschillende domeinen. Daarnaast vereist een crossborder curriculum partnerschap een cultureel sensitieve implementatie strategie.

In Hoofdstuk 3 wordt onderzocht in welke mate het theoretisch raamwerk van toepassing is op medisch curriculum partnerschappen en vormt hierdoor een aanvulling op de bevindingen van hoofdstuk twee. Hiervoor zijn zes medische curriculum partnerschappen geïdentificeerd waarbij het curriculum van een home instituut geïmplementeerd is in een host instituut. Van elk van deze partnerschappen zijn de programma directeuren van zowel home- als host instituut geïnterviewd aan de hand van een vragenlijst die gebaseerd is het theoretisch raamwerk.

De onderzoeksresultaten laten vier contextuele verschillen zien die overbrugd dienen te worden bij ccp: verschillen in gezondheidszorgsysteem, politieke en wetgevende systemen, verschillen in de leer en doceer omgeving en de interacties tussen partners op verschillende niveaus. Hierbij komen veel van de factoren uit het theoretisch raamwerk van hoofdstuk 1 terug. Dit onderzoek levert drie hoofdbijdragen aan de literatuur: ten eerste laat het zien dat het aanbieden van een vergelijkbaar medisch curriculum in het host instituut wat betreft duur en inhoud bemoeilijkt wordt door additionele regelgeving vanuit de overheid. Ten tweede is door programma directeuren opgemerkt dat een home curriculum een hoge mate van vervlechting kent met het nationale gezondheidszorg systeem. Dit vereist extra aanpassingen in onderwijsvormen en activiteiten. Ten derde is het beïnvloeden van de gewenste doceerstijl van host docenten extra uitdagend, omdat in een medisch curriculum de klinische docent een praktiserend arts is, van wie de meesten slechts een klein gedeelte van hun tijd beschikbaar hebben voor onderwijs.

Geen enkele van de onderzochte partnerschappen streeft naar een identiek curriculum: het gezondheidszorg systeem van het host land wordt in het curriculum geïntegreerd via aanpassingen, uitbreiding of toevoeging van casuïstiek, of het toevoegen van een longitudinaal additioneel traject.

Het aanbieden van een gelijkwaardige leerervaring wordt door bovenstaande drie geneeskundespecifieke uitdagingen extra bemoeilijkt. Desondanks geven programma directeuren aan dat, mits de juiste maatregelen worden genomen, een medisch crossborder curriculum partnerschap mogelijk is.

In hoofdstuk 4 staat de rol van de docenten van het host instituut in een crossborder curriculum partnerschap centraal en bouwt daarmee voort op de bevindingen uit zowel hoofdstuk 2 als 3. De voorgaande twee studies hebben enkele potentiële docentgerelateerde uitdagingen aan het licht gebracht. Zo is gebleken dat het creëren van eige- 
naarschap bij de docenten van het host instituut een belangrijke voorwaarde is voor een succesvol partnerschap; doordat zij niet betrokken zijn geweest bij de ontwikkeling van het curriculum materiaal, hebben zij wellicht een lager gevoel van eigenaarschap bij het curriculum. Ook zijn host docenten minder autonoom, omdat zij afhankelijk zijn van de ondersteuning en bereidheid om samen te werken vanuit het home instituut. Ten slotte wordt van de docenten van de host instituten verwacht dat zij in staat zijn hun didactische methoden aan te passen aan de student gecentreerde onderwijsfilosofie die kenmerkend is voor de home instituten. Al deze uitdagingen kunnen mogelijk een uitwerking hebben op de onderwijskwaliteit in het host instituut.

Het onderzoek aan de hand van een Q-sort bracht drie percepties die leven onder host docenten aan het licht. De eerste perceptie bevestigde dat het werken met materiaal van home instituten vaak als moeilijk wordt ervaren doordat het onbekend is voor host docenten. Tegelijkertijd vinden docenten het ook voldoening geven om te werken met nieuwe vormen van onderwijs. Bij een tweede perceptie ligt de nadruk op trots en een behoefte om intensiever samen te werken met docenten van het home instituut. Een derde perceptie weerspiegelde gevoelens van bezorgdheid over de toepasbaarheid en geschiktheid van het home curriculum in de host context.

Deze percepties tonen eens te meer het belang en de complexiteit van de interinstitutionele relaties in deze partnerschappen. Tevens lijken de bevindingen te suggereren, dat naast de uitdagingen, er ook kansen liggen omdat de host docenten erop gebrand zijn om verbonden te zijn en in contact te staan met de home docenten gemeenschap.

Hoofdstuk 5 bouwt voort op de eerder geconstateerde studentgerelateerde uitdagingen van een medisch crossborder curriculum partnerschap. De ervaringen van studenten in deze vorm van internationalisering zijn weinig onderzocht en dat is opmerkelijk aangezien studenten een beeld kunnen geven van de mate van gelijkwaardigheid van de leerervaring ( $\mathrm{Rq} 2$ ) en hun perceptie van de uitdagingen van dit soort partnerschappen (Rq 1).

De studentgerelateerde uitdagingen die naar boven zijn gekomen uit de voorgaande studies zijn verwerkt in een vragenlijst, bestaande uit 31 items, die zes domeinen dekken. Deze zes domeinen zijn: de transitie van voortgezet onderwijs, taal, geschiktheid voor de beroepspraktijk, motieven om voor het host instituut te kiezen, carrière planning, en algemene tevredenheid.

De bevindingen van deze studie wijzen uit dat studenten het gebruik van Engels als voertaal niet als probleem ervaren. Ook geven zij aan de transitie naar een student gecentreerd onderwijsconcept niet als problematisch te ervaren. Deze percepties komen overeen met het beeld dat door de programmadirecteuren werd geschetst in hoofdstuk 4. Daarnaast bleken de meeste host studenten tevreden en positief over hun leerervaring. De host respondenten identificeerden ook zaken die hun leerervaring kunnen verbeteren.

Een opvallende bevinding uit deze studie was dat de heterogene studentenpopulatie in het host instituut, als gevolg van de unieke aantrekkingskracht van crossborder curriculum partnerschappen, tot problemen kan leiden tijdens werkplek leren. Sommige studenten bleken namelijk niet te taal spreken van het host land. Waardoor ze niet 
in staat zijn om rechtstreeks met patiënten en/of staf te communiceren. Dit bleek een grote uitdaging die in de verschillende partnerschappen op een eigen wijze werd opgelost.

Hoofdstuk 6 geeft een rijke beschrijving van de onderwijskundige en organisatorische uitdagingen van een CCP vanuit het perspectief van het home instituut. Aan de hand van een casus studie worden verschillende praktische uitdagingen zichtbaar. Voorbeelden hiervan zijn de overdracht van curriculum materiaal, in het bijzonder materiaal van docenten dat niet op schrift staat, e-learning tools ingebed in het curriculum die in eigendom van derde partijen zijn, of de uitdaging om beide curricula synchroon te laten lopen ondanks de frequente kleine en grote wijzigingen en updates.

De studie laat zien dat de overdracht van materiaal geflankeerd met onderwijskundige trainingen niet automatisch inhoudt dat host docenten de filosofie achter student gecentreerde onderwijsvormen daadwerkelijk internaliseren en toepassen. Het is bijvoorbeeld een uitdaging om een student gecentreerde toets systeem waarin veel nadruk wordt gelegd op feedback en formatieve toetsen in lijn te brengen met de eisen van lokale kwaliteitszorg instanties of verwachtingen van docenten en studenten, die doorgaans veel waarde hechten aan summatieve cijfers.

Daarnaast beschrijft de studie de nieuwe werkprocessen die geïnstitutionaliseerd dienen te worden binnen het home instituut. Hiervoor worden twee modellen geïntroduceerd op een continuüm: een centraal model waarbij een kernteam van home projectmanagers het overgrote merendeel van de communicatie en informatiestromen coördineren en initiëren. De andere kant van het spectrum is een decentraal aansturingmodel waarbij er vele directe communicatie lijnen lopen tussen beide instituten. Het grote voordeel van het decentrale model is dat home staf sneller betrokken kan raken, updates en aanpassingen op een directe manier kunnen worden doorgegeven en dat er een platform ontstaat waardoor kleine en grote onderwijskundige ideeën en suggesties terug kunnen vloeien naar het home instituut. De nadelen van dit aansturingsmodel zijn dat het implicaties heeft voor de rolbeschrijving van home staf en een groter beroep doet op interculturele communicatie en samenwerkingsvaardigheden. Het hoofdstuk argumenteert dat indien de culturele verschillen groot zijn tussen partners, een centraal aansturingsmodel wellicht een grotere kans van slagen biedt. Echter, een beweging op den duur naar een decentraal aansturingsmodel wordt geadviseerd.

Hoofdstuk 7 richt zich specifiek op de derde onderzoeksvraag van deze dissertatie. In dit hoofdstuk presenteren wij 12 tips die een bijdrage leveren aan duurzame (medische) curriculum partnerschappen. Deze tips zijn afkomstig uit een synthese van de voorgaande studies en geclusterd in 4 domeinen: bestuur, curriculum, leeromgeving en relatiemanagement.

In het eerste domein, adviseren wij om in de voorbereidingsfase een masterplan te ontwikkelen dat sturing geeft aan de wijze van samenwerking. In dit plan staan de verwachtingen en verantwoordelijkheden van beide partners op de verschillende onderdelen. Een tweede tip is om een robuust intern kwaliteitssysteem op te zetten dat de doelstellingen van het partnerschap bewaakt en de mogelijkheid biedt om bij de sturen. Een derde tip is om naast de host staf ook de home staf en organisatie voor te bereiden op het partnerschap. 
In het tweede domein, het curriculum, wordt geadviseerd om de inhoud aan te passen aan de context van het host instituut via kleine contextuele wijzigingen, context specifieke toevoegingen aan casuïstiek en het integreren van host specifieke leerlijnen. Een tweede tip is een planmatige benadering van technische en logistieke zaken om de curriculum inhoud over te zetten, te updaten en te monitoren. Een medisch curriculum bestaat doorgaans uit veel verschillende onderwijsformats en kan gebruik maken van tools die niet in eigendom zijn van het home instituut. Een derde tip adviseert partnerschappen om gebruik te maken van de unieke internationale leeromgeving in het host instituut, middels het construeren van onderwijs dat beoogt studenten internationale competenties te verwerven.

Tips om de leeromgeving te bevorderen zijn: het managen van de onvermijdelijke cultuur shock die sommige studenten ervaren door de transitie naar het nieuwe onderwijsconcept. Aandacht besteden aan de overgang naar Engels als instructietaal en de eventuele taalbarrière tussen studenten en patiënten in de klinische fase. Als laatste punt met betrekking tot de leeromgeving wordt het belang aangegeven en de contouren geschetst van een robuust competentieprogramma voor alle stafleden.

De drie tips om de relatie te managen zijn: het zo snel mogelijk opzetten van 'communities of practice', zodat docenten met elkaar in contact komen en er uitwisseling van onderwijskundige ideeën plaats kan vinden. Daarnaast adviseren we om aandacht te besteden aan het promoten van culturele intelligentie om de onvermijdelijke misverstanden tijdens de vele momenten van interculturele samenwerking te minimaliseren en tot slot benadrukking van het belang van heel veel communicatie op het niveau van projectleiders, vakdocenten en het allerhoogste management.

Hoofdstuk 8 begint met een samenvatting van de in hoofdstuk 1 geformuleerde onderzoeksvragen. Vervolgens wordt de focus verlegd naar drie ethische kwesties relevant voor medische crossborder curriculum partnerschappen die vooralsnog onderbelicht zijn gebleven: onderwijs als verhandelbaar goed, de gevaren van etnocentriciteit en de gevaren van kennis vlucht. Vervolgens wordt een toekomst geschetst voor medisch curriculum partnerschappen waarbij meer aandacht komt voor het creëren van een gelijkwaardige bilaterale stroom van informatie, waardoor er voor beide instituten onderwijskundige voordelen mogelijk zijn. Curriculum partnerschappen kunnen op deze wijze een opstapje zijn naar een werkelijk internationale universiteit. Het hoofdstuk eindigt met een overzicht van de belangrijkste limitaties van de dissertatie. Suggesties voor verder onderzoek zijn vervlochten in ethische kwesties, limitaties en toekomstbeeld. 



\section{Chapter 11.}

\section{Valorisation}

The benefits of this dissertation are best captured in our 12 Tips article published in Medical Teacher, chapter 7. Through these 12 tips we intend to provide guidance to those considering or engaged in designing, developing, managing and reviewing a crossborder curriculum partnership or other forms of international educational partnerships. 



\section{Chapter 12.}

\section{Acknowledgments / Dankwoord}

"Van het concert des levens krijgt niemand een programma". Deze tekst stond op een Delfts blauw tegeltje boven de logeerkamerdeur van mijn oma. Als klein manneke vond ik dat een fascinerende spreuk. Als dit wel het geval was geweest, dan had ik in ieder geval vreemd opgekeken als er een wetenschappelijke promotie in mijn levensprogramma had gestaan. Ik beschouw(de) mezelf van nature meer een generalist en in mindere mate iemand voor nauwgezet specialistisch werk.

Het doen van onderzoek werd voor mij een serieuze optie toen ik in 2009 begon als coördinator van een curriculum samenwerking bij de Universiteit Maastricht. Projectmatig een grote uitdaging en daarnaast eentje die direct vragen opriep. Is het nou verstandig wat wij doen: een medisch programma dat ontwikkeld is in Maastricht exporteren naar Saoedi-Arabië? Kan dat? Saoedi-Arabië, nota bene een land met een andere visie op de organisatie van een samenleving? Leidt dit soort vormen van samenwerking in potentie ergens toe? Door de combinatie van praktijk en wetenschap hoopte ik in deze discussie meer beslagen ten ijs te komen.

De kruisbestuiving tussen wetenschap en praktijk bleek een succesvolle strategie. Niet alleen omdat zo een mogelijke schrijversblokkade is voorkomen, maar zeer zeker omdat beide projecten op veel verschillende manieren van elkaars inzichten hebben geprofiteerd. Terugkijkend heb ik een beter beeld gekregen met heldere argumenten, maar worstel ik soms ook nog wel met dezelfde vragen als in het begin.

Ik wil graag de mensen bedanken die deze tocht mede mogelijk hebben gemaakt. Allereerst mijn promotieteam dat mij vrijheid en ruimte heeft gegeven. Albert, ik zie ons nog zitten op een bankje van de luchthaven in Damman, waar mede dankzij een vertraagde vlucht, het zaadje van deze dissertatie is ontkiemd. Dank, voor je snelle en stipte reacties, en vooral het begrip op de hoofdlijnen. Ik ervoer al snel een rotsvast vertrouwen.

Erik, door een bijzondere speling van het lot kruisten onze carrières elkaar. Ik wil je in het bijzonder bedanken voor je snelle en kundige feedback en vooral je onmisbare positieve energie wanneer we een reactie van een tijdschrift binnenkregen. Dankjewel voor de humor en de luchtigheid.

Janneke, de onmisbare schakel in dit PhD team, merci dat je als co-promotor mijn schrijf- en werkwijze hebt 'doorstaan'. Ik heb op onderzoekstechnisch en taalkundig vlak veel van jou mogen opsteken. De afgelopen jaren waren wellicht meer een rollercoaster voor jou dan voor mij. Ik heb het van dichtbij mogen meemaken en wil je zeg- 
gen dat je trots mag zijn op de wijze waarop je het leven inclusief al zijn grillen hebt vastgepakt en overwonnen. Liah en Adam zijn daar het levende bewijs van.

Andrea, merci voor het lenen van je hersenen tijdens het uitschrijven en analyseren van de interviews met de programma coördinatoren. Het was een prettige eerste kennismaking, waarna er nog velen volgden. Houd me op de hoogte van de verrichtingen van Tom en Ajax, en hopelijk treffen we elkaar ergens in de laatste week van juli op de Champs-Élysées. De resterende openstaande uren mag je daarvoor inzetten... ;)

Ilse en Anne, bedankt voor jullie inzet en bijdrage bij het analyseren van de studentendata. Ieder van jullie heeft op zijn eigen manier een talent voor (medische en onderwijskundig) onderzoek en ik hoop dat jullie hier een weg in zullen vinden. Laury, mister Q-sort, merci voor het delen van je expertise en de daaropvolgende ongerelateerde gesprekken!

Big P, once more, thank you for offering your Cypriot home and enlightening me with some insights in your unconventional working methods. Loved it! Thanks for your support and I will always remember your Christmas cards. It was a true privilege working with you.

Also to Steve in Qatar, I am so grateful for your additional efforts to collect data and your continuous interests in this project.

Uiteraard mag 'taalvirtuoos' Angelique niet ontbreken. Enkel mijn opstellen Duits hadden meer rode wijzigingen in vergelijking met jouw, spot-on, verbeteringen op mijn manuscripten. Ik heb een sterk vermoeden dat zonder jouw bijdragen reviewers minder snel verleid zouden zijn geweest om ons gedachtengoed te accepteren.

Annelies Vossen, jouw kunstzinnige talent waarmee je als leek de kern van dit proefschrift hebt kunnen vatten in een enkele tekening bewonder ik zeer!

Naast de bovengenoemde personen, die direct betrokken zijn geweest bij de totstandkoming van dit boekje, wil ik zeer zeker de mensen die onmisbaar zijn geweest in het samenwerkingsproject bedanken. Te beginnen met mijn twee paranimfen:

Marjolijn, kwartiermaakster van het eerste uur, grote dank dat je al mijn 'onhebbelijkheden' hebt getolereerd en wellicht geaccepteerd, bijvoorbeeld wanneer we weer eens met Carlos of Mohammed te mannelijke praat uitsloegen op de kamer of als ik weer eens een onnodig micro-manage mailtje stuurde. Ik hoop stiekem dat je ooit nog eens voor een groep gaat staan als trainer maar tot die tijd: "doe je ding!".

Mohammed, Mattie, nog zo een vreemde wending van het lot, bracht ons weer bij elkaar in Maastricht. Nadat we bij Cinop ieder vanuit zijn eigen ingang bij organisatieverandering samenkwamen. Dank je voor je inzichten en leesvragen tijdens het schrijfproces. Ik geniet van onze 'bespiegelingen' op de multi-culti en globaliserende samenleving en hoop dat we daar in de toekomst voldoende tijd voor vrij blijven maken.

Jill! Waar zal ik beginnen? ;) Collegae die meegaan op missies naar Saoedi-Arabië zijn doorgaans in twee categorieën onder te brengen: een kleine groep ziet bestaande vooroordelen bevestigd en bedankt voor een volgende keer, het merendeel vindt het 
een aangename openbaring en levenservaring. Jouw enthousiasme en reactie waren hierop de statistische 'outliner'.

Sinds een paar jaar ben je het projectteam komen versterken waardoor het vrouwencollege in zorgzame handen is gekomen. Daarnaast ben je een vriendin geworden, iemand, om in jouw woorden te spreken, "waarmee je de oorlog kunt ingaan". Ik weet zeker dat we nog vele 'veldslagen' samen gaan meemaken en ik kijk daar nu al met een glimlach naar uit.

Harry, bedankt voor jouw inspirerende overtuiging waarmee het curriculum project leven werd ingeblazen. De overtuiging dat, zeker in deze tijden waarin de Arabische en de Westerse werelden met elkaar op spanning staan, het leggen van contacten en aangaan van connecties beter werkt dan elkaar te negeren en verder te isoleren. Mirjam, bedankt voor jouw betrokkenheid bij het project en de begeleiding en sturing vanaf het prille begin tot de dag van vandaag. Daarnaast een speciaal dankjewel voor Mascha en alle ITM coördinatoren, zeker in die eerste jaren, voor het openen van de deuren richting het ITM-programma en het wegwijs maken in de organisatie. Carlos, ik kijk met veel plezier terug op de tijd dat we samen een kamer deelden.

Thank you to Sulaiman Al Rajhi faculty, employees and students, who have been great driving forces all these years, not the least for your hospitality, kindness and openness. All of you made doing research rewarding. Mr Abdulaziz, Mr AlQarni, Mr Khalid, Mr Bsiso, Dr Haider en niet te vergeten Ihab, thanks for the numerous (desert) dinners. Not to forget the excellent drivers in all these years, Mr Abudar and Mr Ashraf.

De PhD-kamers, een onmisbare bron van suikers en vetten, soms wat vitamines, en altijd een luchtig en grappig gesprek. Grazie!

Astrid, Monique, Lilian, Nicky, Hennie en Audrey, onmisbare en stillere krachten op de achtergrond. Dank ook aan de ondersteuners voor het jaarlijkse nieuwe image. Merci en zeker voor het meedenken tijdens de fase waarin we de lezingen moesten opnemen. Alle collega's van O\&O en SHE-C voor de fijne en prettige werkomgeving. Collega studieadviseurs, merci voor het warme welkom en de professionele introductie in deze, voor mij nieuwe, tak van onderwijskundige sport.

Lieve familieleden, Peter, Margo, Jules, Veronique, Olivier, Felipa, Lou, Robert, Inge, Isa, Jorg en Axel, merci voor de mooie hartverwarmende momenten die zijn geweest en die ongetwijfeld nog gaan komen.

Senhor Lou, "kunt" u mij nog?, indirect was deze zin en jouw daaropvolgende vergevingsgezinde reactie het fundament voor alles wat er daarna is gebeurd op professioneel terrein.

Wouter, keep dropping in! Emiel, Tom, Jeroen, Frank en Mattijs: ooit gaan we weer op vakantie.

Sjwarte, Bruine en Roeije, kleurinnen en kleinere kleurtjes, jullie tomeloze support was indrukwekkend ;). Ik kijk uit naar de vele weekendjes en oudejaarsavonden die nog gaan komen. Fantastisch toch dat er binnenkort niet genoeg plek meer is aan de Wilhelminastraat en dat we een heuse villa in de Ardennen moeten gaan zoeken? 
Mijn Koga en Canyon: mindfulness therapie en stressreductie samengebald in twee rossen van carbon. Merci, rappe en minder rappe mannen van het MUMC, EPO \& EMO, Trainert, JP, Flandriens, en natuurlijk de Sjerpe Wielrenners Maastricht: Martijn en Steven, uiteraard dank voor het beter maken (ieder op zijn eigen manier ;)).

De Harries en Wieske, ondanks dat een flink deel van onze ontmoetingen zich in deze tropenjaren via de app afspeelt. ;) En daar hebben we al eens een sketch over gedaan. We kijken uit naar de vele persoonlijke etentjes en afspraken die gaan volgen. Take it easy, friends!

Ten slotte, mijn ouders, zonder wie dit hele avontuur letterlijk niet mogelijk zou zijn geweest. Pap, ik besef me steeds vaker dat je toch wel erg vroeg van ons heen bent gegaan. Je hebt helaas vele ijkpunten niet mogen meemaken. Dit is vandaag toch wel een klein verjaardagscadeau. Ik ben dankbaar voor de bagage die jullie in mijn rugzak hebben gestopt. Wellicht is dat nog het grootste cliché; je beseft pas wat het betekent om een ouder te zijn als je zelf kinderen hebt. Mam, dit proefschrift had zonder al jouw oppasbeurten en structurele aanwezigheid op de vrijdagmorgen nog veel langer geduurd. Merci hiervoor, maar veel belangrijker: "Dankjewel voor de moeder die je bent (geweest) en de oma die je nu bent!"

Ze zijn al genoemd, mijn meest dierbare en onmisbare mensen in mijn leven: Erin, Quinten en Valerie, in alfabetische volgorde, want ik zou geen rangorde willen en kunnen maken. Erin en Quinten, de contouren van jullie persoonlijkheden, talenten en kwetsbaarheden worden elke dag meer zichtbaar. Het is een groot privilege om dit te mogen meemaken: volg jullie hart, leef en ontdek, de rest ontvouwt zich vanzelf. We zijn nu al ontzettend trots op jullie!

Lieverd, wie had dat gedacht? Iets dat startte bij een dansles, die ik me nog kan herinneren als de dag van gisteren, is ondertussen twee ontdekkingen verder en nu ook nog eens twee promoties. Gelukkig hebben we geen kaart van het concert des levens, maar begaan we een pad samen dat we zo min mogelijk proberen te plannen. Ik bewonder je om wie je bent. Carpe diem, love you!

En hoe mooi is het om als kroon op dit alles te kunnen schrijven dat ons geliefde soul-quintet werkelijkheid gaat worden met een derde op komst!!! 


\section{Chapter 13.}

\section{About the author}

Dominique Waterval was born on May $7^{\text {th }}, 1978$. After secondary school, he studied general economics from 1996 to 2002 at Maastricht University. Upon graduation, he began his career as a teacher within a student-centred curriculum. This experience triggered his passion for education and spurred his career in this sector. This ambition became formalized nine years later when he obtained his Master of Health Professions Education (MHPE).

From 2003-2004, he worked as an educational trainer in problem-based learning at a university in Mozambique. He was responsible for empowering graduated Mozambican staff to develop, manage, teach, and evaluate student-centred education. After returning to the Netherlands, he briefly worked on e-portfolios and online remedial teaching projects, after which he again moved abroad. This time, he moved to Saudi Arabia along with his wife to work at a newly established medical college in Riyadh. During this period, he was responsible for establishing an assessment unit within the Department of Medical Education.

Upon returning to the Netherlands, he worked as an educational consultant for the Centre for Innovation for Educational Programmes (CINOP). During his time at CINOP, he assisted various vocational schools in the Netherlands in making the transition towards competence-based education.

In 2009, he returned to Maastricht and began working as a project manager for a medical curriculum partnership between the Faculty of Health Medicine and Life Science and a newly established college of medicine in Saudi Arabia. He was responsible for all internal and external project activities and was involved in many of the training workshops over the 11-year duration of the partnership. Dominique Waterval has a broad interest in education, as illustrated by his recent positions as student counsellor and operational manager of the school of Health Professions Education. His research interest is in the implementation of student-centred forms of education, especially in non-Western settings.

Dominique lives in Eijsden together with Valerie and their two children Erin and Quinten. 



\section{Chapter 14.}

\section{SHE dissertation series}

Boymans, T. (06-10-2017) Hip arthroplasty in the very elderly: anatomical and clinical considerations

Zaidi, Z. (04-10-2017) Cultural hegemony in medical education: exploring the visibility of culture in health professions

Harrison, C. (20-09-2017) Feedback in the context of high-stakes assessment: can summative be formative?

Mekonen, H. (30-06-2017) Development of the axial musculo-skeletal system in humans

Taylor, T. (29-03-2017) Exploring Fatigue as a Social Construct: Implications for Work Hour Reform in Postgraduate Medical Education

McLellan, L. (29-03-2017) Prescribing the right medicine: Perspectives on education and practice

Ignacio, J. (09-02-2017) Stress Management in Crisis Event Simulations for Enhancing Performance

Bolink, S. (19-01-2017) Functional outcome assessment following total hip and knee arthroplasty; Implementing wearable motion sensors
Beckers, J. (09-12-2016) With a little help from my e-portfolio. Supporting students' self-directed learning in senior vocational education

Giroldi, E. (07-12-2016) Towards skilled doctor-patient communication. Putting goal-directed and contextspecific communication into (educational) practice

Huwendiek, S. (25-11-2016) Virtual patients for learning of clinical reasoning

Bohle-Carbonell, K. (28-09-2016) May I ask you...? The influence of individual, dyadic \& network factors on the emergence of information exchange in teams

Ginsburg, S. (01-09-2016) Hidden in plain sight, the untapped potential of written assessment comments

Koops, W. (08-06-2016) Computersupported collaborative learning in clinical clerkships

Schlegel, C. (08-06-2016) Simulated and standardized patients in health profession education: the impact of quality improvement 
Sorensen, J. (01-06-2016) Obstetric simulation: designing simulationbased medical education and the role of physical fidelity

Kok, E. (01-04-2016 Developing visual expertise: from shades of grey to diagnostic reasoning in radiology

Van den Eertwegh, V. (11-11-2015) Unravelling postgraduate communication learning; from transfer to transformative learning

Gingerich, A. (03-09-2015) Questioning the rater idiosyncrasy explanation for error variance, by searching for multiple signals within the noise

Goldszmidt, M. (02-09-2015) Communication and reasoning on clinical teaching teams, the genres that shape care and education
Slootweg, I. (19-06-2015) Teamwork of Clinical Teachers in Postgraduate Medical Training

Al-Eraky, M. (21.05.15) Faculty development for medical professionalism in an Arabian context

Wearne, S. (08-04-2015) Is it remotely possible? Remote supervision of general practice registrars

Embo, M. (13-03-2015) Integrating workplace learning, assessment and supervision in health care education

Zwanikken, P. (23-01-2015) Public health and international health educational programmes for low- and middle-income countries: questioning their outcomes and impact 